RODRIGO ALVES DOS SANTOS

ESTUDO DA VIABILIDADE TÉCNICA E ECONÔMICA DE PRODUÇÃO DE PETRÓLEO SINTÉTICO OFFSHORE A PARTIR DE REJEITO RICO $\mathrm{EM} \mathrm{CO}_{2}$

\author{
Dissertação apresentada à Escola \\ Politécnica da Universidade de São Paulo \\ para obtenção do titulo de Mestre em \\ Ciências.
}

SÃO PAULO

2013 
RODRIGO ALVES DOS SANTOS

\title{
ESTUDO DA VIABILIDADE TÉCNICA E ECONÔMICA DE PRODUÇÃO DE PETRÓLEO SINTÉTICO OFFSHORE A PARTIR DE REJEITO RICO $\mathrm{EM} \mathrm{CO} 2$
}

\author{
Dissertação apresentada à Escola \\ Politécnica da Universidade de São Paulo \\ para obtenção do titulo de Mestre em \\ Ciências. \\ Área de Concentração: \\ Engenharia Química \\ Orientador: \\ Prof. Dr. Galo Antonio Carrillo Le Roux
}

SÃO PAULO

2013 
Este exemplar foi revisado e corrigido em relação à versão original, sob responsabilidade única do autor e com a anuência de seu orientador.

São Paulo, 08 de novembro de 2013.

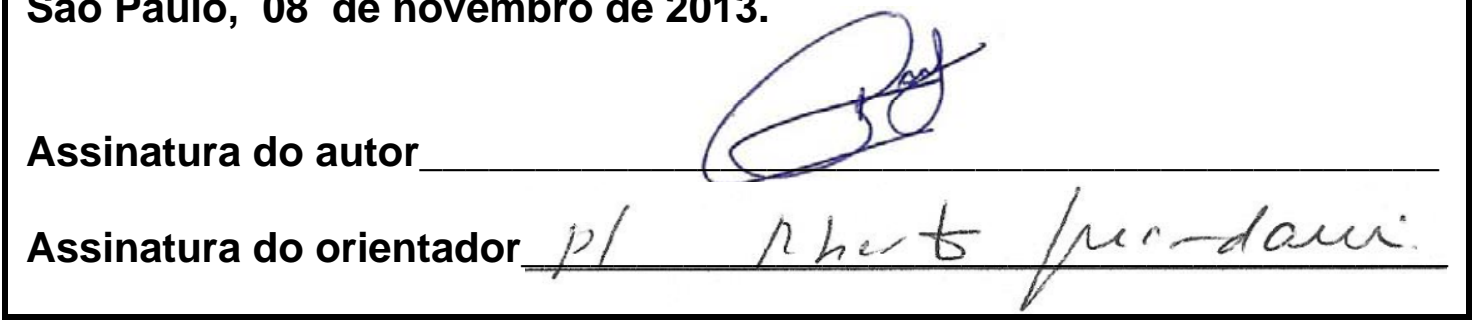

FICHA CATALOGRÁFICA

Santos, Rodrigo Alves dos

Estudo da viabilidade técnica e econômica de produção de petróleo sintético offshore a partir de rejeito rico em $\mathrm{CO}_{2}$ I R.A. dos Santos. -- versão corr. -- São Paulo, 2013.

$100 \mathrm{p}$.

Dissertação (Mestrado) - Escola Politécnica da Universidade de São Paulo. Departamento de Engenharia Química.

1.Petróleo sintético offshore (Produção;Viabilidade) I.Universidade de São Paulo. Escola Politécnica. Departamento de Engenharia Química II.t. 


\section{DEDICATÓRIA}

Dedico esse trabalho à minha querida esposa Ossana pelo amor, compreensão e apoio durante todas as fases da elaboração do mesmo, aos meus filhos Noah e Enzo, pela felicidade e benção da paternidade e à minha mãe Antonia, pelo carinho, dedicação, apoio, educação e caráter à mim oferecidos. 


\section{AGRADECIMENTOS}

A Deus pela saúde e paz a mim oferecida, sem a qual nada aconteceria.

Ao Prof. Dr. Galo A. Carrillo Le Roux pela orientação, apoio e compreensão no desenvolvimento deste trabalho.

A Petrobras pela oportunidade de crescimento pessoal e intelectual oferecida.

Ao amigo Claudio Neves Borges, pelo seu apoio, amizade e conselhos.

À Giovanna Jundurian pelo apoio na revisão do trabalho.

A Secretaria do Departamento de Engenharia Química, em especial ao profissional Alexandre, pelo auxilio administrativo durante esses anos.

Aos membros da banca examinadora pela disponibilização de seu valoroso tempo para avaliação e sugestões de melhoria a este trabalho.

Ao colega Guilherme Rodrigues Junior pela compreensão e aprovação da minha participação no programa de mestrado oferecido pela Petrobras, em detrimento de importantes horas de trabalho. 


\section{EPÍGRAFE}

"Todos os homens, de todos os tempos, e ainda os de hoje, dividem-se entre escravos e livres, porque quem não dispõe de dois terços do próprio dia é um escravo, não importa o que seja de resto: homem de Estado, comerciante, funcionário público ou estudioso." 


\section{RESUMO}

A descoberta de uma nova província petrolífera, conhecida como pré-sal, localizada no litoral brasileiro, representa um novo marco na produção de petróleo mundial. Dentre os vários desafios encontrados para exploração e produção dessa região, a presença de $\mathrm{CO}_{2}$ em grandes concentrações nos fluidos de alguns desses reservatórios tem sido um dos desafios de maior relevância para as empresas que exploram e produzem nessa área (FORMIGLI, 2007). Uma forma alternativa de seqüestro do $\mathrm{CO}_{2}$ retirado do gás natural é a sua utilização como matéria prima ou co-alimentação para a síntese de produtos químicos, em especial aqueles com grande demanda de mercado. Um dos produtos que podem ser obtidos indiretamente a partir do $\mathrm{CO}_{2}$ é o petróleo sintético, produzido pelo processo conhecido como Gas-to-Liquids, ou GTL. Neste trabalho foi analisada a viabilidade técnica, econômica e potencial de captura de $\mathrm{CO}_{2}$, da produção de petróleo sintético, pelo processo GTL, offshore, a partir de dióxido de carbono $\left(\mathrm{CO}_{2}\right)$ e metano $\left(\mathrm{CH}_{4}\right)$, presentes na corrente de rejeito do tratamento do gás processado em uma plataforma de produção de petróleo e gás, através das reformas seca e a vapor, seguida da síntese Fischer-Tropsch. A partir de dados de literatura e com uso de simulador comercial de processos, a simulação do processo foi desenvolvida e diferentes alternativas para reaproveitamento das correntes residuais do processo foram analisadas, incluindo o reciclo e a queima dos efluentes combustíveis, assim como foram aplicadas técnicas de integração energética, otimização e análise econômica de processos. Os resultados indicaram que o processo, mássica e energeticamente integrado, na condição de menor emissão de $\mathrm{CO}_{2}$ e maior retorno financeiro, produziu petróleo sintético de forma técnica e economicamente viável. Os resultados indicaram ainda que o processo GTL, com as tecnologias utilizadas, não é indicado como método de captura de $\mathrm{CO}_{2}$ devido o fato de a geração desse componente para a produção de petróleo sintético ser duas vezes maior que a quantidade alimentada.

Palavras-Chave: $\mathrm{CO}_{2}$, GTL, Fischer-Tropsch. 


\begin{abstract}
The discovery of a new oil province known as pre-salt, located in the Brazilian coast, represents a new frontier in the world's oil production. Among other challenges involved in the exploration and production in that region, the $\mathrm{CO}_{2}$ concentration at high levels in the fluids of some of those reservoirs has been the most relevant challenge for the companies that explore and produce in that area (FORMIGLI, 2007). An alternative to sequestering the $\mathrm{CO}_{2}$ extracted from natural gas is using it as a supply of raw material or as an input to the synthesis of chemical products, especially those with great market demand. One of the products that can be obtained indirectly from $\mathrm{CO}_{2}$ is synthetic fuel, produced by the process known as Gas-toLiquids, or GTL. In this work the technical, economical and potential feasibility of $\mathrm{CO}_{2}$ capture is analyzed, as well as the production of synthetic fuel using the GTL process, offshore, from carbon dioxide $\left(\mathrm{CO}_{2}\right)$ and methane $\left(\mathrm{CH}_{4}\right)$, found in the waste chain of the gas treatment in an oil and gas production platform, through dry and steam reforming, followed by Fischer-Tropsch synthesis. Thus, based on literature data and on the use of a commercial process simulator, the simulation of the suggested process was developed and different alternatives to the reutilization of the waste chains were analyzed, including the recycling and burning of some effluent streams. Techniques of energetic integration, optimization and economic analysis of process have also been applied. The results indicated that the process, mass and energy integrated in the condition of lower $\mathrm{CO} 2$ emissions and greater financial return, produced synthetic oil in a technically and economically feasible way. The results also indicated that the GTL process, with the technologies used, is not suitable as a method for $\mathrm{CO} 2$ capture due to the fact that the generation of this component for the production of synthetic oil is two times greater than the amount fed.
\end{abstract}

Keywords: $\mathrm{CO}_{2}$, GTL, Fischer-Tropsch. 


\section{LISTA DE ILUSTRAÇÕES}

$\begin{array}{ll}\text { Figura } 3.1 \text { - Processo GTL completo. } & 18\end{array}$

Figura 3.2 - Rotas de produção de gás de síntese. 20

Figura 3.3 - Produção do gás de síntese pela pré-reforma adiabática e $\quad 29$ reforma autotérmica.

Figura 3.4 - Insumos e catalisadores. 33

Figura 3.5 - Reatores para a síntese de Fischer-Tropsch. 34

Figura 3.6 - Distribuição teórica mássica de produtos como função da 42 probabilidade de crescimento de cadeia $(\alpha)$.

Figura 3.7- Distribuição teórica molar de produtos como função da probabilidade de crescimento de cadeia $(\alpha)$.

Figura 4.1 - Diagrama de blocos característico de um processamento primário de petróleo e gás natural.

Figura 4.2 - Diagrama de blocos do processamento de petróleo, incluindo 45 o processo proposto.

Figura 4.3 - Diagrama de blocos simplificado do processo de conversão de 48 CO2 a petróleo sintético.

Figura 4.4 - Diagrama de blocos da opção sem membrana. 58

Figura 4.5 - Diagrama de blocos da opção com membrana. 58

Figura 4.6 - Exemplo de um diagrama de intervalos de temperaturas. 61

Figura 4.7 - Exemplo de um diagrama de cascata (inicial e ajustado). $\quad 62$

Figura 4.8 - Exemplo de uma rede integrada de trocadores de calor. $\quad 65$

Figura 4.9 - Fluxograma representativo do sistema de utilidades. $\quad 73$

Figura 4.10 - Fluxograma representativo do sistema de tratamento de água. $\quad 74$

$\begin{array}{ll}\text { Figura } 5.1 \text { - Produção de petróleo das alternativas analisadas. } & 81\end{array}$

Figura 5.2 - Consumo de gás natural das alternativas analisadas. $\quad 82$

Figura 5.3 - Conversão de $\mathrm{CO}_{2}$ para as alternativas analisadas. $\quad 82$

Figura 5.4 - Custo de investimento das alternativas analisadas. 83

Figura 5.5 - Valor presente liquido (VPL) das alternativas analisadas. $\quad 84$

Figura 5.6 - Diagrama de intervalos de temperaturas. 86

Figura 5.7 - Diagrama de cascata de troca térmica. 86

$\begin{array}{lll}\text { Figura } 5.8 \text { - Rede integrada de trocadores de calor. } & 87\end{array}$

Figura 5.9 - Fluxograma final do processo proposto. 88 


\section{LISTA DE TABELAS}

Tabela 3.1 - Principais reações da síntese de Fischer-Tropsch. 32

Tabela 3.2 - Vantagens e desvantagens para os reatores de leito fixo multi- 37 tubulares e reatores de leito de lama.

Tabela 3.3 - Evolução na tecnologia dos reatores. 38

Tabela 3.4 - Características gerais dos principais catalisadores. 40

Tabela 4.1 - Alternativas de integração mássica analisadas. 59

Tabela 4.2 - Exemplo de organização de dados de correntes. 60

Tabela 4.3 - Dados necessários para cada classe de estimativa de custos. $\quad 67$

Tabela 4.4 - Projeção de preços para o petróleo tipo Brent. 69

Tabela 4.5 - Correlações para calculo de despesas operacionais. $\quad 70$

Tabela 4.6 - Projeção de preços para o gás natural Henry Hub. 72

Tabela 4.7 - Consumo energético das utilidades de processo. $\quad 74$

Tabela 5.1 - Dados da simulação do caso base. $\quad 77$

Tabela 5.2 - Composição do óleo produzido pela simulação do caso base. $\quad 78$

Tabela 5.3 - Emissões de $\mathrm{CO}_{2}$ - simulação do caso base. $\quad 79$

Tabela 5.4 - Resultados da simulação para a alternativa sem membrana. $\quad 80$

Tabela 5.5 - Resultados da simulação para a alternativa com membrana. $\quad 80$

Tabela 5.6 - Dados das correntes de processo que participaram da analise. $\quad 85$

$\begin{array}{lll}\text { Tabela } 5.7 \text { - } & \text { Resultados da integração de trocadores de calor do processo } & 88\end{array}$

Tabela 5.8 - Resumo dos resultados obtidos com a integração energética do 89 processo. 


\section{LISTA DE ABREVIATURAS E SIGLAS}

$\begin{array}{ll}\text { ANP } & \text { Agência Nacional de Petróleo e Biocombustíveis } \\ \text { ASF } & \text { Anderson-Schulz-Flory } \\ \text { ATR } & \text { Autothermal Reforming } \\ \text { BTL } & \text { Biomass-To-Liquids } \\ \text { CEPCI } & \text { Chemical Engineering Plant Cost Índex } \\ \text { CM } & \text { Custo operacional } \\ \text { CTL } & \text { Coal-to-Liquids } \\ \text { DMT } & \text { Diferencial Mínimo de Temperatura } \\ \text { EIA } & \text { U.S Energy Information Administration } \\ \text { FPSO } & \text { Floating Production Storage and Offloading } \\ \text { FT } & \text { Fischer-Tropsch } \\ \text { GRAP } & \text { Gás Residual de Alta Pressão } \\ \text { GRBP } & \text { Gás Residual de Baixa Pressão } \\ \text { GTL } & \text { Gas-To-Liquids } \\ \text { HTFT } & \text { High Temperature Fischer-Tropsch } \\ \text { IPCC } & \text { Intergovernmental Panel on Climate Change } \\ \text { LTFT } & \text { Low Temperature Fischer-Tropsch } \\ \text { MPE } & \text { Método do Ponto de Estrangulamento Energético } \\ \text { OTL } & \text { Oil-To-Liquids } \\ \text { PCI } & \text { Poder Calorífico Inferior } \\ \text { PE } & \text { Pinch Point } \\ \text { PFR } & \text { Plug Flow Reactor } \\ \text { POX } & \text { Partial Oxidation } \\ \text { RTL } & \text { Residue-To-Liquids } \\ \text { SMR } & \text { Steam Methane Reforming } \\ \text { TMA } & \text { Taxa Mínima de Atratividade } \\ \text { VPL } & \text { Valor Presente Líquido } \\ \text { WGS } & \text { Water-Gas-Shift } \\ \end{array}$




\section{SUMÁRIO}

1 INTRODUÇÃO

1.1 MOTIVAÇÃO 13

2 OBJETIVOS 16

$\begin{array}{lll}2.1 & \text { OBJETIVO } & 16\end{array}$

3 REVISÃO BIBLIOGRÁFICA 17

3.1 PRODUÇÃO DE COMBUSTÍVEIS LÍQUIDOS SINTÉTICOS 17

3.2 PRODUÇÃO DO GÁS DE SÍNTESE 19

3.2.1 Reforma a Vapor 22

3.2.2 Oxidação Parcial 24

3.2.3 Reforma Auto-térmica 26

3.2.4 Reforma Combinada ou Secundária 29

3.3 SÍNTESE DE FISCHER-TROPSCH 31

3.3.1 Tecnologias para a Síntese de Fischer-Tropsch. 32

3.3.2 Reatores para a Síntese de Fischer-Tropsch 34

3.3.3 Catalisadores 38

3.3.4 Distribuição dos produtos formados 41

4 MATERIAIS E MÉTODOS 44

4.1 DESENVOLVIMENTO E SIMULAÇÃO DO PROCESSO 44

4.1.1 Características da corrente de alimentação. 44

4.1.2 Premissas adotadas no estudo. 46

4.1.3 Descrição do processo proposto. 48

4.1.4 Simulação do processo. 51

4.1.4.1 Reator de reforma 52

4.1.4.2 Combustão catalítica 53

4.1.4.3 Reator Fischer-Tropsch 54 
4.2 INTEGRAÇÃO MÁSSICA E ENERGÉTICA. 56

4.2.1 Integração mássica. $\quad 56$

4.2.2 Integração Energética. $\quad 59$

4.2.2.1 Mínimo consumo de utilidades e ponto de menor diferença de temperatura. $\quad 60$

4.2.2.2 Síntese da rede de trocadores de calor 63

4.3 ANALISE DE VIABILIDADE ECONOMICA 65

4.3.1 Estimativa do capital de investimento 66

$\begin{array}{ll}\text { 4.3.2 Fluxo de caixa } & 69\end{array}$

4.3.2.1 Preço do petróleo $\quad 69$

4.3.2.2 Estimativa do custo operacional 70

$\begin{array}{lll}\text { 4.3.2.3 Custo da matéria-prima } & 71\end{array}$

4.3.2.4 Custo com utilidades $\quad 72$

4.3.2.5 Custo com tratamento de efluentes $\quad 74$

$\begin{array}{lll}\text { 4.3.2.6 Custo com operadores } & 75\end{array}$

5 RESULTADOS E DISCUSSÃO

5.1 SIMULAÇÃO DO CASO BASE

5.2 INTEGRAÇÃO MÁSSICA DO PROCESSO 80

5.3 INTEGRAÇÃO ENERGÉTICA DO PROCESSO 85

6 CONCLUSÕES $\quad 91$

7 CONTINUIDADE DO TRABALHO 93

8 REFERÊNCIAS BIBLIOGRÁFICAS 94

APÊNDICE - A DADOS DE EQUIPAMENTOS - PROCESSO INTEGRADO 


\section{INTRODUÇÃO}

\subsection{MOTIVAÇÃO}

A descoberta da província do pré-sal, localizada na plataforma continental das regiões sudeste e sul, representa um novo marco na história da indústria petrolífera brasileira (FERRO; TEIXEIRA, 2009).

Para transformar as estimativas de reservas de petróleo em riqueza explorada será necessário superar diversas barreiras técnicas em várias áreas que compõem, direta e indiretamente, a cadeia de valor da atividade (FERRO; TEIXEIRA, 2009).

Dentre os vários desafios encontrados para exploração e produção das reservas do pré-sal, a presença de $\mathrm{CO}_{2}$ em grandes quantidades nos fluidos desses reservatórios tem sido um dos desafios de maior relevância para as empresas que exploram e produzem nessa área (FORMIGLI, 2007). Isso porque $0 \mathrm{CO}_{2}$, quando presente no gás natural acima de certas quantidades, pode causar problemas de corrosão nos dutos de transporte e transferência, contaminação atmosférica relacionada ao efeito estufa, dificuldades de comercialização do gás por não atender às exigências da ANP, etc. (IPCC, 2005).

Para desenvolvimento da produção de petróleo e gás dos campos da região

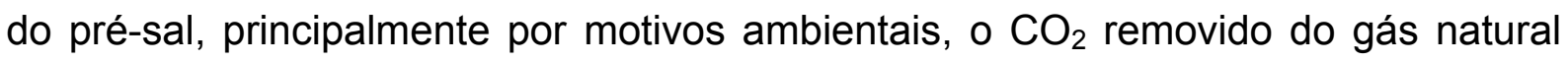
produzido não poderá ser lançado na atmosfera, como acontecia no passado. Todo - $\mathrm{CO}_{2}$ produzido deverá ter uma destinação diferente da atmosfera. Os destinos normalmente utilizados para a deposição do $\mathrm{CO}_{2}$ produzido são a injeção $\mathrm{e}$ estocagem em reservatórios depletados, aqüíferos salinos, reservatórios de carvão e re-injeção em campos produtores para recuperação secundária de petróleo (IPCC, 2005), sendo esse último, o modelo adotado atualmente para as plataformas responsáveis pela produção no pré-sal. 
Uma forma alternativa de seqüestro de $\mathrm{CO}_{2}$ é a sua utilização como matéria prima ou co-alimentação para a síntese de produtos químicos, em especial aqueles com grande demanda de mercado.

Dentro desse cenário, a pesquisa e desenvolvimento de processos e tecnologias que busquem a conversão química do $\mathrm{CO}_{2}$ produzido em plataformas de petróleo em produtos de maior valor agregado e de interesse da indústria química e petroquímica, apresenta-se como uma excelente alternativa para a garantia da preservação ambiental aliada a rentabilidade obtida a partir de um rejeito considerado o maior causador do efeito estufa.

O dióxido de carbono pode reagir com uma série de compostos químicos para a produção dos mais diversos produtos. Um dos produtos obtidos indiretamente a partir do $\mathrm{CO}_{2}$ é o petróleo sintético. Ele é produzido pela síntese de FischerTropsch (FT), que utiliza o gás de síntese (composto basicamente de hidrogênio e monóxido de carbono) como matéria prima. O gás de síntese por sua vez, pode ser produzido pela reação do gás natural (metano) com o $\mathrm{CO}_{2}$ ou com a água, sendo essas reações conhecidas como reforma seca e reforma a vapor, respectivamente. O processo completo (reforma e síntese FT) é conhecido como Gas-to-Liquids, ou GTL.

A síntese de FT é considerada o coração da tecnologia GTL. Através dela o gás de síntese é convertido em uma mistura de hidrocarbonetos composta principalmente por hidrocarbonetos parafínicos de longa cadeia linear e por $\alpha$ olefinas. Em resumo, o processo converte o monóxido de carbono e hidrogênio em hidrocarbonetos líquidos sintéticos (petróleo sintético) de altíssima qualidade, que pode ser misturado ao petróleo produzido, estocado nos tanques da plataforma, aumentando o volume de petróleo produzido e, com isso, aumentando os ganhos da unidade.

Ao se analisar o processamento primário de petróleo em uma plataforma de petróleo, verifica-se que o gás natural (metano) e a água são reagentes naturalmente disponíveis para utilização, tornando o processo GTL uma excelente opção para reaproveitamento do $\mathrm{CO}_{2}$. 
O processo GTL é uma tecnologia amplamente dominada e que há muitos anos é utilizada para conversão de gás natural em combustíveis líquidos sintéticos. Já a utilização do $\mathrm{CO}_{2}$ para a produção do gás de síntese ainda é um tema pouco desenvolvido e utilizado industrialmente, sendo que a grande maioria das pesquisas sobre o tema ainda estão restritas ao meio acadêmico.

Face ao pequeno e disputado espaço disponível em uma plataforma de produção de petróleo, tem-se que a utilização de reatores convencionais para a conversão de $\mathrm{CO}_{2}$ a combustíveis líquidos pode tornar o processo inviável tecnicamente. Nesse cenário, as tecnologias de reatores compactos (micro e milicanais) despontam como uma interessante opção, pois intensificam tanto os processos de conversão química quanto de troca de energia no processo. Essa tecnologia já vem sendo testada para aplicação em um futuro próximo pela Petrobras em parceria com a britânica CompactGTL, em uma planta de demonstração instalada em um sítio de testes em Aracaju/SE (BAXTER, 2010).

Além da CompactGTL, outras duas empresas, Heatric e Velocys, atuam no desenvolvimento de tecnologias específicas para a exploração de reservas de gás remotas ou offshore, que seguem uma linha de pesquisa diferenciada em função do seu produto final, o metanol.

Um dos grandes desafios da planta GTL é a otimização da integração energética da etapa de produção com a etapa de conversão do gás de síntese. (VOSLOO, 2001). Isso porque apesar do processo possuir duas etapas termodinamicamente distintas (reforma endotérmica e síntese FT fortemente exotérmica), a grande diferença de temperatura entre as duas etapas impede que a integração ocorra de forma direta. Apesar disso, as diversas correntes mássicas e energéticas que entram e saem do processo necessitam ser integradas, a fim de reduzir os custos de produção e o consumo de matérias primas. 


\section{OBJETIVOS}

\subsection{OBJETIVO}

Este trabalho tem como objetivo identificar a viabilidade técnica e econômica da produção de hidrocarbonetos líquidos sintéticos, a partir de dióxido de carbono $\left(\mathrm{CO}_{2}\right)$ e metano $\left(\mathrm{CH}_{4}\right)$, presentes na corrente de rejeito do tratamento do gás processado, em uma plataforma de produção de petróleo e gás, localizada na região do pré-sal, através das reformas seca e/ou a vapor seguida da síntese de FischerTropsch.

Para atendimento desse objetivo o trabalho foi realizado da seguinte forma:

- Pesquisa bibliográfica sobre os processos utilizados (reforma seca, reforma a vapor, reforma combinada e síntese de Fischer-Tropsch), metodologias e modelos utilizados no desenvolvimento do trabalho;

- Levantamento e definição das premissas do processo (vazões de entrada e saída, temperaturas, pressões, etc.);

- Simulação matemática do processo, em regime estático, a partir das informações coletadas durante a pesquisa bibliográfica, para obtenção dos dados do processo que servirão de insumo para as análises posteriores;

- Integração mássica do caso base simulado, através do reciclo das correntes residuais do processo (gás e água);

- Análise e seleção da melhor opção de reciclo das correntes residuais;

- Integração energética do processo;

- Dimensionamento dos principais equipamentos;

- Analise de viabilidade econômica do processo. 


\section{REVISÃO BIBLIOGRÁFICA}

\subsection{PRODUÇÃO DE COMBUSTÍVEIS LÍQUIDOS SINTÉTICOS}

A tecnologia para produção de combustíveis líquidos sintéticos (GTL) tem uma longa história. Seu desenvolvimento inicial ocorreu na década de 1920, quando os cientistas alemães Franz Fischer e Hans Tropsch desenvolveram o processo de conversão do gás de síntese (mistura de monóxido de carbono e hidrogênio), produzido a partir do carvão, em combustíveis líquidos. A partir deste desenvolvimento inicial, a tecnologia foi utilizada em escala comercial na Alemanha durante a Segunda Grande Guerra, nos Estados Unidos na década de 1950 e na África do Sul a partir da década de 1950 (ALMEIDA et al., 2004).

Processos para a conversão do gás natural em combustíveis líquidos, como gasolina ou diesel, produzidos a partir da síntese de Fischer-Tropsch (FT) vêm atraindo bastante atenção, uma vez que consistem em uma importante estratégia para a valorização do gás natural existente em áreas remotas, que não pode ser facilmente utilizado para outros fins. Além disso, outros fatores como a pressão ambiental para a redução da queima do gás em flares e o progresso no que se refere ao custo efetivo da tecnologia Fischer-Tropsch, resultante do desenvolvimento de catalisadores mais ativos e da melhoria no projeto dos reatores, contribuem para o aumento do interesse pela tecnologia GTL baseada na síntese de Fischer-Tropsch (VOSLOO, 2001).

A denominação XTL, comumente encontrada na literatura, é empregada para caracterizar a produção de combustíveis líquidos sintéticos a partir de diversas fontes, tais como o gás natural (gas-to-liquids, GTL), carvão (coal-to-liquids, CTL), óleos extrapesados (OTL), biomassa (biomass-to-liquids, BTL) ou resíduo de vácuo (RTL). Essas tecnologias proporcionam a conversão dos insumos mencionados em gás de síntese, substância que pode ser convertida em combustíveis sintéticos como diesel, nafta, lubrificantes e parafinas, com altíssimo grau de pureza (sem elementos poluentes). 
O processo completo de conversão do gás natural para líquidos (Figura 3.1) pode ser dividido em três seções, representadas cada uma por processos distintos (LAAN, 1999; VOSLOO, 2001; KNOTTENBELT, 2002; BASINI, 2005; BREED A. et al., 2005; SOUZA-AGUIAR, 2005)

1. Produção do gás de síntese

2. Conversão do gás de síntese (Síntese Fischer-Tropsch)

3. Refino

Figura 3.1 - Processo GTL completo

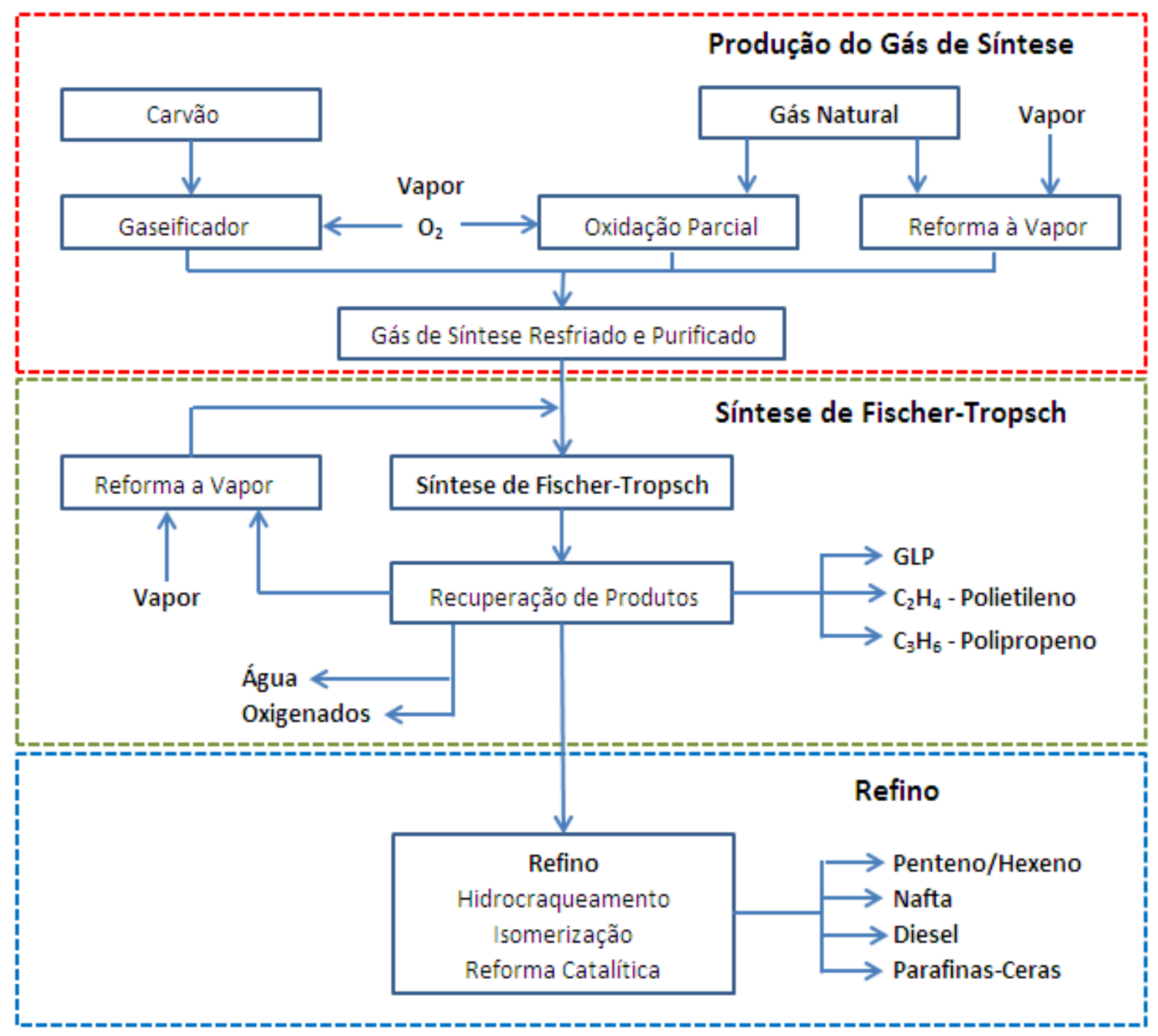

Fonte: adaptado de ALMEIDA et al., 2004

Embora essas três etapas sejam bem estabelecidas, individualmente otimizadas e comercialmente aprovadas, o uso combinado não é largamente 
aplicado, passando a ser um interessante desafio à obtenção de metodologias combinando essas três etapas de forma que se obtenham custos efetivos mais baixos (ALMEIDA et al., 2004).

Um dos grandes desafios da planta GTL é a otimização da integração energética da etapa de produção com a etapa de conversão do gás de síntese. Essa dificuldade é resultado da influência da tecnologia da etapa de produção do gás de síntese na eficiência térmica do processo completo da planta. A escolha da tecnologia de produção determina a necessidade, ou não, de uma planta de produção de oxigênio, influenciando, portanto o custo de capital do processo completo (VOSLOO, 2001).

Atualmente, vem sendo realizados esforços para obtenção de hidrocarbonetos de alto peso molecular e combustíveis líquidos de forma direta, ou seja, sem a obtenção do gás de síntese a partir do metano. No entanto, o processo não apresenta viabilidade, sobretudo por se limitar a baixas conversões e baixa seletividade para os produtos de interesse (KUSMIYATI, 2005).

\subsection{PRODUÇÃO DO GÁS DE SÍNTESE}

Atribui-se o nome de gás de síntese a uma mistura de hidrogênio $\left(\mathrm{H}_{2}\right)$ e monóxido de carbono (CO).

O processo de gaseificação ou produção do gás de síntese pode ser definido como a conversão de qualquer combustível que contenha carbono (carbonáceo) em um produto gasoso que possua poder calorífico. Essa definição inclui processos como pirólise, oxidação parcial e hidrogenação (HIGMAN; VAN DER BURGT, 2003).

O gás de síntese é composto por $\mathrm{CO}$ e $\mathrm{H}_{2}$ com a razão $\mathrm{H}_{2} / \mathrm{CO}$ tipicamente variando entre 5,0:1 e 1,7:1 (RICE; MANN, 2007). A razão $\mathrm{H}_{2} / \mathrm{CO}$ pode variar conforme o tipo de insumo e também com o método de produção da mistura. 
Apesar da possibilidade de poder ser produzido a partir de diversos insumos, o mais comum para a produção de gás de síntese na indústria química é o gás natural (RICE; MANN, 2007).

A reforma do gás natural (em especial do metano) a gás de síntese é dada através de quatro processos distintos: oxidação parcial, reforma autotérmica, reforma a vapor e reforma seca (IYER et al., 2003).

A figura 3.2 apresenta um esquema simplificado dessas reações.

Figura 3.2 - Rotas de produção de gás de síntese

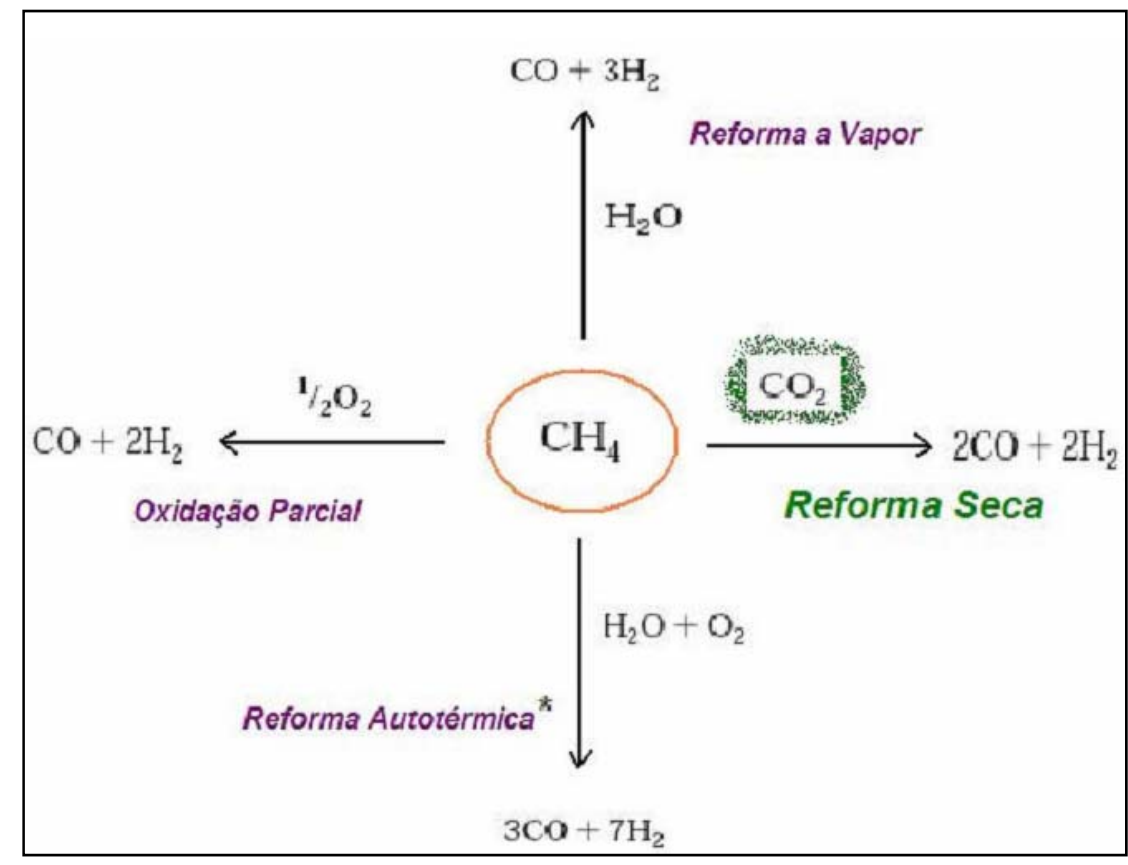

Fonte: Elaboração própria. ( ${ }^{*} \mathrm{~A}$ Reforma Autotérmica consome $3 \mathrm{CH}_{4}$ )

O gás de síntese é utilizado na indústria química para a obtenção de amônia, $\mathrm{H}_{2}$ e metanol, assim como é utilizado em outros processos como oxo-álcoois, ácido acético, anidro acético, fosgênio e acrilatos. Também é utilizado como fonte de hidrogênio para processos de refino de petróleo como: hidrocraqueamento, hidrotratamento e hidrodesulfurização (RICE; MANN, 2007). 
Existem quatro principais tecnologias de produção de gás de síntese bem estabelecidas (PEÑA et al. 1999, VOSLOO, 2001; BAKKERUD, 2005; KESHAV e BASU, 2007):

- Reforma a Vapor (Steam Methane Reforming - SMR)

- Oxidação Parcial (Partial Oxidation - POX)

- Reforma Autotérmica (Autothermal Reforming - ATR)

- Reforma Combinada (Combined ou Two-step Reforming)

Entre os quatro processos citados é possível identificar dois processos básicos distintos para a produção do gás de síntese: a reforma a vapor e a oxidação parcial. Os outros dois são combinações desses dois processos (KESHAV; BASU, 2007).

Quando considerado o número de plantas em funcionamento, a SMR é a tecnologia comercialmente dominante (WILHELM et al., 2001; RICE e MANN, 2007). Quando se utiliza como critério a capacidade total de produção do gás de síntese das plantas em funcionamento, a POX é o processo atualmente dominante (HIGMAN; VAN DER BURGT, 2003). Essa diversidade é conseqüência da diferença de escala entre a indústria química, onde a SMR é dominante, e a indústria de energia, onde o processo POX tem sido preferencialmente utilizado.

Além das quatro principais e bem estabelecidas tecnologias para a produção de gás de síntese, podemos citar outras tecnologias que também estão disponíveis, como por exemplo, a Reforma Compacta (Compact Reforming-CP), Reforma de Alto Fluxo (High Flux Reformer-HFR), Haldor Topsoe Convective Reformer (HTCR), Oxidação Parcial de Alta Eficiência (High Efficiency Oxidation Process-HOP), Reforma por Membranas Cerâmicas (Ceramic Membrane Reforming-CMR), a Reforma com Trocador de Calor (Heat Exchange Reforming-HER), Reforma com Trocador de Calor entre Produtos e Insumos (Product/Feed Heat Exchange- P/F $\mathrm{HE}$ ), a Reforma com Gás Aquecido (Gas-Heated Reforming - GHR), etc. (BAKKERUD, 2005). 
Todos esses novos processos, de uma forma ou de outra, são baseados e utilizam uma ou mais das principais tecnologias já citadas (SMR, POX e ATR). Essas tecnologias são patenteadas e fruto de pesquisas das principais empresas envolvidas com a produção de gás de síntese para posterior produção de seu principal insumo, seja ele amônia, hidrocarbonetos, metanol, ou outro qualquer.

Embora algumas ainda não sejam comerciais, estas tecnologias possuem um grande potencial para dominarem o mercado futuro das plantas de geração de gás de síntese, pois foram desenvolvidas com o objetivo exclusivo de propiciar a redução nos custos de operação e de capital, seja através do aumento da eficiência energética, da redução do consumo de insumos ou da obtenção de produtos com maior pureza, eliminando etapas subseqüentes no processo.

\subsubsection{Reforma a Vapor}

A reforma a vapor (SMR) consiste basicamente na conversão do gás natural por reação com vapor de água em altas temperaturas em um processo catalítico. Tanto a alta temperatura quanto a grande quantidade de calor requeridas nesse processo, são fornecidas através de queimadores localizados no interior dos fornos, onde se encontram reatores tubulares, nos quais ocorre o processo de conversão (GEROSA, 2007; KESHAV e BASU, 2007; SONG e GUO, 2006; RICE e MANN, 2007).

As principais reações ocorridas nesse processo podem ser representadas de forma simplificada pela equação 3.1 e equação 3.2 (KESHAV e BASU, 2007; BHARADWAJ e SCHMIDT, 1995; RICE e MANN, 2007).

$$
\begin{array}{lll}
\mathrm{CH}_{4}+\mathrm{H}_{2} \mathrm{O} \rightarrow \mathrm{CO}+3 \mathrm{H}_{2} & \Delta \mathrm{H} 298 \mathrm{~K}=205,92 \mathrm{~kJ} / \mathrm{mol} & \text { (Equação 3.1) } \\
\mathrm{CH}_{4}+\mathrm{CO}_{2} \rightarrow 2 \mathrm{CO}+2 \mathrm{H}_{2} & \Delta \mathrm{H} 298 \mathrm{~K}=247,32 \mathrm{~kJ} / \mathrm{mol} & \text { (Equação 3.2) }
\end{array}
$$

Como pode ser visto através das equações 3.1 e 3.2, a reforma a vapor é um processo endotérmico que ocorre na presença de catalisador (normalmente a base de níquel). Opera-se o processo com excesso de vapor em relação às quantidades 
estequiométricas de vapor/carbono (V/C) variando de 2:5 a 4:5 (MATAR, 2000), em temperaturas na faixa e $750^{\circ} \mathrm{C}$ a $900^{\circ} \mathrm{C}$ e pressões entre $20 \mathrm{~atm}$ e $50 \mathrm{~atm}$.

No SMR é necessário trabalhar com excesso de um dos reagentes, no caso, o vapor, para deslocar o equilíbrio químico no sentido direto das reações, ou seja, seguindo o princípio de Le Chatellier (GEROSA, 2007). De acordo com Marschner e Renner (2002), o excesso não deve alterar ou prejudicar o resultado do processo.

Outra razão, pela qual se deve utilizar um excesso de vapor, é a de prevenir a deposição de carbono na superfície do catalisador. Esta deposição poderia causar um fenômeno conhecido como hot-spot, o que reduziria a vida útil deste (GEROSA, 2007).

Dependendo do uso a que se destina o gás de síntese, as plantas de reforma a vapor possuem, além do reator de reforma a vapor, unidades complementares. Por exemplo, as plantas destinadas à produção de $\mathrm{H}_{2}$ possuem uma unidade dedicada à reação de deslocamento de água (Water-Gas-Shift - WGS), que tem o papel de aumentar a produção de $\mathrm{H}_{2}$ pela reação abaixo representada (BHARADWAJ e SCHMIDT, 1995; PEÑA et al., 1999):

$$
\mathrm{CO}+\mathrm{H}_{2} \mathrm{O} \rightarrow \mathrm{CO}_{2}+\mathrm{H}_{2} \quad \Delta \mathrm{H} 298 \mathrm{~K}=-41 \mathrm{~kJ} / \mathrm{mol}
$$

A reação representada pela equação 3.3 é levemente exotérmica e ocorre também durante a produção normal do gás de síntese, porém em menor extensão por conta da temperatura em que o processo se passa.

Uma grande vantagem do processo SMR é que este não necessita de uma planta auxiliar para o fornecimento de oxigênio, o que resulta em uma redução nos custos e no espaço destinado à instalação da planta.

Apesar dessa vantagem este processo apresenta problemas como 0 consumo de energia, o custo de construção e a obtenção do gás de síntese relativamente rico em hidrogênio, com uma razão $\mathrm{H}_{2} / \mathrm{CO}$ entre 3 e 5 , que é alta em relação à razão ideal necessária para a síntese FT (KESHAV; BASU, 2007). 
Uma razão $\mathrm{H}_{2} / \mathrm{CO}$ mais adequada para a síntese de FT pode ser obtida com a reciclagem ou adição de $\mathrm{CO}_{2}$ ao insumo da reação. Apesar dessa possibilidade, a adição de $\mathrm{CO}_{2}$ pode causar problemas como a formação de carbono devido à reação de decomposição do metano, representada pela equação 3.4 , problemas com a desativação de catalisadores e metal dusting corrosion, como resultado da Reação de Boudouard, representada pela equação 3.5 (SONG e GUO, 2006; PEÑA et al., 1999).

$$
\begin{array}{ll}
\mathrm{CH}_{4} \rightarrow \mathrm{C}+2 \mathrm{H}_{2} & \Delta \mathrm{H} 298 \mathrm{~K}=75 \mathrm{~kJ} / \mathrm{mol} \\
2 \mathrm{CO} \rightarrow \mathrm{C}+\mathrm{CO}_{2} & \Delta \mathrm{H} 298 \mathrm{~K}=172 \mathrm{~kJ} / \mathrm{mol}
\end{array}
$$

A reciclagem ou adição de $\mathrm{CO}_{2}$ ao insumo da reação é muito atrativa, uma vez que contribui para o consumo de $\mathrm{CO}_{2}$ e $\mathrm{CH}_{4}$, principais causadores do efeito estufa e pelo potencial energético da produção de $\mathrm{H}_{2}$, que pode ser destinado a células combustíveis, contribuindo para transformar o custo do seqüestro de $\mathrm{CO}_{2}$ em benefícios econômicos (MAITRA e EDWARDS, 1995).

Hou et al (2006) testaram catalisadores de diversos tipos de materiais $(\mathrm{Ru}$, $\mathrm{Rh}, \mathrm{Pt}, \mathrm{Ir}, \mathrm{Ni}, \mathrm{Co}$ ) para esta síntese, com sucesso na inibição da formação de coque, e obtiveram uma conversão de $\mathrm{CO}_{2}$ de até $85 \%$, nas condições reacionais de 1 bar e $800^{\circ} \mathrm{C}$.

O processo SMR exige que a matéria-prima de entrada seja isenta de compostos sulfurosos, pois os mesmos são considerados como veneno para o catalisador a base de níquel, reduzindo a sua vida útil (SUPP; BREJC; MIRON, 2002).

\subsubsection{Oxidação Parcial}

A oxidação parcial consiste na reação de hidrocarbonetos (em especial o metano) com certa quantidade de oxigênio, insuficiente para que aconteça a combustão completa, que ocorre em faixas de temperaturas entre $1100^{\circ} \mathrm{C}$ e $1600^{\circ} \mathrm{C}$ e pressões de até $15 \mathrm{MPa}$, para produção de gás de síntese (GENROSA, 2007). 
Neste processo, o metano misturado com pequena quantidade de vapor é oxidado dentro do reator, gerando o dióxido de carbono que reage com o próprio metano, gerando monóxido de carbono e hidrogênio. Ocorre também a reação do metano com o vapor d'água, tal como na reforma a vapor, porém em menor escala. A primeira reação, altamente exotérmica, produz energia para as duas etapas subseqüentes que são endotérmicas. O processo global é exotérmico.

As reações do processo POX podem ser representadas pelas equações 3.1, 3.2 e 3.6 ou pela reação global 3.7 (AASBERG-PETERSEN et al., 2001; BASINI, 2005):

$$
\begin{array}{llll}
\mathrm{CH}_{4}+2 \mathrm{O}_{2} \rightarrow \mathrm{CO}_{2}+2 \mathrm{H}_{2} \mathrm{O} & \Delta \mathrm{H}=-889 \mathrm{~kJ} / \mathrm{mol} & \text { (Equação 3.6) } \\
\mathrm{CH}_{4}+\mathrm{CO}_{2} \rightarrow 2 \mathrm{CO}+2 \mathrm{H}_{2} & \Delta \mathrm{H}=247 \mathrm{~kJ} / \mathrm{mol} \text { (Equação 3.2) } \\
\mathrm{CH}_{4}+\mathrm{H}_{2} \mathrm{O} \rightarrow \mathrm{CO}+3 \mathrm{H}_{2} & \Delta \mathrm{H}=206 \mathrm{~kJ} / \mathrm{mol} \text { (Equação 3.1) } \\
\mathrm{CH}_{4}+1 / 2 \mathrm{O} 2 \rightarrow \mathrm{CO}+2 \mathrm{H}_{2} & \Delta \mathrm{H}=-58 \mathrm{~kJ} / \mathrm{mol} \text { (Equação 3.7) }
\end{array}
$$

A composição do gás de síntese obtido tanto no processo SMR, quanto no POX pode ser manipulada dentro de certos limites. Isso é possível com a alteração de algumas condições do processo e/ou com a adição de novas etapas. Apesar da possibilidade de manipulação, a necessidade de uma razão $\mathrm{H}_{2} / \mathrm{CO}$ de aproximadamente 2 para a síntese de FT não permite uma utilização totalmente satisfatória da SMR ou da POX para aplicações GTL (WILHELM et al., 2001).

Outra variável crítica é o teor de metano no gás de síntese (que deve estar abaixo de $3 \% \mathrm{v} / \mathrm{v}$ em base seca). Neste caso, por exemplo, a rota POX acaba precisando aplicar temperaturas muito elevadas $\left(1300^{\circ} \mathrm{C}-1400^{\circ} \mathrm{C}\right)$ para obter elevada conversão de metano e reduzir a formação de fuligem, isto leva a custos muito altos de investimento e operação (BASINI, 2005).

O deslocamento de água (equação 3.3), equilíbrio do metano (equação 3.1), equilíbrio do ácido sulfídrico (equação 3.8), produção e equilíbrio de $\mathrm{CO}_{2}$ (equações 3.9 e 3.2) são variáveis capazes de alterar o tempo padrão, a fim de que o equilíbrio do processo seja atingido, bem como influenciar na estequiometria de saída (GEROSA, 2007). 


$$
\begin{array}{lll}
\mathrm{CO}+\mathrm{H}_{2} \mathrm{O} & \rightarrow \mathrm{CO}_{2}+\mathrm{H}_{2} & \text { ( Equação 3.3 ) } \\
\mathrm{CH}_{4}+\mathrm{H}_{2} \mathrm{O} \rightarrow \mathrm{CO}+3 \mathrm{H}_{2} & \text { ( Equação 3.1) } \\
\mathrm{H}_{2} \mathrm{~S}+\mathrm{CO}_{2} \rightarrow \mathrm{H}_{2} \mathrm{O}+\mathrm{COS} & \text { ( Equação 3.8 ) } \\
\mathrm{CO}+1 / 2 \mathrm{O}_{2} \rightarrow \mathrm{CO}_{2} & \text { (Equação 3.9) } \\
\mathrm{CH}_{4}+\mathrm{CO}_{2} \rightarrow 2 \mathrm{CO}+2 \mathrm{H}_{2} & \text { (Equação 3.2 ) }
\end{array}
$$

Existem dois tipos de oxidação parcial, a catalítica e a não-catalitica. O que diferencia os dois tipos é a presença ou não de catalisador. Todas as reações citadas anteriormente ocorrem, compulsoriamente, no interior do reator.

Para unidades não catalíticas, as reações de 3.1, 3.2, 3.3, 3.8 e 3.9 ocorrem e a temperatura de saída da mistura gasosa tende a ser mais alta. Neste tipo de processo, é necessária a instalação de unidades de remoção de $\mathrm{CO}_{2}$ e compostos sulfurosos antes do envio do gás de síntese para as unidades de produção de amônia e metanol.

$\mathrm{Na}$ oxidação parcial catalítica, a conversão química ocorre no reator sem 0 uso de um queimador (AASBERG-PETERSEN et al., 2001; BAKKERUD, 2005; KESHAV e BASU, 2007).

Nas unidades de POX catalítico, a matéria prima de entrada deve estar isenta de compostos sulfurosos, já que estes danificam o catalisador. Logo, a reação 3.8 não ocorre. A presença do catalisador faz com que a temperatura do processo seja um pouco mais baixa. Dessa forma, a temperatura de saída da mistura gasosa é de aproximadamente $1000^{\circ} \mathrm{C}$ (GEROSA, 2007).

\subsubsection{Reforma Auto-térmica}

A reforma auto-térmica consiste na junção dos dois processos anteriores (SMR e POX). O gás natural (basicamente metano) é misturado e reagido com vapor e oxigênio, sendo queimado em uma câmara de combustão. O processo é dito autotérmico, pois a necessidade energética da reação da reforma a vapor é suprida pela própria reação de oxidação parcial. 
As reações representadas pelas equações $3.1,3.3$ e 3.10 representam o processo (AASBERG-PETERSEN et al., 2001):

$$
\begin{array}{lll}
\mathrm{CH}_{4}+3 / 2 \mathrm{O}_{2} \rightarrow \mathrm{CO}+2 \mathrm{H}_{2} \mathrm{O} & \Delta \mathrm{H}=-520 \mathrm{~kJ} / \mathrm{mol} & \text { (Equação 3.10) } \\
\mathrm{CH}_{4}+\mathrm{H}_{2} \mathrm{O} \rightarrow \mathrm{CO}+3 \mathrm{H}_{2} & \Delta \mathrm{H}=206 \mathrm{~kJ} / \mathrm{mol} & \text { (Equação 3.1) } \\
\mathrm{CO}+\mathrm{H}_{2} \mathrm{O} \rightarrow \mathrm{CO}_{2}+\mathrm{H}_{2} & \Delta \mathrm{H}=-41 \mathrm{~kJ} / \mathrm{mol} & \text { (Equação 3.3) }
\end{array}
$$

O agente oxidante utilizado pode ser o gás atmosférico ou oxigênio puro.

O gás parcialmente oxidado passa através de um leito catalítico, normalmente de níquel, onde ocorre a reação do metano não queimado com o vapor, graças ao elevado conteúdo energético do gás de combustão gerado na câmara. A Reforma autotérmica gera uma menor formação de fuligem, com menor consumo de oxigênio quando comparada com a Oxidação Parcial.

A ATR faz uso de catalisador, na presença de oxigênio e vapor, para a reforma do gás natural. Por apresentar condições menos severas que a POX, como a temperatura de saída dos gases em aproximadamente $1.000^{\circ} \mathrm{C}$, e utilizar a razão V/C maior que 1,3, o gás de síntese obtido não apresenta fuligem, e apresenta menos amônia e HCN quando comparado ao processo POX (VOOSLO, 2001).

Analisando-se a ATR sob os aspectos relacionados às condições de processo tais como, temperatura e pressão, nota-se seu posicionamento entre o SMR e o POX. Seus valores típicos para temperatura e pressão estão na faixa de 2 a $4 \mathrm{MPa}$ e $800^{\circ} \mathrm{C}$ a $1000^{\circ} \mathrm{C}$, respectivamente (MARSCHNER, 2002). Outras fontes de pesquisa consultadas, tal como Chen (2005), apontam temperaturas de até $1200^{\circ} \mathrm{C}$.

A reação de combustão ocorre rapidamente e gera elevada temperatura no interior do reator. Como o processo exige a injeção de oxigênio, é recomendável que exista uma planta de separação e limpeza do ar atmosférico, o que encarecerá o processo. A necessidade ou não da planta de separação está relacionada ao uso final do gás de síntese produzido. 
O processo ATR tem como vantagem a produção de um gás de síntese ideal para vários processos posteriores a conversão (GEROSA, 2007).

A razão $V / C$ de 1,3 resulta em um gás de síntese com uma razão $\mathrm{H}_{2} / \mathrm{CO}$ de aproximadamente 2,5 , que ainda é mais alta que a necessária para a síntese de FT (VOOSLO, 2001; BASINI, 2005).

$\mathrm{O}$ controle para a obtenção de uma razão adequada de $\mathrm{H}_{2} / \mathrm{CO}$ pode ser conseguido com a combinação da redução da razão $\mathrm{V} / \mathrm{C}$ e a reciclagem de $\mathrm{CO}_{2}$ para o reformador (VOOSLO, 2001; RICE e MANN, 2007). Apesar dessa possibilidade, quanto maior a reciclagem do gás rico em $\mathrm{CO}_{2}$ para o reformador, maior terá que ser capacidade da etapa de produção de gás de síntese por tonelada de produto, consequentemente os custos e as dimensões também aumentarão.

A geração do gás de síntese com composição que permita a aplicação direta em processos Fischer-Tropsch está condicionada a altas temperaturas na reforma e a razões V/C baixas, na ordem de 0,3 (WILHELM et al., 2001).

Comercialmente, utilizam-se razões V/C de 1,3, o que permite a obtenção de gás de síntese com razão $\mathrm{H}_{2} / \mathrm{CO}$ de 2,5. Porém, testes realizados pela Sasol e Haldor Topsøe na planta da Sasol na África do Sul apresentaram resultados positivos para razões V/C menores que 1,3 (VOSLOO, 2001).

De acordo com Chen (2005), quando o processo ATR é realizado nas condições ideais de operação, com uma quantidade correta e precisa de ar, combustível e vapor, a eficiência teórica pode ser maior que a do processo SMR convencional $(93,9 \%$ contra $91,7 \%)$.

Uma vantagem do processo ATR é a sua flexibilidade para as matérias primas de entrada, pois é possível trabalhar tanto com hidrocarbonetos gasosos, denominados leves, quanto os mais pesados, tais como a nafta petroquímica, gasolina e óleo diesel. 
Entre os processos SMR, o POX (catalítico e não catalítico) e a ATR, este ultimo é o mais recente e o que mais precisa ser melhorado. De acordo com Chen (2005), grandes evoluções poderão surgir com respeito à redução da relação oxigênio:carbono. Isto deverá significar uma redução na temperatura do processo. $O$ ideal seria ter-se entre $650^{\circ} \mathrm{C}$ e $900^{\circ} \mathrm{C}$. O autor também aponta que avanços nas pesquisas dos catalisadores deverão reduzir o tempo de residência nos reatores.

O processo ATR oferece grande perspectivas de melhorias tanto para sua utilização sozinha como em conjunto como é o caso da tecnologia Haldor Topsøe Exchange Reformer (HTER) (BAKKERUD, 2005).

\subsubsection{Reforma Combinada ou Secundária}

Quando o conceito ATR é aplicado a reatores que utilizam, como insumo, gases parcialmente reformados em um reformador preliminar, estes reatores formam uma subcategoria no processo ATR chamada de reforma combinada ou secundária (WILHELM et al., 2001; KESHAV e BASU, 2007). A figura 3.3 apresenta um esquema característico da reforma combinada:

Figura 3.3 - Produção do gás de síntese pela pré-reforma adiabática e reforma autotérmica.

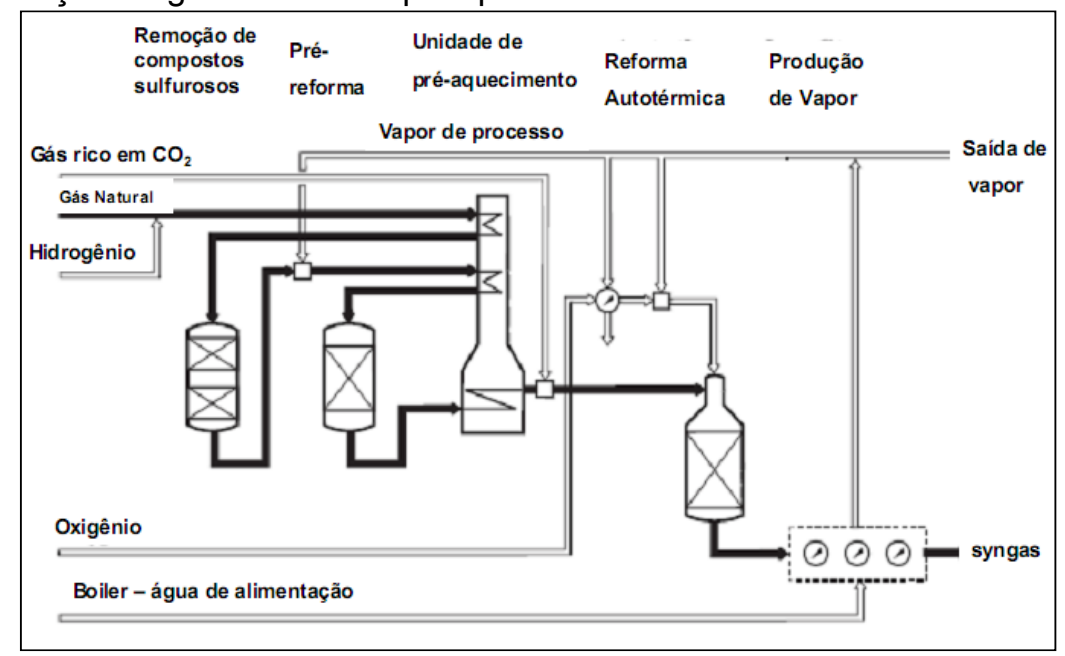

Fonte AASBERG-PETERSEN et al., 2003).

A principal característica desse processo é que o primeiro estágio, baseado na SMR, e o segundo estágio, baseado na ATR, ocorrem em diferentes reatores (KESHAV; BASU, 2007). As principais etapas do processo são: dessulfurização, pré- 
reforma (adiabatic pré-reforming), ATR e recuperação de calor (AASBERGPETERSEN et al, 2003).

A pré-reforma é um processo adiabático, que ocorre num reator de leito fixo com uso de $\mathrm{Ni}$ como catalisador. Nesta etapa, os hidrocarbonetos são convertidos em uma mistura de $\mathrm{CH}_{4}, \mathrm{H}_{2}$ e $\mathrm{CO}_{2}$ (AASBERG-PETERSEN et al., 2003).

Nesta configuração a parte principal da síntese de gás em uma unidade GTL é a ATR, mas o uso da pré-reforma reduz o volume de $\mathrm{O}_{2}$ consumido em relação ao volume de produto obtido (AASBERG-PETERSEN et al., 2003).

O gás de baixa pressão obtido na primeira etapa SMR tem a sua pressão aumentada no processo ATR, eliminando a necessidade de um compressor e consequentemente o custo associado a sua utilização. Apesar disso, a utilização de dois reatores aumenta os custos envolvidos (KESHAV; BASU, 2007).

Uma planta GTL pode ter sua eficiência térmica aumentada em 1 ou $2 \%$, dependendo do grau de integração energética e de condições específicas de operação, com a utilização da reforma combinada (VOOSLO, 2001).

Os custos envolvidos na reforma combinada são menores que a SMR e maiores que a ATR e a sua utilização dependerá do custo do gás natural (VOOSLO, 2001).

A ATR e a Reforma combinada são distintas, mas os usuários e os fornecedores das tecnologias nem sempre fazem essa distinção. Na maioria dos casos a reforma combinada é chamada de ATR. A maioria das plantas comerciais envolve as duas tecnologias, especialmente plantas de metanol que utilizam oxigênio e plantas para a produção de amônia que utilizam ar no lugar de oxigênio (WILHELM et al., 2001). 


\subsection{SÍNTESE DE FISCHER-TROPSCH}

A síntese de Fischer-Tropsch (FT) é considerada o coração da tecnologia Gas-to-Liquids. Na síntese de FT, por meio de reações exotérmicas, o gás de síntese é convertido em uma mistura complexa de hidrocarbonetos lineares, nãolineares e produtos oxigenados, sendo os principais produtos hidrocarbonetos parafínicos de longa cadeia linear e por a-olefinas (TAVASOLI et al, 2006; LAAN, 1999; STELMACHOWSKI e NOWICKI, 2003). Esta conversão, catalisada por metais, é altamente exotérmica e sua reação pode ser esquematicamente representada pela equação 3.11 (DIJK, 2001).

$$
\mathrm{nCO}+2 \mathrm{nH}_{2} \rightarrow-\left(\mathrm{CH}_{2}\right) \mathrm{n}-+\mathrm{nH}_{2} \mathrm{O} \quad \Delta \mathrm{H}=-165 \mathrm{~kJ} / \mathrm{mol} \quad \text { (Equação 3.11) }
$$

A etapa da síntese de FT é formada por: reatores, reciclagem e compressão do gás de síntese que não foi convertido na síntese $\mathrm{FT}$, remoção do $\mathrm{H}_{2}$ e do $\mathrm{CO}_{2} \mathrm{e}$ separação dos produtos da síntese de FT (LAAN, 1999).

Considerando que o maior custo de investimento entre os processos envolvidos na tecnologia GTL consiste na etapa de obtenção do gás de síntese, o processo de conversão FT deve utilizar este gás com a maior eficiência possível. Isso faz com que a seletividade do processo seja considerada parâmetro chave na otimização da etapa de conversão. Neste aspecto, a formação de hidrocarbonetos de cadeias superiores a cinco átomos de carbono deve ser preferida à formação de metano e outros gases de baixa massa molar (TAVASOLI et al., 2006). As principais reações ocorridas durante a síntese de FT estão resumidas na tabela 3.1. 
Tabela 3.1 - Principais reações da síntese de Fischer-Tropsch

\begin{tabular}{ll}
\hline Reações Principais & \\
\hline 1. Produção de Parafinas & $(2 \mathrm{n}+1) \mathrm{H}_{2}+\mathrm{n} \mathrm{CO} \rightarrow \mathrm{C}_{\mathrm{n}} \mathrm{H}_{2 \mathrm{n}+2}+\mathrm{n} \mathrm{H}_{2} \mathrm{O}$ \\
\hline 2. Produção de Olefinas & $2 \mathrm{n} \mathrm{H}_{2}+\mathrm{n} \mathrm{CO} \rightarrow \mathrm{C}_{\mathrm{n}} \mathrm{H}_{2 \mathrm{n}}+\mathrm{n} \mathrm{H} \mathrm{H}_{2} \mathrm{O}$ \\
\hline 3. Deslocamento de Gás d'água & $\mathrm{CO}+\mathrm{H}_{2} \mathrm{O} \leftrightarrow \mathrm{CO}_{2}+\mathrm{H}_{2}$ \\
\hline Reações Secundárias & \\
\hline 4. Produção de Álcoois & $2 \mathrm{n} \mathrm{H}_{2}+\mathrm{n} \mathrm{CO} \rightarrow \mathrm{C}_{\mathrm{n}} \mathrm{H}_{2 \mathrm{n}+2} \mathrm{O}+(\mathrm{n}-1) \mathrm{H}_{2} \mathrm{O}$ \\
\hline 5. Reação de Boudouard & $2 \mathrm{CO} \rightarrow \mathrm{C}+\mathrm{CO}_{2}$ \\
\hline Reações de Modificação no Catalisador & \\
\hline \hline 6. Redução/ Oxidação do Catalisador & a. $\mathrm{M}_{\mathrm{x}} \mathrm{O}_{\mathrm{y}}+\mathrm{y} \mathrm{H} \mathrm{H}_{2} \leftrightarrow \mathrm{y} \mathrm{H} \mathrm{H}_{2} \mathrm{O}+\mathrm{x} \mathrm{M}$ \\
\hline 7. Formação de Carbeto & b. $\mathrm{M}_{\mathrm{x}} \mathrm{O}_{\mathrm{y}}+\mathrm{y} \mathrm{CO} \leftrightarrow \mathrm{y} \mathrm{CO}+\mathrm{x} \mathrm{M}$ \\
\hline
\end{tabular}

Fonte: LAAN, 1999.

\subsubsection{Tecnologias para a Síntese de Fischer-Tropsch}

A natureza fortemente exotérmica das reações de Fischer-Tropsch torna a remoção de calor do reator um parâmetro crítico do processo Gas-to-liquids, o que motiva o constante desenvolvimento de novos equipamentos com objetivo de um aproveitamento energético mais eficiente (DALAI e DAVIS, 2008; SILVA, 2004).

Para processos que visam à obtenção de produtos com maiores pesos moleculares, tais como ceras, diesel e lubrificantes especiais, são utilizadas temperaturas entre $200-240^{\circ} \mathrm{C}$, sendo denominadas LTFT (Low Temperature Fischer-Tropsch) (DRY, 2002). A operação em temperaturas mais elevadas (300$350^{\circ} \mathrm{C}$ ), processo chamado HTFT (High Temperature Fischer-Tropsch), é utilizada para produção de nafta (petroquímica) e a-olefinas (MARTíNEZ et al., 2007).

O processo de alta temperatura (HTFT) utiliza o Fe como catalisador, a uma temperatura de aproximadamente $340^{\circ}$. O processo de baixa temperatura (LTFT) utiliza tanto o $\mathrm{Fe}$ quanto o Co como catalisador e opera a uma temperatura aproximada de $230^{\circ} \mathrm{C}$ (VOOSLO, 2001; DRY, 2002). 
Por ser uma reação exotérmica e por causa da alta atividade do catalisador Co, como já dito anteriormente, a troca de calor do reator para o seu resfriamento é fundamental (VOOSLO, 2001). A água é um produto primário da reação de FT e o $\mathrm{CO}_{2}$ pode ser produzido pela reação WGS (LAAN, 1999). A Figura 3.4 mostra as faixas de aplicação para os catalisadores Fe e Co.

Figura 3.4 - Insumos e catalisadores

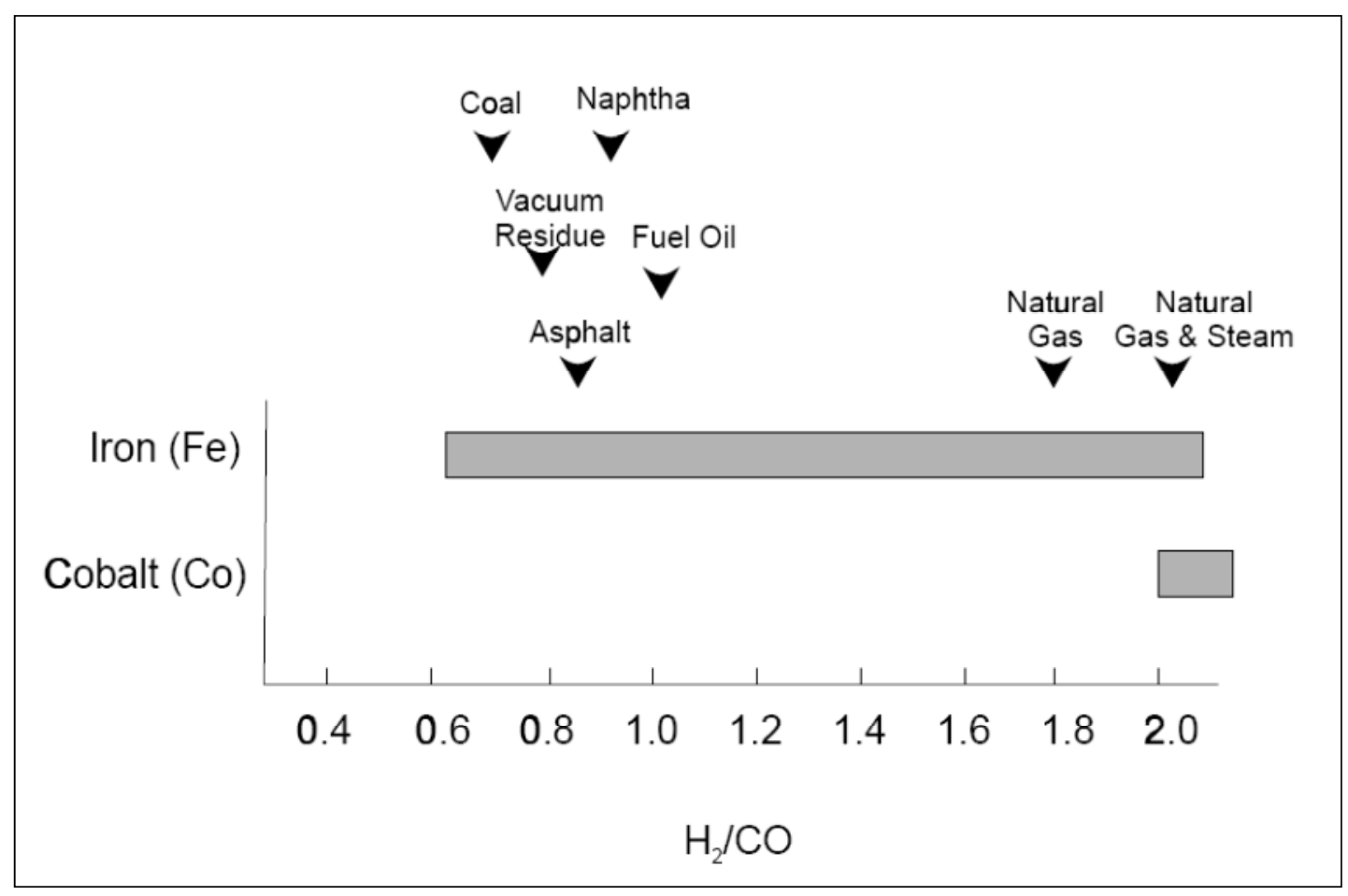

Fonte: LAAN, 1999.

Embora a distribuição de produtos demonstre a característica de polimerização da síntese de Fischer-Tropsch, seu mecanismo de crescimento de cadeias ainda não está plenamente consolidado e ainda é objeto de muito estudo (SILVA, 2004).

Outro aspecto importante no desenvolvimento de reatores comerciais é o grande número de produtos gerados com diferentes pressões de vapor. 


\subsubsection{Reatores para a síntese de Fischer-Tropsch}

Conforme Steynberg et al. (1999), Espinoza et al. (1999) e Dry (2002), são quatro os principais modelos de reatores encontrados na indústria:

1. Reator de leito fixo multi-tubular ou tipo Arge (Multi Tubular Trickle Bed Reactor) (Figura 3.5a);

2. Reator de leito fluidizado circulante ou tipo Kellogg (riser) (Circulating Fluidized Bed Reactor) (Figura 3.5b);

3. Reator de leito fluidizado (Fluidized Bed Reactor) (Figura 3.5c);

4. Reator de leito fluidizado trifásico ou reator de leito de lama (Slurry Bubble Column Reactor) (Figura 3.5d).

Figura 3.5 - Reatores para a síntese de Fischer-Tropsch: a. Reator de leito fixo multi-tubular; b. Reator de leito fluidizado circulante (CFB); c. Reator de leito fluidizado (FFB); d. Reator de leito de lama

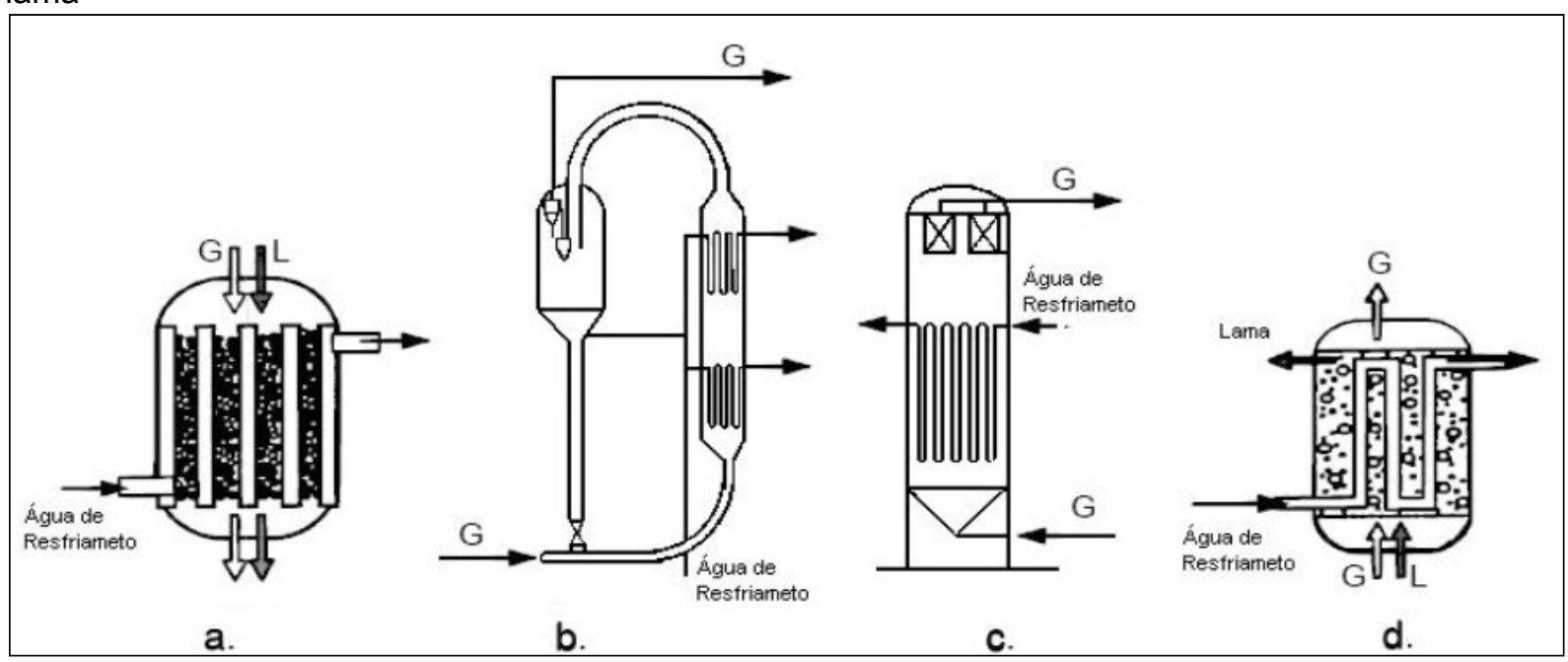

Fonte: LAAN, 1999.

Os reatores de leito fixo multi-tubular e os de leito de lama são normalmente utilizados para operações a baixa temperatura (LTFT) e os de leito fluidizado (CFB e FFB) para operações a alta temperatura (HTFT) (DRY, 2002).

Os diferentes projetos básicos para cada tipo de reator mostram características e limitações no que concerne aos requisitos básicos da reação, tais como: capacidade de transferência de calor, perda de carga, tempo de residência, regeneração ou troca de catalisador e comportamento do catalisador. As diversas 
faixas possíveis de produtos gerados também impõem limitações para a escolha do reator (DRY, 2002).

Os reatores de leito fixo multi-tubulares (Figura 3.5a) são utilizados para a produção de parafinas lineares de alta massa molar. O calor liberado na reação FT é removido pela água que circula ao redor dos tubos reatores, com geração de vapor. Sendo o principal objetivo a produção de parafinas, estes reatores operam a temperaturas relativamente baixas $\left(\sim 225^{\circ} \mathrm{C}\right)$. Em temperaturas mais elevadas (acima de $280^{\circ} \mathrm{C}$ ), além de ocorrer uma redução na seletividade para a produção da parafina, é possível ocorrer a deposição de fuligem sobre as partículas do catalisador, que pode levar ao entupimento do reator (plugging) (DRY, 1990).

Os reatores de leito fluidizado circulante (CFB) (Figura 3.5b) são utilizados para a produção de olefinas e óleos de baixa massa molar. A produção de óleos pesados e parafinas devem ser evitadas, pois um excessivo molhamento do catalisador pode resultar na aglomeração de partículas com conseqüente perda de fluidização do leito. A remoção do calor gerado na reação ocorre parcialmente em trocadores de calor e parcialmente pela corrente de gases efluentes do reator (DRY, 1990; ALMEIDA et al., 2004).

Os reatores do tipo leito fluidizado (FFB) (Figura 3.5c) foram desenvolvidos posteriormente ao CFB e, na época, estimava-se que seu custo seria $50 \%$ do custo de um reator CFB de capacidade equivalente. Os FFB's são reatores mais simples e de menor porte.

Steynberg et al. (1999) e Dry (2002) descrevem muitas vantagens apresentadas pelo modelo de leito fluidizado borbulhante quando comparado ao modelo CFB tipo Kellogg. Os custos de construção do FFB são 40\% menores, sendo que para uma mesma capacidade, o FFB em geral é menor. O inventário do catalisador utilizado no reator FFB está sempre na zona de reação, fazendo com que a razão catalisador/gás seja duas vezes superior. Em termos energéticos, as velocidades do gás de alimentação, por não precisar arrastar o catalisador consigo, são reduzidas no FFB, fazendo com que o seu diâmetro seja maior, possibilitando gerar uma maior quantidade de vapor devido à área da sua serpentina ser superior. 
Ainda conforme o autor, outras vantagens incluem menor razão de reciclo e menor queda de pressão no leito, reduzindo os custos do compressor para reciclo do gás, facilidade para scale-up, menor consumo de catalisador e menor taxa de deposição de coque.

Finalmente, os reatores de leito de lama (3.5d) são similares aos reatores do tipo FFB, exceto pelo catalisador estar suspenso em uma fase líquida, como parafina fundida resultante da síntese de FT. Nesses reatores, o gás de síntese é alimentado pelo fundo, sendo distribuídos pelo vaso no qual se encontram dispersos produtos líquidos da reação com partículas do catalisador sólido suspensas. Os gases reagentes se difundem das bolhas de gás através da fase líquida para a partícula do catalisador, onde reagem. Os hidrocarbonetos mais pesados permanecem em suspensão na fase slurry (lama), enquanto que os produtos gasosos e o gás de síntese não convertido saem pelo topo. Assim como no outro modelo usado no processo LTFT, há uma serpentina que gera vapor decorrente da troca térmica (ESPINOZA et al., 1999).

Geerlings et al. (1999) compararam os dois modelos utilizados no processo LTFT. Apresentou como vantagens para utilização dos multi-tubulares a facilidade de scale-up, a ausência de uma etapa necessária para separação das partículas do catalisador dos produtos líquidos, a ausência de problemas relacionados ao atrito do catalisador e a possibilidade de utilizar uma maior carga de catalisador dentro do reator. No entanto, o reator de leito de lama não apresenta limitações quanto à difusão intrapartícula por utilizar partículas com menor diâmetro, a operação é próxima da isotermicidade devido à excelente troca térmica e os catalisadores podem ser adicionados ou removidos durante a operação.

Os primeiros estudos mostraram que, para elevadas temperaturas $\left(\sim 320^{\circ} \mathrm{C}\right)$, o reator de leito de lama possui menor conversão do que o sistema multi-tubular. Além disto, nessas condições, a parafina é hidrocraqueada resultando em uma perda da fase líquida média. Portanto, o reator de lama não compete com os sistemas FFB/CFB e foi, então, concebido como uma alternativa para o reator multitubular de leito fixo para produção de parafinas a baixas temperaturas (DRY, 1990). 
As vantagens e desvantagens das duas principais tecnologias de reatores F-T utilizadas para obtenção de produtos de alta massa molar, reator de leito fixo multitubular e reator de lama, são mostradas na tabela 3.2.

Tabela 3.2 - Vantagens e desvantagens para os reatores de leito fixo multi-tubulares e reatores de leito de lama

\begin{tabular}{|c|c|c|}
\hline & Reator de leito fixo multi-tubular & Reator de leito de lama \\
\hline Vantagens & Maior fator de escala (10 000) & $\begin{array}{l}\text { Baixa perda de carga no reator } \\
\text { Excelente característica de } \\
\text { transferencia de calor } \\
\text { Sem limites para difusẫo } \\
\text { Reposiçẫo contínua de catalisador } \\
\text { Menor custo }\end{array}$ \\
\hline Desvantagens & $\begin{array}{l}\text { Tamanho das particulas de } \\
\text { catalisador (maiores) } \\
\text { Necessidade de distribuiçâo } \\
\text { uniforme das correntes de gás e } \\
\text { líquido em todos os tubos } \\
\text { Maior peso } \\
\text { Maior custo }\end{array}$ & $\begin{array}{l}\text { Menor fator de escala ( } 500 \text { ) } \\
\text { Necessidade de separaçâo entre o } \\
\text { catalisador e os produtos liquidos } \\
\text { Perda de finos de catalisador em } \\
\text { virtude do atrito entre as particulas }\end{array}$ \\
\hline
\end{tabular}

Fonte:LAAN, 1999.

As empresas detentoras de tecnologias Gas to Liquids estão constantemente buscando a otimização de seus processos. A Sasol, a Rentech e a Exxon utilizam em seus processos reatores de leito de lama e a Shell e a Syntroleum utilizam reatores de leito fixo multi-tubulares (CHEM SYSTEMS, 2001). A tabela 3.3 apresenta a evolução ocorrida na tecnologia dos reatores utilizados pela Sasol a partir da década de 50. 
Tabela 3.3 - Evolução na tecnologia dos reatores da empresa Sasol

\begin{tabular}{|c|c|c|}
\hline & $\begin{array}{c}\text { ALTA TEMPERATURA } \\
\text { Reações e Produtos: Fase Gás } \\
\text { Produtos: Gasolina e Olefinas Leves }\end{array}$ & $\begin{array}{l}\text { BAIXA TEMPERATURA } \\
\text { Produtos: Fase Liquida } \\
\text { Produtos: Principalmente Diesel }\end{array}$ \\
\hline 1950 a 1980 & $\begin{array}{c}\text { Tecnologia: Reator Synthol } \\
\text { Tipo: CFB } \\
\text { Período: } 1950 \text { a } 1987\end{array}$ & $\begin{array}{l}\text { Tecnologia: Reator Arge } \\
\text { Tipo: Leito fixo multi-tubular } \\
\text { Período: } 1950 \text { a } 1985\end{array}$ \\
\hline A partir de 1990 & $\begin{array}{c}\text { Tecnologia: Reator Advanced Synthol } \\
\text { Tipo: FFB } \\
\text { Período: a partir de } 1989 \text { (atual) }\end{array}$ & $\begin{array}{c}\text { Tecnologia: Reator Slurry Phase } \\
\text { Tipo: Leito de lama } \\
\text { Periodo: a partir de } 1993 \text { (atual) }\end{array}$ \\
\hline
\end{tabular}

Fonte: HEYDENRICH, 2005.

\subsubsection{Catalisadores}

Como ocorre na maioria dos processos industriais, os catalisadores empregados na Síntese de Fischer-Tropsch são heterogêneos. Em termos gerais, dentre as principais vantagens da catálise heterogênea comparada à homogênea destaca-se a facilidade na separação do catalisador, a flexibilidade na sua regeneração e os menores custos associados (MOULIJN; MAKKEE; VAN DIEPEN, 2001).

A composição do catalisador utilizado no processo é dependente do tipo de tecnologia empregada na reação. No processo HTFT, a reação é realizada exclusivamente com catalisadores à base de ferro em reatores de leito fluidizado borbulhante ou de leito fluidizado circulante. A sua aplicação no processo LTFT possui uma maior variabilidade. A unidade SASOL-1 utiliza dois diferentes tipos de catalisadores à base de ferro para seus modelos de reatores (multi-tubular e slurry). A unidade da Shell utiliza catalisadores à base de cobalto em reatores de leito fixo multi-tubulares, enquanto que a planta da Oryx utiliza o mesmo tipo de catalisador, mas em reatores slurry (DE KLERK, 2008).

Conforme Dry (2002), os catalisadores utilizados no processo FT possuem como fase ativa metais de transição tais como $\mathrm{Fe}, \mathrm{Ni}$, Co e $\mathrm{Ru}$, os quais apresentam atividade necessária para sua aplicação comercial. 
Embora todos os metais do grupo VIII possuam alguma atividade para a formação da ligação C-C durante a hidrogenação de $\mathrm{CO}$, os metais com maior atividade para a síntese de Fischer-Tropsch, em ordem decrescente, são: rutênio $(\mathrm{Ru})$, ferro $(\mathrm{Fe})$, cobalto $(\mathrm{Co})$ e níquel $(\mathrm{Ni})$. Esta atividade está relacionada com a capacidade dos metais de dissociar a ligação CO (DIJK, 2001).

Os catalisadores mais utilizados comercialmente são os catalisadores à base de ferro ou cobalto. Segundo Dijk (2001) a principal desvantagem para a utilização de níquel como catalisador é a formação de compostos voláteis, carbonila-metal, o que limita a pressão de reação e, conseqüentemente, reduz a produtividade dos reatores FT. Em condições industriais, catalisadores à base de $\mathrm{Ni}$ produziriam principalmente metano. Apesar de o rutênio ser o metal de maior atividade catalítica na síntese de FT, seu uso está limitado a estudos acadêmicos em função do seu alto custo no mercado.

Catalisadores à base de ferro, cujo custo é relativamente baixo, possuem como fase ativa carbeto de ferro formado durante a síntese. Óxidos de ferro também são formados e atuam como catalisadores da reação de deslocamento de gás d'água (water-gas-shift) a qual é muito útil quando o gás de síntese é originado a partir da gaseificação do carvão, o qual tipicamente possui uma razão $\mathrm{H}_{2} / \mathrm{CO}$ muito baixa, havendo excesso de CO (YANG et al., 2004; WAN et al., 2006; HAYAKAWA, TANAKA e FUJIMOTO, 2007). Esta alta atividade em relação à reação de deslocamento de água resulta em uma baixa eficiência de carbono para o processo Gas to Liquids, justificada por uma maior perda de carbono na forma de $\mathrm{CO}_{2}$. À elevada temperatura $\left(\sim 340^{\circ} \mathrm{C}\right)$, catalisadores à base de ferro são seletivos para a formação de olefinas de baixa massa molar, com baixa seletividade para formação de metano. A aplicação desses catalisadores para a produção de parafinas de alta massa molar é limitada em função da tendência para formação de carbono elementar, o que causa desativação do catalisador.

Os catalisadores contendo cobalto como metal ativo têm a sua aplicação exclusivamente nos processos LTFT, visto produzirem excesso de metano e $\mathrm{CO}_{2} \mathrm{em}$ temperaturas mais altas (DRY, 2002). Os catalisadores à base de cobalto, de maior custo, possuem como fase ativa cobalto metálico, justificado pela baixa tendência de 
formação de carbeto de cobalto nas condições de processo. A atividade da reação de deslocamento de água é baixa para estes catalisadores, o que faz com que a água seja o principal produto oxigenado da reação.

Comparados aos catalisadores à base de ferro, os catalisadores à base de cobalto possuem maior seletividade para formação de hidrocarbonetos pesados, pois as olefinas tendem a ser readsorvidas no catalisador dando continuidade ao processo de crescimento de cadeia (DIJK, 2001).

A maior atividade por peso do metal, maior resistência à desativação pela água, menor atividade para a reação de deslocamento e a menor produção de oxigenados são vantagens que os catalisadores contendo cobalto apresentam frente aos catalisadores à base de ferro (MARTÍNEZ et al., 2003). Os catalisadores à base de cobalto são quase que exclusivamente do tipo suportados devido ao alto custo deste metal, limitando a sua composição a pequenas quantidades bem dispersas sobre um suporte poroso.

De acordo com a Rentech (2006), licenciadora de tecnologias para síntese de Fischer-Tropsch, uma comparação resumida entre as características dos catalisadores à base de ferro e cobalto é dada na tabela 3.4.

Tabela 3.4 - Características gerais dos principais catalisadores

\begin{tabular}{ccc}
\hline \hline Parâmetro & Ferro (Fe) & Cobalto (Co) \\
\hline \hline Vida Útil & Curta & Longa \\
\hline Custo & Baixo & Elevado \\
\hline Tipo & Precipitado / Fundido & Suportado \\
\hline Razão $\mathrm{H}_{2}: \mathrm{CO}($ Gás de Síntese) & $0,7: 1$ a $2: 1$ & $2: 1$ \\
\hline Característica dos Produtos & Olefinica & Parafinica \\
\hline Subprodutos & $\mathrm{CO}_{2}$, vapor, energia elétrica & $\mathrm{H}_{2} \mathrm{O}$, vapor, energia elétrica \\
\hline
\end{tabular}

Fonte: RENTECH, 2006.

Em função da elevada atividade e vida útil longa, catalisadores à base de cobalto são, atualmente, a melhor escolha para conversão do gás de síntese em combustíveis líquidos (VOSLOO, 2001). 


\subsubsection{Distribuição dos produtos formados}

A síntese de FT é um processo de crescimento das cadeias de carbono na superfície do catalisador. Em cadeias de qualquer comprimento existe a probabilidade de crescimento, pela adição de mais um carbono, ou da interrupção do crescimento, geralmente pela hidrogenação da cadeia. (STELMACHOWSKI; NOWICKI, 2003).

De acordo com Dijk (2001) a distribuição dos produtos da síntese de FischerTropsch pode ser descrita baseada em um processo de polimerização, de acordo com a equação 3.12 :

$$
F n=n(1-\alpha)^{2} \alpha^{n-1}
$$

Onde: Fn é a fração de átomos de carbono convertida em hidrocarbonetos de cadeia com $\mathrm{n}$ átomos de carbono e $\alpha$ a probabilidade de crescimento de cadeia

O mecanismo de reação consiste em uma polimerização que leva a uma distribuição de produtos com diferentes pesos moleculares e que é denominado de distribuição Anderson-Schulz-Flory (ASF). Essa distribuição determina uma relação entre o rendimento do produto e o numero de carbonos, mostrando uma seletividade desde produtos gasosos (hidrocarbonetos leves), passando pelos produtos líquidos (hidrocarbonetos de peso intermediário) até ceras (hidrocarbonetos sólidos).

O modelo proposto por Anderson, Schulz e Flory é um modelo estatístico simples que relaciona de forma linear o logaritmo da massa molar do hidrocarboneto e o seu numero de carbonos.

Fatores como temperatura, pressão e razão $\mathrm{H}_{2} / \mathrm{CO}$ são extremamente importantes para a seletividade da síntese de Fischer-Tropsch e influenciam a distribuição Anderson-Schulz-Flory (ASF) (SILVA, 2004; DIJK, 2001).

Todo o espectro do produto da síntese é caracterizado por um parâmetro singular denominado parâmetro da probabilidade de crescimento de cadeia (a). A figura 3.6 mostra a distribuição de produtos em função de $\alpha$. 
Figura 3.6 - Distribuição teórica mássica de produtos como função da probabilidade de crescimento de cadeia ( $\alpha$ ) de acordo com a distribuição ASF.

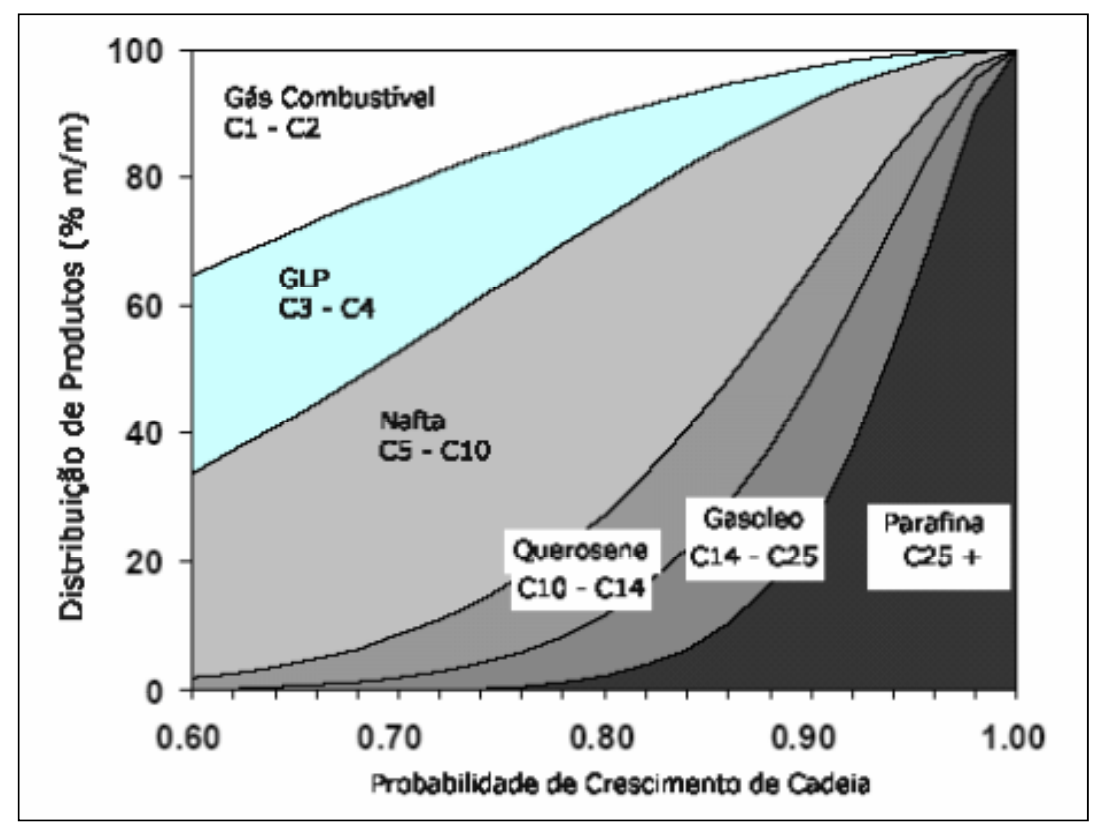

Fonte: Adaptado de DIJK, 2001.

Outra forma de representar a distribuição ASF é apresentada na figura 3.7 onde é possível notar que as cadeias carbônicas cujo comprimento vai de C9 a C11 são contadas duas vezes, em ambos produtos, gasolina e óleo diesel.

Figura 3.7 - Distribuição teórica molar de produtos como função da probabilidade de crescimento de cadeia $(\alpha)$ de acordo com a distribuição ASF.

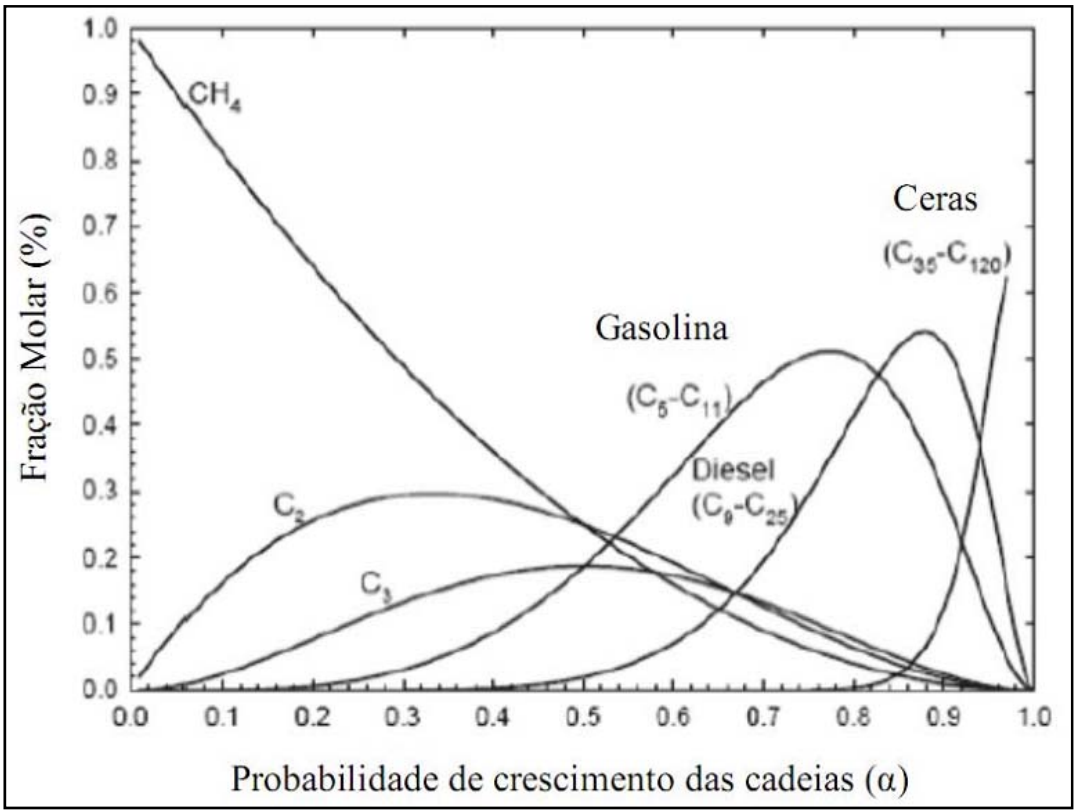

Fonte: Adaptado de LAAN, 1999. 
O parâmetro da probabilidade de crescimento de cadeia ( $\alpha$ ) por sua vez, pode ser obtido a partir da temperatura da reação e frações molares de $\mathrm{H}_{2}$ e CO alimentados, utilizando-se a equação proposta por Song et al. (2004).

$$
\alpha=\left(\mathrm{A} \frac{\mathrm{y}_{C O}}{\mathrm{y}_{H_{2}}+\mathrm{y}_{C O}}+\mathrm{B}\right)[1-0.0039(\mathrm{~T}-533)] \quad \text { (Equação 3.13) }
$$

Os parâmetros $A$ e $B$ são ajustados como $A=0,2332+/-0,0740$, $B=0,6330$ $+/-0,0420$ e a temperatura em Kelvin.

A distribuição ASF é válida somente quando há a presença da constante probabilística de crescimento de cadeias de hidrocarbonetos, uma vez que a reação primordial consiste em uma adição um-a-um de um monômero a cadeia em crescimento. Entretanto, na prática, a distribuição dos produtos difere significativamente da teoria da distribuição ASF, conforme Dijk (2001) e Laan (1999), principalmente devido à hidrogenação e à reinserção das olefinas durante o crescimento das cadeias.

Steynberg e Dry (2004) explicam que a distribuição ASF somente seria possível, sem alterações, se as condições cinéticas no interior do reator fossem constantes a cada ponto da superfície catalítica da síntese o que, em verdade, não é possível de ser obtido.

Os principais desvios experimentais em relação às produções previstas pela distribuição ASF são uma relativa elevação na seletividade para a produção de metano, relativa baixa seletividade para a produção de etano e uma maior seletividade para produção de hidrocarbonetos de alto peso molecular. Dijk (2001) afirma que os produtos primários formados podem, em certo ponto do processo, influenciar a distribuição dos demais hidrocarbonetos, também causando desvios na distribuição teórica ideal proposta por Anderson, Schulz e Flory. 


\section{MATERIAIS E MÉTODOS}

Nesse capítulo são apresentadas as premissas, metodologias e ferramentas utilizadas para simulação, integração mássica e energética e avaliação econômica, a fim de identificar a viabilidade técnica e econômica do projeto em estudo.

\subsection{DESENVOLVIMENTO E SIMULAÇÃO DO PROCESSO}

Antes de iniciar a construção do modelo representativo do processo de produção de petróleo sintético a partir de uma corrente rica em $\mathrm{CO}_{2}$, faz-se necessária a caracterização dessa corrente, assim como uma breve explicação sobre sua origem e a definição de algumas premissas.

\subsubsection{Características da corrente de alimentação}

O petróleo e o gás natural associado a ele, após serem retirados do reservatório, necessitam passar por um processamento inicial, a fim de que possam atender uma especificação mínima e possam deixar a plataforma. A figura 4.1 representa um diagrama de blocos característico de um processamento primário em uma plataforma de petróleo:

Figura 4.1 - Diagrama de blocos característico de um processamento primário de petróleo e gás natural.

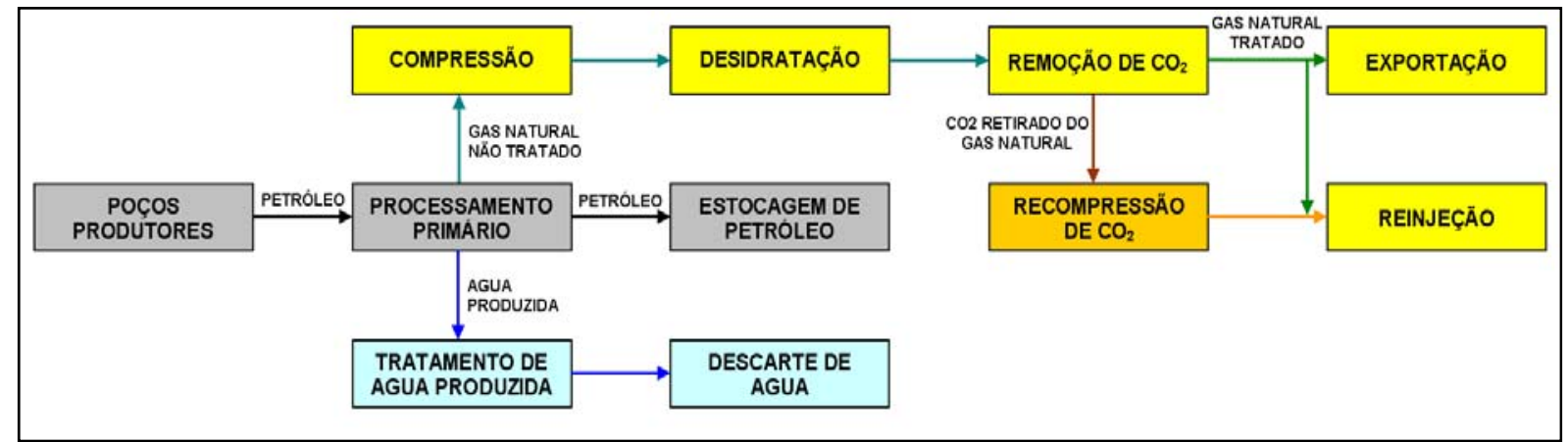

Fonte: Elaboração própria.

Durante o processamento primário de um petróleo rico em $\mathrm{CO}_{2}$, devido às propriedades termodinâmicas desse componente, o mesmo tende a se concentrar nas frações mais leves produzidas, ou seja, o gás natural. Dentre os vários 
problemas causados pela presença de $\mathrm{CO}_{2}$ em alta concentração, a corrosão e a diminuição do poder calorífico (perda de especificação) são os mais importantes, fazendo com que o gás natural necessite de tratamento para remoção desse componente, para que possa ser movimentado e comercializado.

Existem diversas tecnologias, consolidadas ou não, disponíveis para separação do $\mathrm{CO}_{2}$ de correntes de gás natural. Para processos com grande vazão de gás natural a ser tratado e altos teores de $\mathrm{CO}_{2}$, a tecnologia mais adequada é a separação por membranas (BAKER e LOKHANDWALA, 2008).

Normalmente, depois de separada, a corrente rica em $\mathrm{CO}_{2}$ é comprimida e reinjetada no reservatório, a fim de evitar que o mesmo seja lançado na atmosfera.

Neste trabalho, a corrente de permeado da separação por membranas, composta basicamente por $\mathrm{CO}_{2}$ e $\mathrm{CH}_{4}$, ao invés de reinjetada, será convertida em petróleo sintético pelo processo GTL. O diagrama representativo do processamento primário, incluindo o processo em estudo, é apresentado na figura 4.2:

Figura 4.2 - Diagrama de blocos do processamento de petróleo, incluindo o processo proposto.

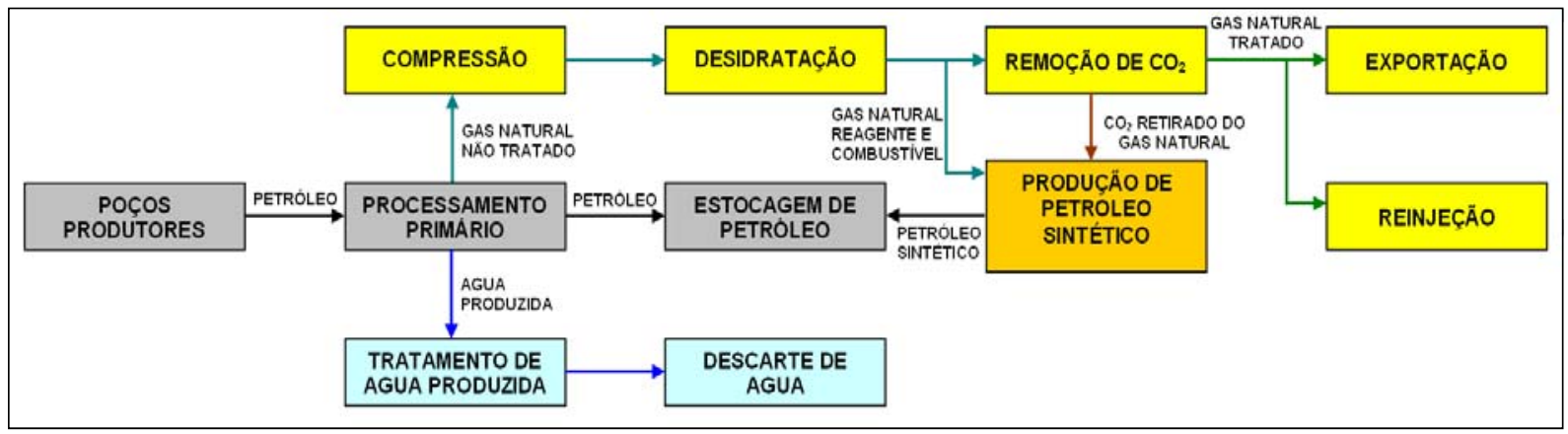

Fonte: Elaboração própria. 


\subsubsection{Premissas adotadas no estudo.}

Como já citado anteriormente, o objetivo principal do trabalho é avaliar a viabilidade da conversão de uma corrente rica em $\mathrm{CO}_{2}$, retirado do gás natural, em petróleo sintético.

A corrente rica em $\mathrm{CO}_{2}$, também chamada de permeado do sistema de membranas, apresenta as seguintes características na entrada do processo, inerentes às condições de saída do processo de tratamento com membranas:

$$
\begin{array}{ll}
\text { - Pressão } & : 300 \mathrm{kPa} \\
\text { - Temperatura } & : 35^{\circ} \mathrm{C} \\
\text { - Composição } & : 55 \% \text { de } \mathrm{CO}_{2} \text { e } 45 \% \text { de } \mathrm{CH}_{4} \\
\text { - Vazão } & : \text { dependente da vazão de gás natural tratado. }
\end{array}
$$

A vazão de alimentação de carga para o processo variará de acordo com o consumo de gás natural requerido pelo processo em análise. Isso porque, o gás natural consumido no processo é retirado da corrente de alimentação das membranas poliméricas, influenciando diretamente na vazão da corrente que passa pelas membranas e, consequentemente da vazão de permeado das membranas, carga do processo.

A conversão do resíduo a petróleo sintético será conduzida em duas etapas:

- Produção do gás de síntese a partir da carga alimentada;

- Produção de petróleo sintético a partir do gás de síntese.

$\mathrm{Na}$ primeira etapa, o resíduo é convertido a gás de síntese, composto basicamente de $\mathrm{H}_{2}$ e $\mathrm{CO}$ através da reforma seca combinada com a reforma a vapor do metano.

A tecnologia SMR (steam methane reforming) combinada à reforma seca foi escolhida por não necessitar de uma unidade de produção de oxigênio (como a tecnologia POX e ATR, por exemplo), reduzindo assim seus custos de implantação e 
operação. A tecnologia SMR foi a tecnologia também adotada na unidade compacta experimental de produção de petróleo sintético da Petrobras construída em parceria com empresa britânica CompactGTL (BAXTER, 2010).

Devido ao caráter predominantemente endotérmico das reações de reforma, há a necessidade do fornecimento de energia para que as mesmas aconteçam. $O$ fornecimento de energia ao reator de reforma é feito pela combustão catalítica do gás natural, retirado do gás que entra nas membranas, com ar atmosférico.

Para a segunda etapa, o gás de síntese produzido na primeira etapa é convertido em petróleo sintético através da síntese de Fischer-Tropsch a baixa temperatura (LTFT).

A tecnologia escolhida para o reator Fischer-Tropsch neste trabalho foi a de leito fixo compacto, também da CompactGTL. Existem algumas unidades no mundo operando com outras tecnologias, como o reator em leito de lama e fluidizado, mas em função de diversos artigos disponíveis na literatura e apesar da dificuldade na remoção do calor gerado em função da elevada exotermicidade da reação, os reatores em leito fixo tendem a apresentar um projeto final mais simples.

Para os equipamentos simulados, foram adotadas as seguintes premissas:

Trocadores $\quad$ : Tipo PCHE com perda de carga de $10 \mathrm{kPa}$; (PERRY) Mínima diferença de temperatura entre as correntes de $15^{\circ} \mathrm{C}$;

Forno : Eficiência de $81 \%$ do PCl; (TURTON, et al, 2012)

Compressores : Eficiência politrópica de 78\%; (TURTON, et al, 2012) Movidos por turbinas a gás com eficiência de $40 \%$ do $\mathrm{PCI}$.

Bombas : Eficiência adiabática de $75 \%$ 


\subsubsection{Descrição do processo proposto.}

O diagrama de blocos simplificado (sem reciclos e integrações energéticas) do processo em análise está representado na figura 4.3:

Figura 4.3 - Diagrama de blocos simplificado do processo de conversão de $\mathrm{CO}_{2}$ a petróleo sintético.

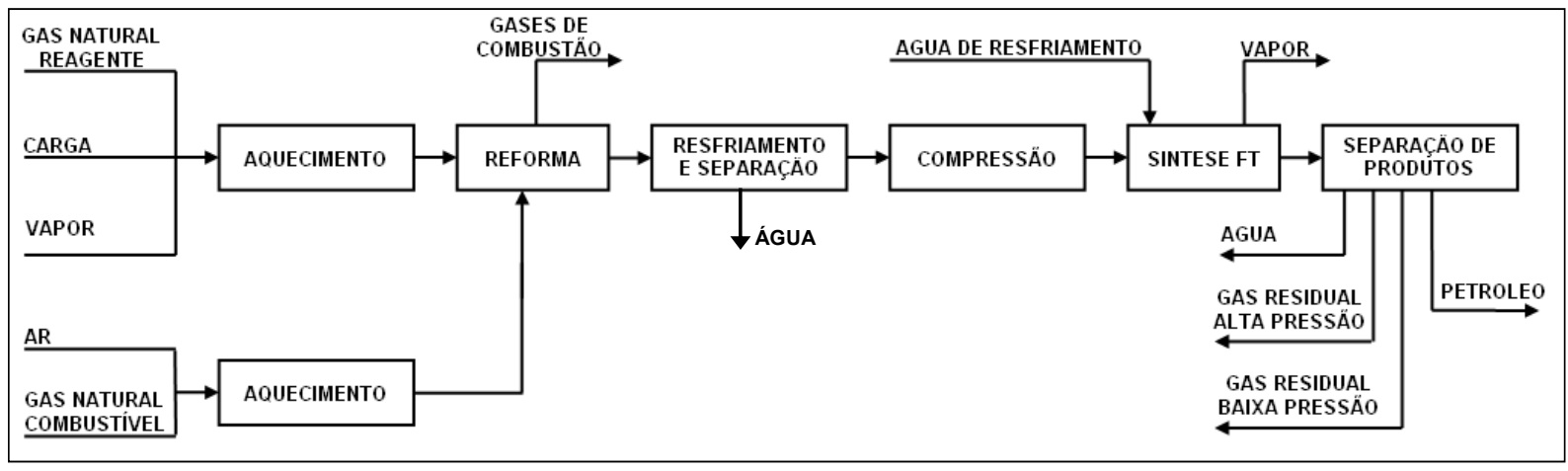

Fonte: Elaboração própria.

A corrente de alimentação do processo (CARGA), contendo $55 \%$ de $\mathrm{CO}_{2} \mathrm{e}$ $45 \%$ de $\mathrm{CH}_{4}$, é aquecida em um forno até a temperatura de reação, $790^{\circ} \mathrm{C}$, e enviada ao reator de reforma.

Antes do aquecimento, ocorre a adição de gás natural (GAS NATURAL REAGENTE) e água (VAPOR) à alimentação. Isso possibilita que a reforma a vapor ocorra, combinada à reforma seca, favorecendo a produção de um gás de síntese com relação $\mathrm{H}_{2} / \mathrm{CO}$, em torno de 2,18 , evitando o consumo do $\mathrm{H}_{2}$ produzido pela reação de water-gas-shift, assim como a deposição de carbono na superfície do catalisador pela decomposição do $\mathrm{CH}_{4}$ em excesso.

Os produtos alimentados no reator de reforma são convertidos a gás de síntese em temperatura de $790^{\circ} \mathrm{C}$ e pressão de $290 \mathrm{kPa}$.

Em comparação com outros processos de reforma que operam com temperaturas da ordem de $900^{\circ} \mathrm{C}$ e pressões mais elevadas, a temperatura da etapa de reforma do processo em estudo será mais baixa e limitada a $790^{\circ} \mathrm{C}$. Isso porque o limite de temperatura indicado pelo ASME VIII para estruturas soldadas (brazed structures), como no caso dos reatores compactos, é de $815^{\circ} \mathrm{C}$. A pressão de 
operação é conseqüência da pressão de saída da corrente de rejeito do processo de membranas, menos as perdas de carga até sua chegada ao reator de reforma. A operação em pressão reduzida também é uma maneira de compensar a limitação de temperatura e aumentar a conversão do processo.

Como as reações envolvidas no processo de reforma são em sua grande maioria endotérmicas, é necessário o fornecimento de energia para que elas ocorram, sendo essa energia fornecida pela combustão catalítica de gás natural com ar atmosférico.

Os produtos das reações de reforma são resfriados até $35^{\circ} \mathrm{C}$ e enviados para um separador bifásico onde a água não reagida e/ou produzida no reator de reforma necessita ser removida, afim de não influenciar no equilíbrio da síntese de FischerTropsch, por ser um de seus produtos. A temperatura de resfriamento está baseada na máxima temperatura de entrada nos compressores e é a temperatura também adotada para o resfriador inter estágios dos compressores.

As pressões aplicadas aos reatores da síntese FT normalmente variam de 10 a 40 bar, sendo que baixas pressões favorecem a produção de gases e altas pressões favorecem a produção de graxas. Para esse trabalho, o gás de síntese, oriundo do separador bifásico, tem sua pressão elevada até $2510 \mathrm{kPa}$, em dois estágios de compressão, e é enviado para o reator da síntese de Fischer-Tropsch.

O gás de síntese é alimentado ao reator da síntese $\mathrm{FT}$ a $187,5^{\circ} \mathrm{C}$ e $2500 \mathrm{kPa}$, condições ideais para o processo a baixa temperatura (LTFT), conforme indicado por Steynberg e Dry (2004). Ainda segundo os autores, a conversão esperada nessas condições é de $80 \%$, conversão essa utilizada nesse trabalho e também coerente com a informada pela CompactGTL para o seu processo.

O gás de síntese alimentado ao reator da síntese FT é convertido em hidrocarbonetos de cadeias com diferentes tamanhos através de reações de polimerização. Os produtos dessa polimerização são os hidrocarbonetos sintéticos propriamente ditos, $\mathrm{CO}_{2}$, gás de síntese não convertido e grande quantidade de água. 
Os produtos do reator da síntese FT são resfriados até $95^{\circ} \mathrm{C}$ e encaminhados para um separador trifásico a fim de separar o petróleo, a água produzida e o gás residual de alta pressão (GRAP). A temperatura de $95^{\circ} \mathrm{C}$ foi adotada a fim de liquefazer a grande maioria da água presente na corrente de produtos da síntese FT.

O petróleo retirado do separador trifásico é resfriado até $50^{\circ} \mathrm{C}$, temperatura máxima para envio do petróleo aos tanques de carga do FPSO, tem sua pressão reduzida para $400 \mathrm{kPa}$, a fim de vaporizar os hidrocarbonetos na fase gasosa que ainda possam estar presentes, e encaminhado para um separador bifásico. Lá, o gás residual de baixa pressão (GRBP) é retirado da corrente de petróleo e encaminhado para reaproveitamento.

O petróleo sintético produzido, com baixo teor de água e pressão de vapor Reid inferior a $12 \mathrm{psi}$, é encaminhado para os tanques de carga, podendo ser misturado ao petróleo produzido pelo FPSO ou ser estocado e exportado separadamente, conforme a conveniência do mercado.

Devido ao caráter extremamente exotérmico das reações envolvidas na síntese Fischer-Tropch, é necessária a utilização de um fluido de resfriamento para remoção da energia gerada. O fluido normalmente utilizado nas plantas GTL e também utilizado neste estudo é a água.

A água de resfriamento é alimentada ao reator $\mathrm{FT}$ a $35^{\circ} \mathrm{C}$, onde é vaporizada à temperatura de $205^{\circ} \mathrm{C}$ e $1711 \mathrm{kPa}$, respeitando a mínima diferença de temperatura de troca térmica entre as correntes de processo, adotada neste estudo. Após deixar o reator FT, o vapor saturado gerado é resfriado e condensado até $35^{\circ}$ e enviado para um vaso pulmão, de onde é bombeado de volta para o reator. 


\subsubsection{Simulação do processo.}

A fim de simular o processo proposto e obter os principais dados utilizados nas análises, foi escolhido o simulador comercial de processos industriais Aspen HYSYS em sua versão 7.3, disponível para uso acadêmico no departamento de Engenharia Química da Escola Politécnica da USP.

Para aplicações envolvendo petróleo, gás e petroquímica, a equação de estado Peng-Robinson é a equação geralmente recomendada, sendo a equação de estado selecionada para as simulações do processo em estudo. Melhorias nesta equação de estado permitem que ela possua uma precisão para uma variedade de sistemas em uma grande variedade de condições. Ela resolve rigorosamente a maioria dos sistemas monofásicos, bifásicos e trifásicos, com um alto grau de eficiência e confiabilidade.

No separador trifásico existente no processo, devido sua a maior importância para o processo, foi priorizado o rigor da separação liquido-gas, também sendo utilizada a equação de estado Peng-Robinson. Apesar disso, devido à considerável diferença de densidades entre o petróleo produzido e a água, não são esperadas diferenças significativas entre a separação óleo-água simulada em relação a real.

$\mathrm{Na}$ definição do elenco de substâncias químicas envolvidas no processo, primeiramente foram selecionadas todas as substâncias participantes das reformas seca e a vapor, além das substâncias relacionadas às reações paralelas as reações de reforma.

Para as substâncias envolvidas na etapa de conversão do gás de síntese foram selecionadas, além das substâncias já envolvidas nas reações de reforma, os hidrocarbonetos de caráter parafínico (ligações simples) de C1 até C30, produzidos pela síntese de Fischer-Tropsch.

Com base nas premissas adotadas, o fluxograma base do processo em análise (sem reciclo e integração energética) em Hysys foi construído e a simulação executada. 
A descrição detalhada dos três reatores utilizados, principais equipamentos do processo, serão detalhados nos sub-capítulos a seguir.

\subsubsection{Reator de reforma}

A principal reação envolvida na etapa de reforma do processo em análise é a reforma seca, representada pela reação abaixo. Nessa reação o $\mathrm{CH}_{4}$ é reformado com $\mathrm{CO}_{2}$ a fim de produzir $\mathrm{CO}$ e $\mathrm{H}_{2}$, também conhecido como gás de síntese.

$$
\mathrm{CO}_{2}+\mathrm{CH}_{4} \rightarrow 2 \mathrm{CO}+2 \mathrm{H}_{2}
$$

Além da reação de reforma seca, outras reações paralelas, desejadas e não desejadas, ocorrem. As principais reações do processo são a reforma a vapor do $\mathrm{CH}_{4}$ e reação de deslocamento da água (WGS), decomposição do $\mathrm{CH}_{4}$ reagente de reações cruzadas, e reações de remoção de carbono. Essas reações estão listadas abaixo (JIANGUO ZHANG, 2008):

$$
\begin{array}{lll}
\mathrm{CO}_{2}+\mathrm{H}_{2} & \rightarrow & \mathrm{CO}+\mathrm{H}_{2} \mathrm{O} \\
\mathrm{H}_{2} \mathrm{O}+\mathrm{CH}_{4} & \rightarrow & \mathrm{CO}+3 \mathrm{H}_{2} \\
\mathrm{CH}_{4} & \rightarrow & \mathrm{C}+2 \mathrm{H}_{2} \\
\mathrm{C}+\mathrm{CO}_{2} & \rightarrow & 2 \mathrm{CO} \\
\mathrm{C}+\mathrm{H}_{2} \mathrm{O} & \rightarrow & \mathrm{CO}+\mathrm{H}_{2} \\
\mathrm{CH}_{4}+2 \mathrm{CO}_{2} & \rightarrow & 3 \mathrm{CO}+\mathrm{H}_{2} \mathrm{O}+\mathrm{H}_{2} \\
\mathrm{CH}_{4}+3 \mathrm{CO}_{2} & \rightarrow & 4 \mathrm{CO}+2 \mathrm{H}_{2} \mathrm{O}
\end{array}
$$

Para representação da etapa de reforma do processo, foi selecionado o reator de Gibbs, disponível na biblioteca do simulador utilizado.

O "reator de Gibbs" calcula a composição de equilíbrio no reator, na pressão e temperatura especificadas, quando a energia livre de Gibbs é mínima. Ele foi escolhido para simplificação da simulação e devido à proximidade de resultados obtidos em comparação a um processo real. 
A temperatura de reação foi especificada pela especificação da temperatura de saída da fase gasosa do reator, sendo a energia consumida durante a reação calculada pelo simulador em função das conversões do reator e representada pela corrente de energia ligada ao reator.

Para especificação da razão $\mathrm{H}_{2} / \mathrm{CO}$ que entra no reator de $\mathrm{FT}$ foi inserida uma função de ajuste na corrente de alimentação de vapor. Quanto maior a injeção de vapor, maior a razão $\mathrm{H}_{2} / \mathrm{CO}$, devido ao favorecimento da reforma a vapor.

Com o aumento da injeção de vapor, ocorre o aumento da conversão de hidrocarbonetos e a diminuição da conversão de $\mathrm{CO}_{2}$, aumentando com isso o teor de $\mathrm{CO}_{2}$ no gás de síntese produzido, o que não é interessante para o reator FT. A injeção de gás natural para as reações de reforma favorece o aumento da conversão de $\mathrm{CO}_{2}$, pois aumenta a disponibilidade de $\mathrm{CH}_{4}$ para as duas reformas (seca e a vapor).

\subsubsection{Combustão catalítica}

Conforme já citado anteriormente, devido ao caráter endotérmico das reações de reforma, é necessário o fornecimento de energia para que essas reações aconteçam da forma desejada. Para este estudo, primeiramente a energia necessária será fornecida pela combustão catalítica adiabática de gás natural com ar atmosférico. Com a evolução do estudo, correntes de gás residual também poderão ser usadas como gás combustível para fornecer energia.

Como simplificação da simulação, assim como no reator de reforma, para o desenvolvimento das reações acima foi utilizado um reator de Gibbs, alimentado por ar atmosférico e gás natural.

Para controle das vazões de alimentação desse reator foram inseridas duas funções, uma de set e uma de ajuste. A primeira ajusta a vazão de ar baseada na vazão de combustível alimentada ao reator, através de uma relação de multiplicação

direta, de forma a controlar a temperatura da combustão (temperatura da chama). Já a segunda, tem a função de controlar a vazão de alimentação de combustível, de 
forma a produzir a energia necessária às reações de reforma. Ela utiliza a energia consumida nas reações de reforma como set-point.

Para cálculo desse reator foi utilizada uma perda de carga de $20 \mathrm{kPa}$, a mesma que foi utilizada no reator de reforma, temperatura de combustão de $810^{\circ} \mathrm{C}$.

Por se tratar de um reator adiabático, toda a energia proveniente da combustão fica na corrente de gases de combustão desse reator. A transferência dessa energia para o reator de reforma é realizada através de um trocador de calor que simula essa transferência de energia, reduzindo a temperatura da corrente de gases exaustos de $810^{\circ} \mathrm{C}$ para $805^{\circ} \mathrm{C}$.

\subsubsection{Reator de Fischer-Tropch}

As principais reações da síntese de FT são as envolvidas na formação dos hidrocarbonetos, sendo essas reações as que serão consideradas na simulação do reator. Para efeito de simplificação da simulação, não foram consideradas as reações de deslocamento da água (water-gas-shift), formações de álcoois, ácidos e de deposição de carbono sobre o catalisador (Boudouard).

Para a simulação do reator da síntese FT foi utilizada a distribuição de produtos ASF (Anderson-Schulz-Flory) que, apesar de apresentar alguns desvios, fornece uma qualidade em seus resultados que atende o requerido pelo trabalho, sendo também o modelo utilizado por El-Halwagi et al. (2010).

Pelo modelo proposto, a distribuição dos produtos obtidos pela síntese FT pode ser obtida através de uma através de uma equação que utiliza um fator "alpha" como principal parâmetro e, este, por sua vez, pode ser correlacionado com as pressões parciais do $\mathrm{H}_{2}$ e $\mathrm{CO}$ alimentados e a temperatura de reação.

Como já citado, neste trabalho serão utilizados reatores do tipo compacto chamados de milicanais. Esses reatores possuem o comportamento de um reator do tipo PFR (Plug Flow Reactor), consistindo-se de milicanais retangulares recheados com pequenas folhas metálicas de baixa queda de pressão revestidas com 
catalisador, por onde passa a mistura reacional. As vantagens da tecnologia são baseadas no uso de canais com pequeno diâmetro para aumentar a transferência de calor e massa em uma ou duas ordens de magnitude. Apesar da taxa de transporte de massa das reações ser inversamente proporcional ao diâmetro dos canais, o processo compensa essa característica com um aumento da área da superfície por unidade de volume, resultando em um aumento do total de produtividade por unidade de volume (TONKOVICH et al., 2004).

Devido às peculiaridades e complexidade das equações cinéticas envolvidas na produção do petróleo sintético, não foi possível a utilização de reatores do tipo PFR, disponíveis na biblioteca do Hysys 7.3.

Devido à impossibilidade de utilização de um reator PFR, foi utilizado um reator de conversão, onde foram inseridas as 30 reações de formação de hidrocarbonetos (C1 até o C30). As conversões de cada uma dessas reações foram calculadas com o uso da ferramenta spreadsheet do simulador.

Foram importadas para o spreadsheet as variáveis: pressão total, fração molar de $\mathrm{H}_{2}$, fração molar de $\mathrm{CO}$, vazão de $\mathrm{CO}$ e temperatura, todas da corrente de alimentação do reator. Essas variáveis foram utilizadas para o cálculo das pressões parciais de $\mathrm{H}_{2}$ e $\mathrm{CO}$, utilizadas para cálculo do alpha e, em seguida, da distribuição dos produtos da síntese F-T.

A partir da distribuição dos produtos (ASF) e das 30 equações para formação de hidrocarbonetos, obteve-se o consumo de CO relativo a cada reação. A partir do consumo relativo e da conversão total de CO adotada, determinou-se a conversão de cada reação.

As conversões calculadas pelo spreadsheet, para cada reação, foram então exportadas para suas respectivas reações no reator de conversão.

$\mathrm{O} \mathrm{CO}_{2}$ quando presente em altas concentrações na alimentação do reator de F-T pode causar o favorecimento de reações para formação de metano e outros hidrocarbonetos de baixo peso molecular, não desejados pelo processo 
(HILDEBRANDT et al., 2010). Dessa forma, a porcentagem máxima de $\mathrm{CO}_{2}$ permitida na alimentação do reator F-T adotada foi de $10 \%$.

\subsection{INTEGRAÇÃO MÁSSICA E ENERGÉTICA.}

A integração de processos (mássica e energética) é uma forma eficiente de a indústria aumentar sua produtividade através da redução no consumo de energia, água e matéria-prima, redução em emissões de gases e na geração de rejeitos.

Neste trabalho, após a simulação do caso base, foram analisadas as possibilidades de integração mássica das correntes residuais do processo e a síntese da rede de trocadores de calor, assim como a análise usando a tecnologia Pinch para identificação das quantidades mínimas de utilidades requeridas para aquecimento e resfriamento das correntes de processo. Esse subcapitulo detalha as análises e metodologias utilizadas.

\subsubsection{Integração mássica.}

A partir da simulação do caso base (sem reciclos mássicos ou energéticos), foram identificadas três correntes com potencial para reaproveitamento (reciclo):

- Água produzida;

- Gás residual de alta pressão;

- Gás residual de baixa pressão.

A primeira corrente é composta basicamente por uma água oleosa que, após uma separação simples, pode ser usada como alimentação no reator de reforma, reduzindo o consumo de água doce do processo e, conseqüentemente, o gasto com a geração dessa matéria-prima. 
Já para as correntes de gás residual as seguintes opções de reciclo são possíveis:

- Carga no reator de reforma;

- Carga no reator FT;

- Queima para fornecimento de energia para as reações de reforma.

Para a corrente de gás residual de alta pressão, devido o seu alto teor de $\mathrm{CO}_{2}$, não reagido na etapa de reforma, o reciclo para o reator FT não é uma opção interessante. Isso porque o seu reciclo aumenta a concentração desse componente na corrente que alimenta o reator $\mathrm{FT}$, obrigando o aumento da injeção de gás natural na etapa de reforma a fim de aumentar a conversão de $\mathrm{CO}_{2}$ nessa etapa e conseguir atender a especificação de entrada do reator $\mathrm{FT}$, em $10 \%$. Logo, o reciclo para o reator de reforma e/ou a queima seriam as opções mais favoráveis para utilização desse gás.

Outra opção para destinação do gás residual de alta pressão é utilizar a separação por membranas para recuperar o $\mathrm{H}_{2}$ presente nessa corrente e reciclá-lo para o reator $\mathrm{FT}$. O rejeito dessa membrana pode ser consumido como combustível ou reciclado para o reator de reforma.

Já para a corrente de baixa pressão, o ideal é o seu consumo como combustível, uma vez que seu alto teor de $\mathrm{CO}_{2}$ não é interessante nem para a síntese FT nem para a reforma. Devido à sua baixa vazão em relação ao gás residual de alta pressão, o seu destino como combustível não apresenta impactos consideráveis ao processo.

Pela análise prévia das opções de reciclo, foram identificadas duas opções de processamento para o gás residual de alta pressão como sendo interessantes para o processo, uma sem (figura 4.4) e uma com uso de membranas para recuperação de $\mathrm{H}_{2}$ (figura 4.5).Para a segunda opção, os dados da separação por membranas foram fornecidos pela empresa Air Liquide e consideram uma recuperação de aproximadamente $90 \%$ do $\mathrm{H}_{2}$ presente na corrente do gás residual. 
Cada opção de processamento possui duas alternativas de encaminhamento do gás que, no caso da opção sem membranas é o próprio gás residual, e na opção com membranas é o rejeito da mesma. Uma alternativa é a queima e a outra o reciclo para o reator de reforma.

Figura 4.4 - Diagrama de blocos da opção sem membrana.

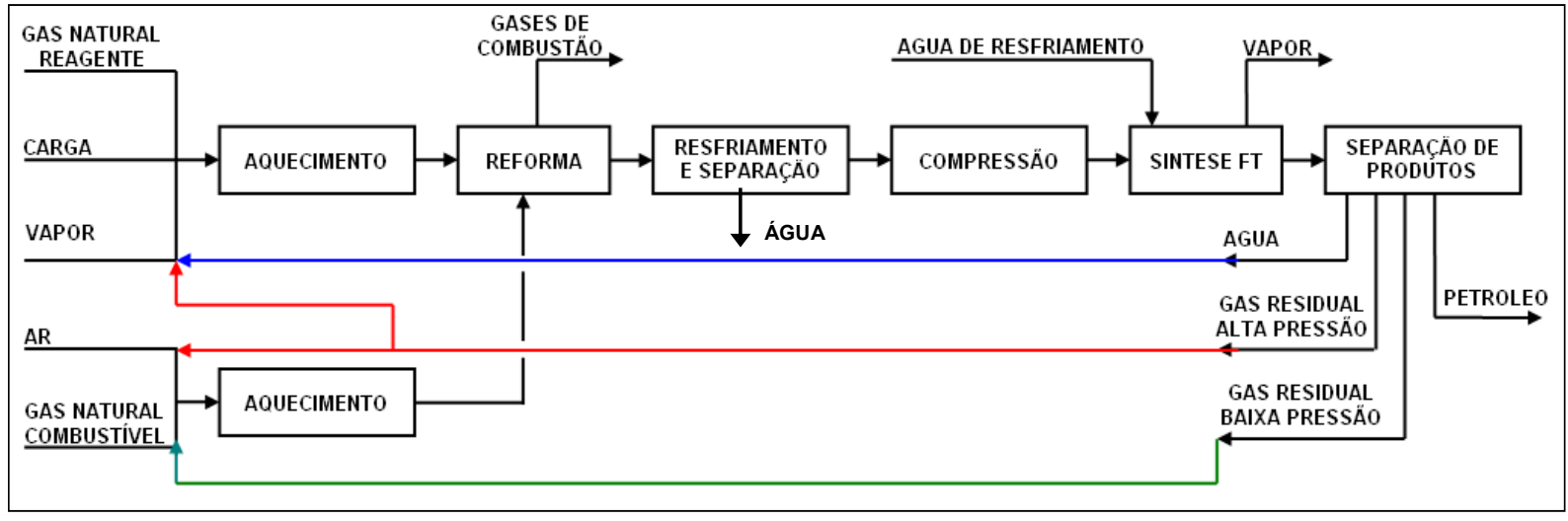

Fonte: Elaboração própria.

Figura 4.5 - Diagrama de blocos da opção com membrana.

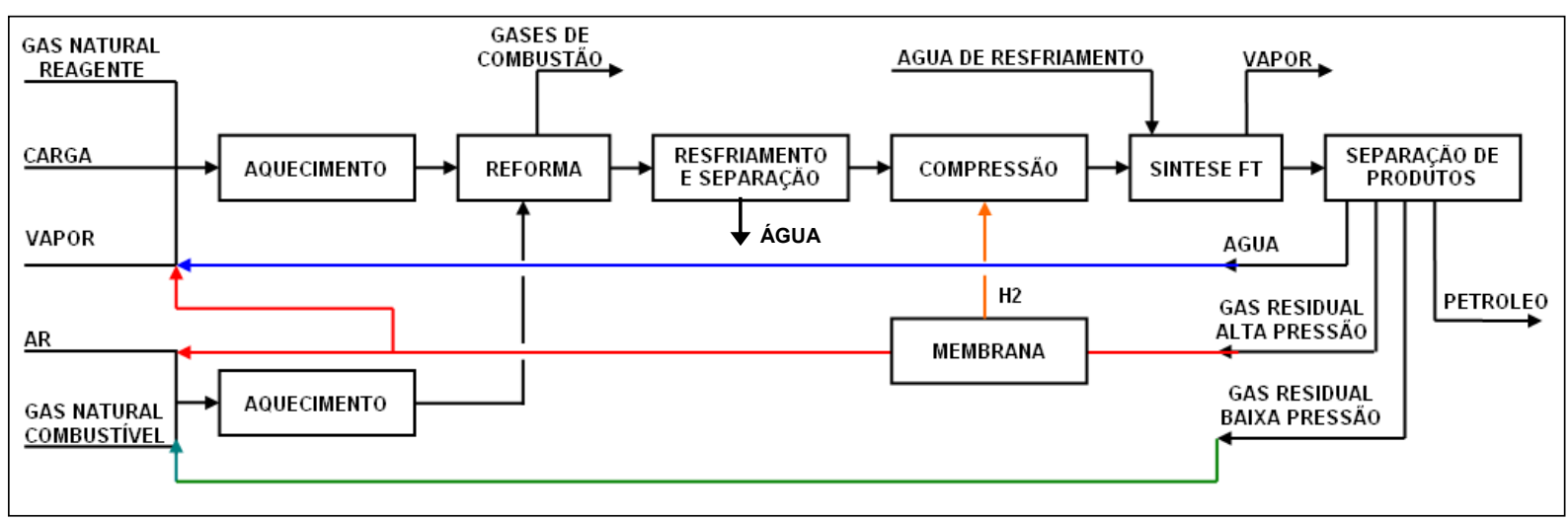

Fonte: Elaboração própria.

As duas opções passaram por uma análise de sensibilidade para seleção da opção tecnicamente mais interessante. $\mathrm{Na}$ análise de sensibilidade, a proporção gás reciclado/gás queimado foi variada de $0 \%$ a $100 \%$, em degraus de $20 \%$, totalizando 10 casos para análise, conforme descrito na Tabela 4.1. 
Tabela 4.1 - Alternativas de integração mássica analisadas.

\begin{tabular}{|c|c|c|c|}
\hline Caso & $\begin{array}{c}\text { Gás } \\
\text { Combustível }\end{array}$ & \multicolumn{2}{|c|}{$\begin{array}{l}\text { Carga para } \\
\text { Reforma }\end{array}$} \\
\hline 1.1.1.1 1 & $80 \%$ & 1.1.1.2 & $20 \%$ \\
\hline 2 & $60 \%$ & \multicolumn{2}{|c|}{$40 \%$} \\
\hline 3 & $40 \%$ & \multicolumn{2}{|c|}{$60 \%$} \\
\hline 4 & $20 \%$ & \multicolumn{2}{|c|}{$80 \%$} \\
\hline 5 & $0 \%$ & \multicolumn{2}{|c|}{$100 \%$} \\
\hline 6 & $80 \%$ & \multicolumn{2}{|c|}{$20 \%$} \\
\hline 7 & $60 \%$ & \multicolumn{2}{|c|}{$40 \%$} \\
\hline 8 & $40 \%$ & \multicolumn{2}{|c|}{$60 \%$} \\
\hline 9 & $20 \%$ & \multicolumn{2}{|c|}{$80 \%$} \\
\hline 10 & $0 \%$ & \multicolumn{2}{|c|}{$100 \%$} \\
\hline
\end{tabular}

Fonte: Elaboração própria.

\subsubsection{Integração Energética.}

O principal objetivo da integração energética de processos é a utilização eficiente da energia contida nas correntes quentes de processo para aquecimento das correntes frias e com isso reduzir os custos com utilidades quentes e frias. Dessa forma, é desejável estabelecer a máxima recuperação de energia possível em um processo, antes de planejar uma rede de trocadores, isto é, determinar as utilidades mínimas requeridas para aquecimento e resfriamento na rede de trocadores, determinando a necessidade de aquecimento e resfriamento requeridos pelo processo (SEADER et al, 2003).

Para a análise energética do processo proposto, será utilizada a tecnologia Pinch, também conhecida como Método do Ponto de Estrangulamento Energético (MPE). A aplicação da análise Pinch para melhor uso da energia de processos industriais é a alternativa mais explorada nos estudos realizados até hoje, embora muitos avanços também tenham sido obtidos em outras aplicações.

A análise energética do processo foi dividida em duas etapas, sendo a primeira a determinação do consumo mínimo de utilidades quentes e frias e 
determinação do ponto de menor diferença de temperatura (temperatura de pinch) e a segunda a síntese da rede de trocadores de calor do processo.

O estudo da síntese da rede de trocadores não se restringe às análises realizadas nesse trabalho. Outras análises envolvendo $\circ$ uso de técnicas mais aprimoradas de otimização matemática (MILP), divisão das correntes que trocam calor na rede, entre outras, são utilizadas quando se necessita de um resultado mais preciso, como por exemplo, na fase de detalhamento de um projeto para posterior construção.

Por se tratar de um estudo conceitual, este trabalho não fará uso de técnicas complexas para realização da análise energética do processo em estudo.

4.2.2.1 Mínimo consumo de utilidades e ponto de menor diferença de temperatura (Pinch).

Primeiramente os dados do processo básicos para a análise energética foram organizados em uma tabela (Tabela-4.2). Os dados básicos das correntes de processo necessários para a aplicação do MPE foram: vazão mássica, temperaturas de entrada ( $(\mathrm{Te})$ e de saída (Ts) e calor específico $(\mathrm{Cp})$, que para esse estudo foi utilizado o valor médio entre o $\mathrm{Cp}$ de entrada e o $\mathrm{Cp}$ de saída. Alternativamente, alguns autores usam as temperaturas e a taxa de capacidade calorífica (M.Cp).

Tabela 4.2 - Exemplo de organização de dados das correntes.

\begin{tabular}{|c|c|c|c|c|}
\hline Número & $\mathrm{Te}\left({ }^{\circ} \mathrm{C}\right)$ & $\mathrm{Ts}\left({ }^{\circ} \mathrm{C}\right)$ & $\mathbf{M C} \mathbf{p}\left(\mathbf{k W} /{ }^{\circ} \mathbf{C}\right)$ & $\mathbf{h}\left(\mathbf{k W} / \mathbf{m}^{20} \mathbf{C}\right)$ \\
\hline 1 & 20 & 135 & 2,0 & 0,7 \\
\hline 2 & 170 & 60 & 3,0 & 0,3 \\
\hline 3 & 80 & 140 & 4,0 & 0,5 \\
\hline 4 & 150 & 30 & 1,5 & 0,3 \\
\hline Util. Quente & 330 & 250 & --- & 0,5 \\
\hline Util. Fria & 15 & 20 & - & 0,5 \\
\hline
\end{tabular}

Fonte: Elaboração própria.

Outro parâmetro importante que deve ser definido desde o inicio é o diferencial mínimo de temperatura (DMT) entre as correntes frias e quentes que trocam energia. Na realidade, o DMT estará presente em alguns trocadores da rede. 
Um valor comumente encontrado na literatura é $10^{\circ} \mathrm{C}$. Para esse estudo, foi adotado, conservativamente, o valor de $\mathrm{DMT}=15^{\circ} \mathrm{C}$.

A determinação do consumo mínimo de utilidades iniciou-se pelo ajuste das temperaturas que alimentam a tabela problema. Isso foi feito reduzindo-se a temperatura de entrada e saída das correntes quentes pelo DMT, mantendo as temperaturas das correntes frias sem alteração. $O$ ajuste da temperatura das correntes quentes em função do DMT visa trazer tanto as correntes quentes quanto as frias para uma mesma referencia, para que os balanços de energia sejam efetuados respeitando o DMT (SEADER et al, 2003).

A partir do ajuste das temperaturas das correntes quentes, todas as temperaturas foram ranqueadas, começando pelo $T_{0}$ para a maior temperatura. Esse ranqueamento de temperaturas foi usado para a construção de um diagrama de intervalos de temperaturas (Figura 4.6), onde as correntes de processo frias de um lado e quentes do outro, foram plotadas, utilizando escalas para cada conjunto, a fim de facilitar a identificação das correntes que participam de cada intervalo.

Figura 4.6 - Exemplo de um diagrama de intervalos de temperaturas.

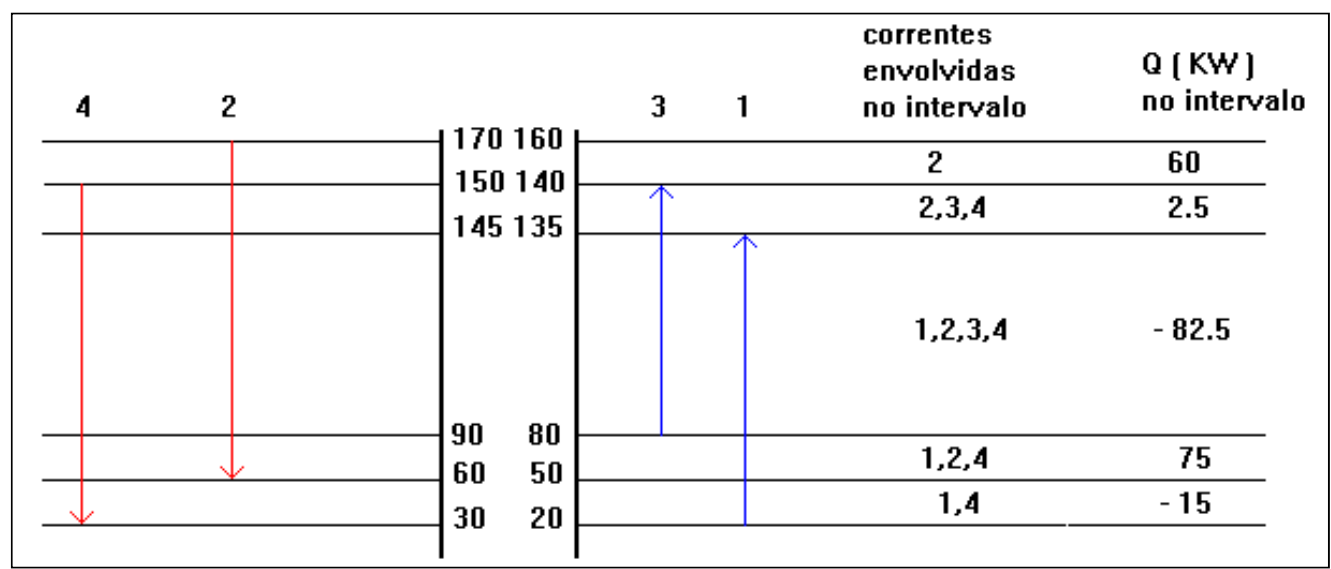

Fonte: Elaboração própria.

As correntes envolvidas em cada intervalo podem trocar energia na medida de suas necessidades respeitando o DMT. Em cada intervalo foi calculado balanço de energia trocado, utilizando o balanço do MCp das correntes que participam do intervalo, multiplicado pelo intervalo de temperatura. A partir desse balanço foi 
construído o diagrama de cascata para apresentação dos resultados referentes ao consumo mínimo de utilidades (Figura 4.7).

Figura 4.7 - Exemplo de um diagrama de cascata (inicial e ajustado)

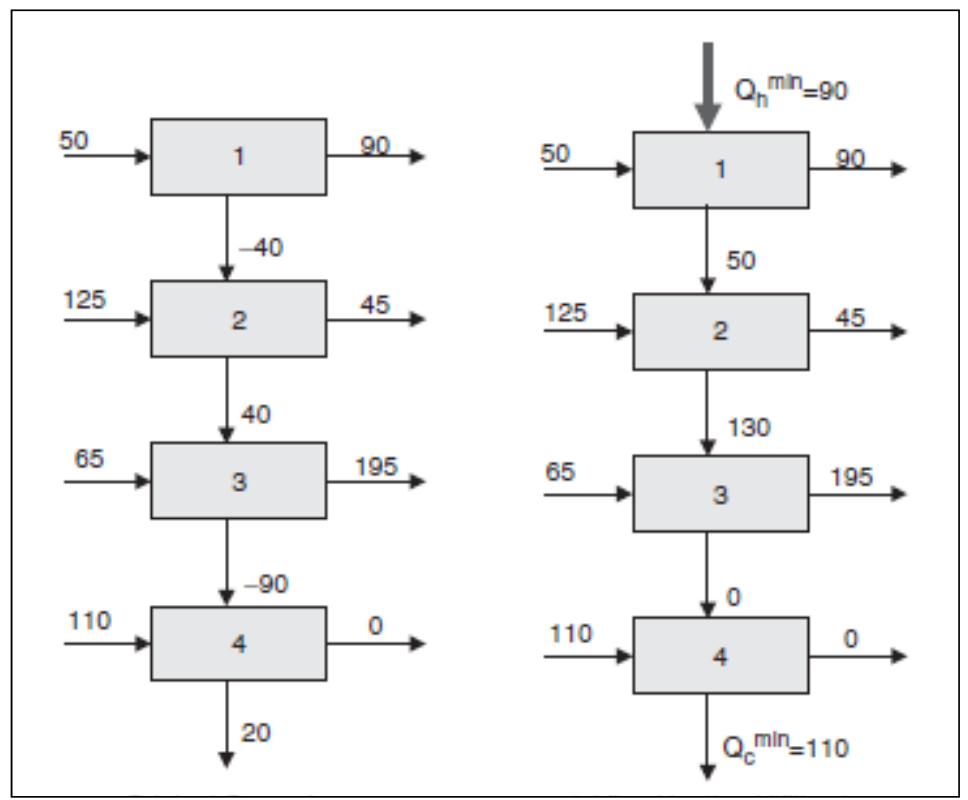

Fonte: EI-HALWAGI, 2003.

Ao final da cascata, havendo resíduos negativos no diagrama, a fim de satisfazer a segunda lei da termodinâmica, estes devem ser removidos porque o calor não pode fluir de uma fonte a baixa temperatura para uma de alta temperatura. A forma de corrigir os residuais negativos é adicionar energia a alta temperatura. Isso foi feito acrescendo o valor do maior resíduo negativo na entrada do diagrama (entrada de utilidade quente). Após essa correção, um dos residuais será zero, ou seja, não haverá passagem de energia pelo limite inferior destes intervalos, definindo assim o chamado Ponto de Estrangulamento Energético - PE (pinch point). Normalmente os processos, quando apresentam pinch, ele é único. O ponto de pinch divide o processo em dois sub-processos: um acima do pinch em equilíbrio com as utilidades quentes e outro abaixo em equilíbrio com as utilidades frias. sendo essa a temperatura do pinch frio (PE) que acrescido do DMT indica a temperatura de pinch quente.

Os somatórios das utilidades quentes e frias utilizadas, nesta condição de cascata com integração no interior e entre os intervalos de temperatura, definem o consumo mínimo de utilidades quente $(\mathrm{Qq})$ e fria $(\mathrm{Qf})$, respectivamente. 
A identificação do PE e as suas características permitem que se realizem as seguintes observações:

(1) não se deve transferir energia pelo PE a fim de que se use o mínimo de utilidades;

(2) acima do PE só se deve usar utilidade quente e abaixo só utilidade fria.

Há processos nos quais se identifica a necessidade de somente um tipo de utilidade, em um determinado DMT. Nestes não há pinch. Eles são chamados de problemas limites (threshold problems). O aumento do DMT pode levar ao aparecimento do PE. Muito menos freqüentes são os problemas com múltiplos PE's. Nestes, a região acima do maior PE está em equilíbrio com as utilidades quentes, enquanto a região abaixo do menor PE encontra-se em equilíbrio com as utilidades frias. As regiões entre os PE's encontram-se equilibradas termicamente, não sendo necessária a utilização de utilidades para fechar os respectivos balanços térmicos.

\subsubsection{Síntese da rede de trocadores de calor}

De posse do consumo mínimo de utilidades e conhecendo o PE, partiu-se para a síntese da rede de trocadores de calor.

Para a síntese da rede de trocadores, o MPE fornece regras para a combinação das correntes que chegam e partem do PE. Para a síntese afastada do PE, o MPE não indica regras específicas, ao contrário, cada problema é trabalhado de forma independente e segundo suas peculiaridades.

Em problemas com um PE, a proposta de rede de trocadores é originada da junção de duas redes sintetizadas de forma independente. Estas redes são originadas a partir das regras do MPE dividindo o problema original em dois subproblemas: um acima do PE no qual somente se deve utilizar utilidades quentes e outro abaixo do PE no qual são utilizadas as utilidades frias.

Existem duas regras para o desenvolvimento de uma rede de trocadores, uma relacionada ao número de correntes e outra relacionando os MCp's das correntes 
participantes da combinação. Essas regras são enunciadas e comentadas a seguir para a região acima do PE. Para a região abaixo do PE, onde se lê quente, leia-se fria e vice-versa e onde se lê acima, leia-se abaixo.

(1) O número de correntes quentes imediatamente acima do PE tem que ser menor ou igual ao número de correntes frias imediatamente acima do PE. Caso contrário, devem-se dividir correntes frias até que o número de correntes quentes e frias se iguale.

A síntese envolvendo correntes que tocam o PE é a mais severa quanto à possibilidade de violação do DMT. Portanto, todas as correntes quentes devem ser retiradas do $\mathrm{PE}$ por correntes frias que tocam o $\mathrm{PE}$, caso contrário haverá necessidade de utilização de utilidade fria acima do PE, o que gera consumo acima do mínimo.

(2) Deve-se combinar a corrente quente imediatamente acima do PE que tenha MCp menor ou igual ao MCp da corrente fria também imediatamente acima do PE.

Quando se realiza uma combinação entre uma corrente quente e uma corrente fria que tocam o PE, a extremidade do trocador de calor com essas temperaturas já estará com a diferença de temperaturas entre as correntes, igual ao DMT. Assim, caso essa regra seja violada, o diferencial na outra extremidade necessariamente será menor que o DMT.

O resultado da combinação das correntes envolvidas nas trocas térmicas da unidade, respeitando as regras estabelecidas para essa combinação, é uma rede de trocadores, conforme a figura 4.8. 
Figura 4.8 - Exemplo de uma rede integrada de trocadores de calor.

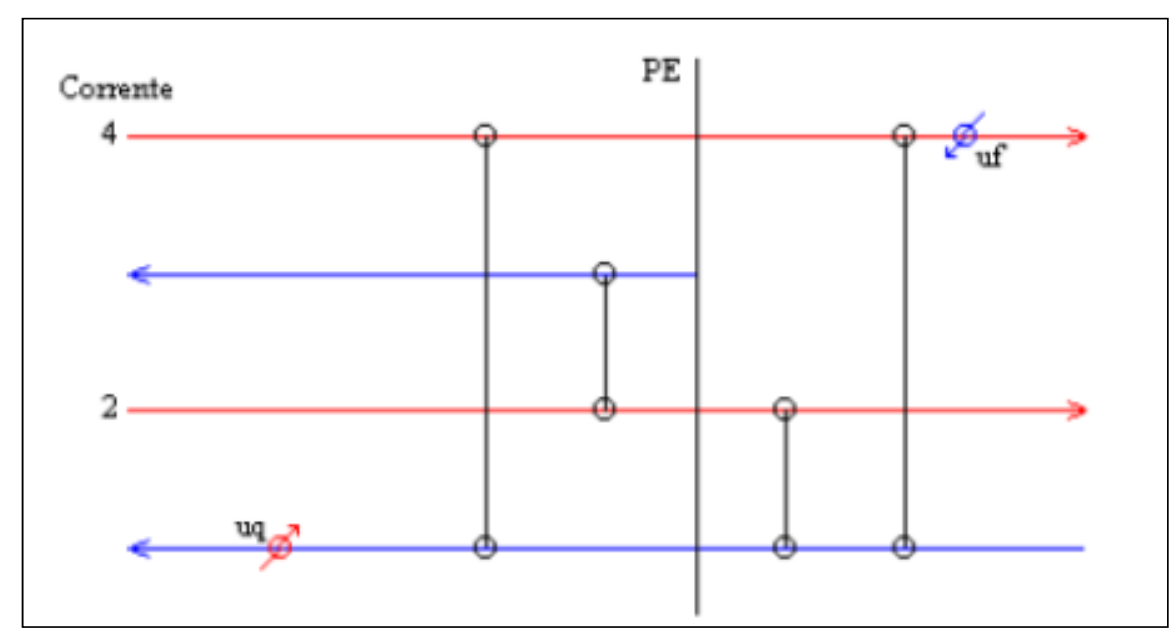

Fonte: Elaboração própria.

\subsection{ANÁLISE DE VIABILIDADE ECONÔMICA}

A análise da viabilidade do investimento para a planta GTL será baseada no critério do Valor Presente Líquido (VPL). Segundo este critério, o investimento só deve ser realizado quando o valor dos fluxos de caixa futuros do investimento for maior que o custo de investimento (PINDYCK e RUBINFELD, 2005). A utilidade do critério do VPL é que todo o fluxo de caixa do projeto, incluindo investimentos, receitas e custos, é transformado em um valor monetário que pode ser comparado a outros projetos (ROBERTSON, 1999). O VPL pode ser representado pela Equação 4.4:

$$
V P L=-C+\frac{\prod_{1}}{(1+r)^{1}}+\frac{\prod_{2}}{(1+r)^{2}}+\frac{\prod_{3}}{(1+r)^{3}}+\cdots+\frac{\prod_{n}}{(1+r)^{n}}
$$

onde,

$\mathrm{C}=$ custo de capital

$r=$ taxa mínima de atratividade

$\mathrm{n}=$ vida útil da planta

$\Pi$ = lucro ou prejuízo 
A equação representa o benefício líquido que será obtido pela empresa como resultado do seu investimento (PINDYCK E RUBINFELD, 2005). Assim, o investimento considerado no estudo terá um resultado viável economicamente apenas quando o resultado da equação for positivo (VPL $>0$ ).

De modo geral, recursos financeiros disponíveis serão deslocados ao iniciar um novo investimento, deixando, portanto, de auferir retornos de outra possível fonte. Em conseqüência, a nova proposta deve, no mínimo, render o equivalente aos juros das aplicações deslocadas. Este retorno é conhecido como Taxa Mínima de Atratividade (TMA), que pode ser uma aplicação de baixo risco, ou outra aplicação que o investidor venha a ter. A escolha da TMA é de grande importância na decisão de alocação dos recursos, sendo que para esse estudo foi aplicada a taxa de $10 \%$, comumente utilizada em projetos da área de petróleo e gás.

A planta terá vida útil de 20 anos, menos que o tempo normal de operação de uma plataforma de petróleo que é de 25 anos e igual à vida útil das plataformas afretadas de companhias internacionais.

\subsubsection{Estimativa do capital de investimento}

Dependendo do grau de detalhamento utilizado para se estimar o capital necessário para a construção de uma indústria, tem-se um valor mais ou menos preciso. Quanto maior a quantidade de informações utilizadas, melhor será o resultado alcançado.

Existem cinco classes normalmente aceitas para classificar o grau de precisão da estimativa do investimento, indo da menos precisa para a mais precisa: estimativa de ordem de magnitude, estudo estimativo, estimativa preliminar, estimativa definitiva e estimativa detalhada (TURTON et al, 2012). Na Tabela 4.3 estão listados os dados normalmente utilizados para cada uma das cinco classes citadas. 
Tabela 4.3 - Dados necessários para cada classe de estimativa de custos.

\begin{tabular}{|c|c|c|}
\hline $\begin{array}{c}\text { Classe de } \\
\text { Estimativa }\end{array}$ & Dados Necessários & Precisão \\
\hline $\begin{array}{c}\text { Ordem de } \\
\text { Magnitude }\end{array}$ & $\begin{array}{c}\text { Normalmente baseada em investimentos realizados em } \\
\text { outros empreendimentos já realizados. }\end{array}$ & 4 a 20 \\
\hline $\begin{array}{c}\text { Estudo } \\
\text { Estimativo }\end{array}$ & $\begin{array}{c}\text { Dimensionamento preliminar dos principais } \\
\text { equipamentos envolvidos no processo (incluindo } \\
\text { bombas, compressores, turbinas, vasos e torres). }\end{array}$ & 3 a 12 \\
\hline $\begin{array}{c}\text { Estimativa } \\
\text { Preliminar }\end{array}$ & $\begin{array}{c}\text { Melhor dimensionamento dos equipamentos, arranjo } \\
\text { preliminar dos equipamentos, estimativa de tubulações, } \\
\text { instrumentação, energia necessária e utilidades. }\end{array}$ & 2 a 6 \\
\hline $\begin{array}{c}\text { Estimativa } \\
\text { Definitiva }\end{array}$ & $\begin{array}{c}\text { Especificação preliminar de todos os equipamentos, } \\
\text { utilidades, instrumentação, eletricidade e off-sites. }\end{array}$ & 1 a 3 \\
\hline $\begin{array}{c}\text { Estimativa } \\
\text { Detalhada }\end{array}$ & $\begin{array}{c}\text { Engenharia completa de todos os processos, off-sites e } \\
\text { utilidades. }\end{array}$ & 1 \\
\hline
\end{tabular}

Fonte: Turton et al. (2012).

Quando se estima o capital de investimento pelo método detalhado, esperase que o custo estimado esteja dentro da faixa de $+6 \%$ a $-4 \%$ da faixa de precisão (TURTON et al, 2012).

Para o processo em estudo, será realizado um estudo estimativo, baseado no dimensionamento preliminar dos principais equipamentos envolvidos no processo.

Para estimativa preliminar do custo de investimento do processo foi utilizada a técnica Bare Module Cost (TURTON et al, 2012). Essa técnica consiste na estimativa do custo de um determinado equipamento, a partir de uma característica do mesmo (área, energia requerida, etc.), utilizando uma correlação com fatores específicos do equipamento e material construtivo do mesmo.

Para obtenção do custo o equipamento, primeiramente é feita a estimativa do custo do mesmo, operando em pressão ambiente, e construído em aço carbono. A equação a seguir foi utilizada para esse cálculo: 


$$
\log _{10} C_{p}{ }^{0}=K_{1}+K_{2} \log _{10}(A)+K_{3}\left[\log _{10}(A)\right]^{2} \quad \text { (Equação 4.5) }
$$

Onde $\mathrm{C}_{\mathrm{p}}{ }^{0}$ é o custo do equipamento operando em pressão ambiente $\mathrm{e}$ construído em aço carbono, $\mathrm{K}_{1}, \mathrm{~K}_{2}$ e $\mathrm{K}_{3}$ são os fatores tabelados relativos ao equipamento a ser calculado e A é uma propriedade do equipamento (área, volume, energia, etc.).

Para obtenção do custo total de produção do equipamento e também levar em conta as características construtivas e de operação do equipamento, aplica-se a equação a seguir:

$$
\mathrm{C}_{\mathrm{BM}}=\mathrm{C}_{\mathrm{p}}^{0}\left[\mathrm{~B}_{1}+\mathrm{B}_{2} \mathrm{~F}_{\mathrm{P}} \mathrm{F}_{\mathrm{M}}\right]
$$

Onde $\mathrm{C}_{\mathrm{BM}}$ é o custo total de produção do equipamento, $\mathrm{B}_{1}$ e $\mathrm{B}_{2}$ são os fatores tabelados relativos ao equipamento a ser calculado e $F_{P}$ e $F_{M}$ são os fatores de correção para a pressão de operação e do material utilizado na sua construção, respectivamente. $F_{M}$ é tabelado e $F_{P}$ pode ser calculado pela seguinte equação:

$$
\log _{10} F_{p}=C_{1}+C_{2} \log _{10}(P)+C_{3}\left[\log _{10}(P)\right]^{2} \quad \text { (Equação 4.7) }
$$

$\mathrm{C}_{1}, \mathrm{C}_{2}$ e $\mathrm{C}_{3}$ são os fatores tabelados relativos ao equipamento a ser calculado e P é sua pressão de operação em barg.

O custo total do processo é encontrado somando-se os custos individuais de construção de cada equipamento. O valor obtido está referenciado ao ano de 2001 e deve ser corrigido pelo índice CEPCI (Chemical Engineering Plant Cost Índex), conforme equação abaixo:

$$
I_{2}=I_{1}\left(\frac{A_{2}}{A_{1}}\right)
$$

Onde:

$\mathrm{I}_{2}$ - valor do investimento desejado

$I_{1}$ - valor do investimento base

$A_{2}$ - índice para o ano desejado

$A_{1}$ - índice para o ano do investimento base 
O índice utilizado como base foi o do ano de 2001 que era 397. O índice para atualização foi o de dezembro de 2012 em 584,6.

Uma referência para este trabalho foi o custo de capital de investimento relativo de USD 35.000,00 por barril/dia produzido, informado por um dos fabricantes da tecnologia compacta para uma planta com produção entre 159 e $795 \mathrm{~m}^{3} / \mathrm{dia}$ de petróleo sintético (1.000 e 5.000 barris/dia) (RICHES, 2007).

\subsubsection{Fluxo de caixa}

Para estimar o lucro ou prejuízo aferido pelo processo, é necessário calcular a receita oriunda do petróleo produzido, assim como os custos operacionais da planta. A seguir são apresentadas as metodologias e premissas utilizadas para estimativa do fluxo de caixa do processo.

\subsubsection{Preço do petróleo}

A produção de petróleo é a única fonte de receita do processo proposto. Apesar de ser um petróleo de qualidade superior ao petróleo referência, Brent, o que Ihe agregaria um maior valor de comercialização, devido à possibilidade de misturálo ao petróleo convencional produzido, foi adotada a projeção apresentada no relatório do U.S. Energy Information Administration - EIA (EIA, 2013) para o petróleo do tipo Brent, de 2010 a 2040:

Tabela 4.4 - Projeção de preços para o petróleo tipo Brent

\begin{tabular}{|l|c|c|c|c|c|c|c|}
\hline Ano & 2010 & 2011 & 2020 & 2025 & 2030 & 2035 & 2040 \\
\hline Preço (USD/barril) & 81,31 & 111,26 & 105,57 & 117,36 & 130,47 & 145,41 & 162,28 \\
\hline
\end{tabular}

Fonte: EIA. 2013. 


\subsubsection{Estimativa do custo operacional}

Diversos são os custos envolvidos na produção de um determinado produto em uma instalação industrial, sendo alguns fáceis de serem estimados, enquanto outros exigem maior detalhamento do projeto. Normalmente esses custos estão divididos entre os custos diretos, indiretos e despesas gerais

A soma dos custos diretos de produção com os indiretos e as despesas gerais resulta no custo de operação (CM). Em um projeto de uma nova planta, é possível fazer uma estimativa de seu custo operacional conhecendo o capital de investimento, além de custos com operadores, utilidades, tratamento de efluentes e matéria-prima. As demais despesas podem ser calculadas através de correlações, mostradas na Tabela 4.5. As equações apresentam uma faixa típica de fatores de multiplicação e, na falta de informações mais completas sobre os custos, é utilizado o valor médio (TURTON et al, 2012).

Tabela 4.5 - Correlações para cálculo de despesas operacionais (TURTON et al,. 2012)

\begin{tabular}{|c|c|}
\hline \multicolumn{2}{|l|}{ 1-Custos Diretos } \\
\hline Matéria Prima & $\mathrm{C}_{\mathrm{MP}}$ \\
\hline Tratamento de Efluentes & $\mathrm{C}_{\mathrm{TR}}$ \\
\hline Utilidades & $\mathrm{C}_{\mathrm{UT}}$ \\
\hline Operadores & $\mathrm{C}_{\mathrm{OP}}$ \\
\hline Direção, Supervisão ( $C_{D S}$ ) & ( de 0,1 a 0,25$) * \mathrm{C}_{\mathrm{OP}}$ \\
\hline Manutenção e Reparos ( $\mathrm{C}_{\mathrm{MR}}$ ) & $(\text { de } 0,02 \text { a } 0,1)^{*} \mathrm{Cl}$ \\
\hline Insumos para Operação & $($ de 0,1 a 0,2$){ }^{*} C_{M R}$ \\
\hline Laboratório & $(\text { de } 0,1 \text { a } 0,2)^{*} \mathrm{C}_{\mathrm{OP}}$ \\
\hline Patentes e Royalties & ( de 0,1 a 0,06$) * C_{M}$ \\
\hline \multicolumn{2}{|l|}{ 2-Custos Indiretos } \\
\hline Depreciação & $0,1 * \mathrm{Cl}$ \\
\hline Impostos e Seguro & $(\text { de } 0,014 \text { a } 0,05)^{*} \mathrm{Cl}$ \\
\hline Custos da Planta & $($ de 0,5 a 0,7$) *\left(C_{O P}+C_{D S}+C_{M R}\right)$ \\
\hline \multicolumn{2}{|l|}{ 3- Despesas Gerais } \\
\hline Custos Administrativos & $0,15 *\left(C_{O P}+C_{D S}+C_{M R}\right)$ \\
\hline Custos com vendas e distribuição & $($ de 0,02 a 0,2$) *{ }^{*} C_{M}$ \\
\hline Pesquisa \& Desenvolvimento & $0,05 * \mathrm{C}_{\mathrm{M}}$ \\
\hline
\end{tabular}

Fonte: TURTON et al. (2012). 
O custo operacional pode ser calculado pela seguinte equação:

$$
\mathrm{C}_{\mathrm{m}}=1,234\left(\mathrm{C}_{\mathrm{MP}}+\mathrm{C}_{\mathrm{TR}}+\mathrm{C}_{\mathrm{UT}}\right)+2,734 \mathrm{C}_{\mathrm{OP}}+0,141 \mathrm{Cl}
$$

Para a realização da análise econômica foram utilizados valores médios para as faixas apresentadas na tabela 4.5 .

\subsubsection{Custo da matéria-prima}

$\mathrm{O}$ processo utiliza o rejeito das membranas (corrente rica em $\mathrm{CO}_{2}$ ) e gás natural como matéria prima.

A corrente rica em $\mathrm{CO}_{2}$, por ser um rejeito do processo, não possui um custo agregado, sendo seu custo considerado nulo para esse estudo. Cabe ressaltar que esse custo poderia ser negativo por causa dos custos relacionados à operação e manutenção do flare e o pagamento de royalties, caso esse gás viesse a ser queimado e, principalmente, devido aos custos de reinjeção, com o objetivo único de evitar a sua queima.

O gás natural é a principal matéria-prima do processo GTL e, devido a isso, seu preço tem forte impacto nas despesas da planta. Por se tratar de um gás retirado diretamente da planta de processamento de petróleo, o gás utilizado não atende as especificações necessárias para a sua comercialização, dificultando com isso a estimativa de seu preço de comercialização. Esse gás, devido à necessidade de tratamento, possui um valor de mercado inferior ao gás especificado.

Existem centros de mercado para comercialização de gás natural nos EUA, Reino Unido, Bélgica e Alemanha, onde são determinados os preços de comercialização do gás nesses países. O mais desenvolvido é o Henry Hub, nos EUA, que é utilizado como referência no mercado americano e, em alguns casos, no mercado mundial. Portanto, o Henry Hub será usado como referência para o preço do gás natural utilizado no processo. 
A projeção do preço Henry Hub, de 2010 a 2040, foi obtida a partir do relatório do U.S. Energy Information Administration - EIA (EIA, 2013) e são apresentados a seguir:

Tabela 4.6 - Projeção de preços para o gás natural Henry Hub .

\begin{tabular}{|l|c|c|c|c|c|c|c|}
\hline Ano & 2010 & 2011 & 2020 & 2025 & 2030 & 2035 & 2040 \\
\hline Preço (USD/1.10 $\mathrm{BTU})$ & 4,46 & 3,98 & 4,13 & 4,87 & 5,40 & 6,32 & 7,83 \\
\hline
\end{tabular}

Fonte: EIA (2013).

\subsubsection{Custo com utilidades}

O custo de utilidades do processo envolve as correntes de água de resfriamento, água utilizada como alimentação do reator de reforma e gás combustível, sendo este último calculado da mesma forma que o gás natural utilizado como matéria-prima no capítulo anterior.

O processamento primário em um FPSO utiliza água tanto para resfriamento, como para aquecimento de suas correntes. Logo, não foi necessária a instalação de uma nova unidade de captação e tratamento de água para o processo proposto, sendo utilizada a unidade existente no FPSO para esse fim.

Em um FPSO o resfriamento das correntes quentes do processo é realizado por um sistema fechado de água de resfriamento. Nesse sistema, após ser utilizada para resfriamento das correntes de processo, as correntes quentes são resfriadas com água salgada e bombeadas novamente para o sistema de resfriamento.

Já a água salgada utilizada para resfriamento é captada diretamente do mar, filtrada e enviada para os trocadores do sistema de resfriamento, sendo devolvida ao mar na seqüência. A captação de água salgada também é responsável pelo fornecimento de água ao sistema de osmose reversa, onde a água salgada é transformada em doce e encaminhada para os consumidores, entre eles o vapor de alimentação do reator de reforma e reposição do sistema de água de resfriamento e sistema de resfriamento do reator FT. A figura 4.9 apresenta um fluxograma 
representativo dos sistemas de agua de resfriamento, aquecimento e fornecimento de agua doce.

Figura 4.9 - Fluxograma representativo do sistema de utilidades de uma plataforma.

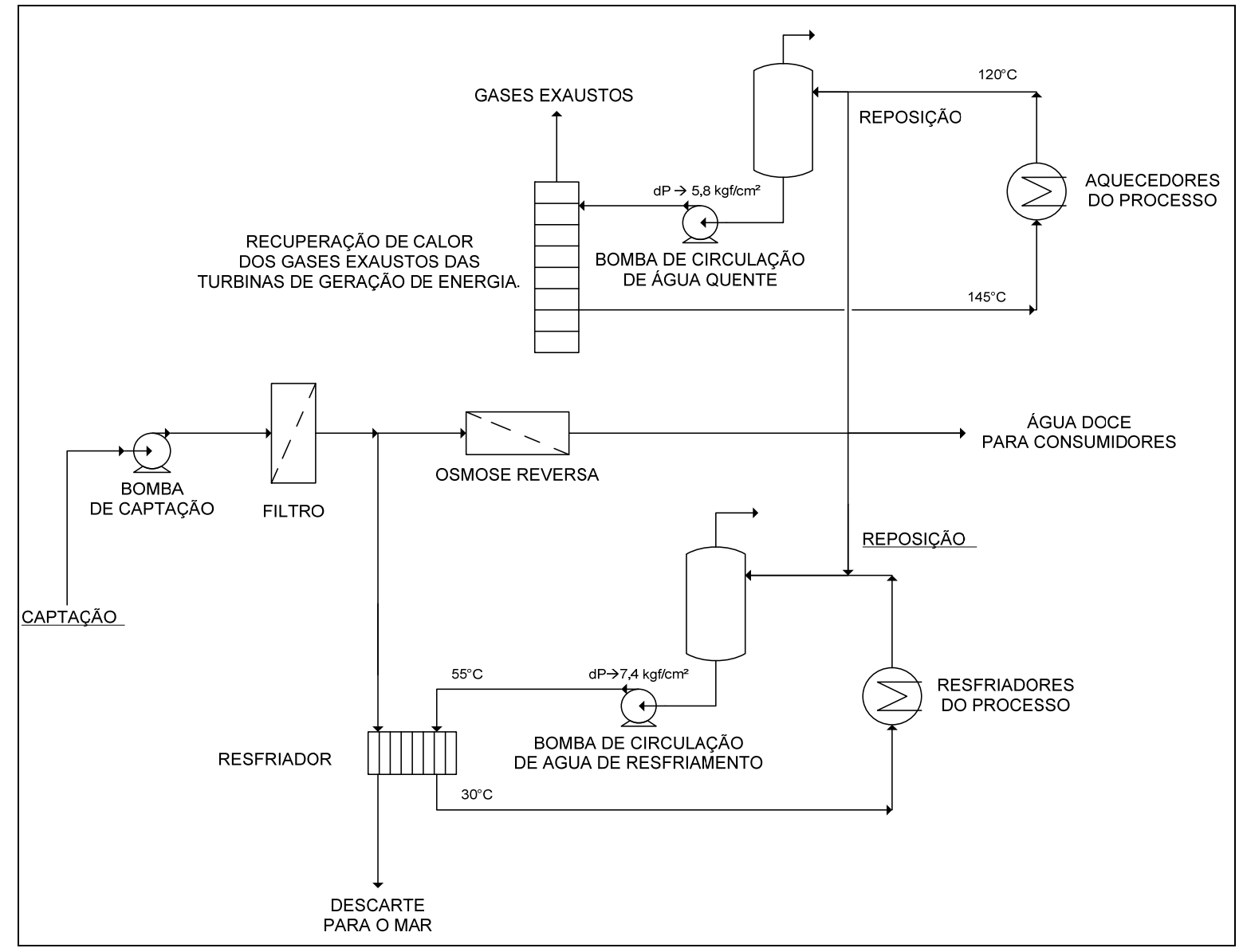

Fonte: Elaboração própria.

O custo atrelado ao sistema de resfriamento e reposição de água está diretamente ligado ao consumo energético de suas bombas de captação e movimentação, que por sua vez está ligado ao consumo de combustível por parte das turbinas geradoras de energia do FPSO. Logo, os gastos com o sistema de utilidades serão aferidos pelo consumo de gás combustível relativo ao sistema e o preço do gás combustível indicado no item anterior. 
O consumo energético relativo a cada utilidade consumida é apresentado na tabela 4.7:

Tabela 4.7 - Consumo energético das utilidades de processo

\begin{tabular}{|ll|}
\hline \multicolumn{1}{|c|}{ Processo } & $\mathbf{k J} / \mathbf{m}^{\mathbf{3}}$ \\
\hline Captação & 2650,7 \\
\hline Circulação Resfriamento & 2687,0 \\
\hline Distribuição Água Doce & 3013,8 \\
\hline
\end{tabular}

Fonte: Elaboração própria.

\subsubsection{Custo com tratamento de efluentes}

O único rejeito do processo é a água produzida e, assim como na geração de utilidades, o processo proposto também utilizará o sistema de tratamento de efluentes do FPSO para tratar seus rejeitos. O sistema de tratamentos de efluentes de um FPSO possui equipamentos muito simplificados, sendo composto basicamente por hidrociclones e flotação, sendo esse último o único que possui consumo de energia em sua bomba de circulação. A figura 4.10 apresenta um fluxograma representativo do sistema de tratamento da agua produzida pelo processamento primário de petróleo e gás natural.

Figura 4.10 - Fluxograma representativo do sistema de tratamento de água de uma plataforma.

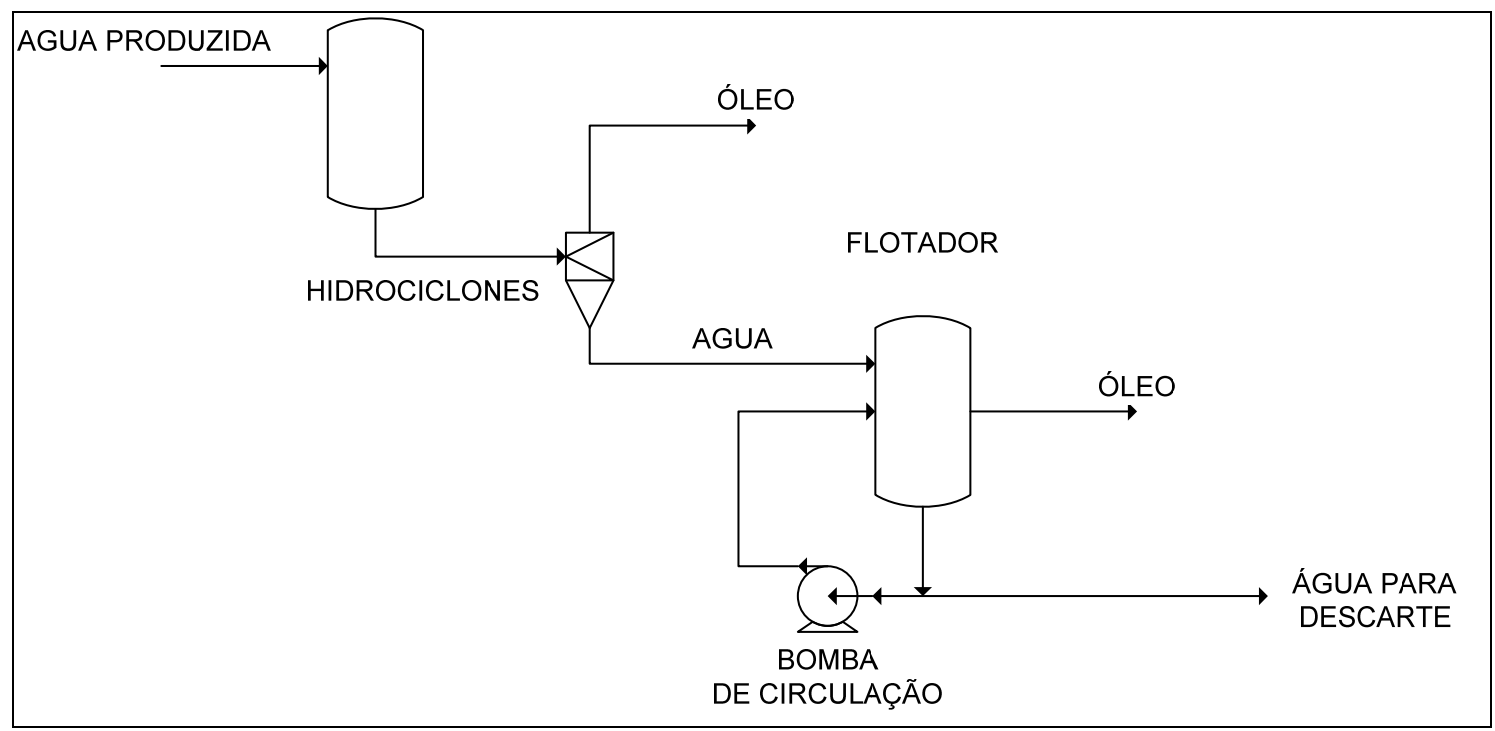

Fonte: Elaboração própria. 
O custo atrelado ao sistema de tratamento de efluentes, assim como ao de utilidades, está diretamente ligado ao consumo energético da bomba de circulação, que por sua vez está ligado ao consumo de combustível por parte das turbinas geradoras de energia do FPSO. Logo, os gastos com o sistema de utilidades serão aferidos pelo consumo de gás combustível relativo ao sistema e o preço do gás combustível indicado anteriormente.

O consumo energético relativo ao sistema de tratamento de efluentes foi de $1.379,8 \mathrm{~kJ} / \mathrm{m}^{3}$

\subsubsection{Custo com operadores}

O custo com operadores é função do número necessário de trabalhadores por turno para fazer com que a planta produza e do salário médio pago a cada operador.

Turton et al (2012) sugere uma equação que relaciona o número de trabalhadores por turno com o número de equipamentos em uma planta de processo. Porém, devido o processo proposto se tratar de um sistema adicional em uma planta de processamento primário de petróleo, que utiliza alguns dos sistemas auxiliares existentes nessa planta e por essa já possuir um número específico de operadores, foi adotado um número fixo de operadores adicionais atenderem o novo sistema.

Em operação normal, uma planta de processamento primário de petróleo e gás natural possui, em média, sete operadores por turno por unidade, sendo dois responsáveis pelo painel de controle e cinco responsáveis pela operação local. A esse número, foi adotado que dois operadores adicionais por turno serão suficientes para sua operação.

Seguindo a metodologia sugerida por Turton et al (2012), o número de operadores por turno deve ser multiplicado por 4,5 para obtenção do número de operadores por ano para operação da planta que, no caso foi de 9 operadores. 
Considerando o salário médio de USD 2.500,00 por mês de cada operador e uma carga de tributos trabalhistas de igual valor, tem-se o que o custo de cada operador é de USD 60.000,00 por ano. Multiplicando o custo anual pelo número de operadores, tem-se que o custo com operadores é de USD 540.000,00 por ano. 


\section{RESULTADOS E DISCUSSÃO}

Neste capítulo serão apresentados os resultados das simulações e análises realizadas neste estudo, assim como as suas respectivas discussões.

\subsection{SIMULAÇÃO DO CASO BASE}

A simulação do caso base serviu principalmente para validar e testar os modelos utilizados, assim como confirmar a possibilidade de produção de petróleo sintético a partir do rejeito das membranas utilizadas no tratamento de gás.

As principais informações extraídas da simulação do caso base estão apresentadas na tabela abaixo:

Tabela 5.1 - Dados da simulação do caso base.

\begin{tabular}{|ll|l|}
\hline Carga processada & $(\mathrm{kmol} / \mathrm{h})$ & 1383 \\
\hline Gás consumido & $(\mathrm{kmol} / \mathrm{h})$ & 1896 \\
\hline Petróleo produzido & $\left(\mathrm{m}^{3} / \mathrm{h}\right)$ & 13,56 \\
\hline Água consumida & $\left(\mathrm{m}^{3} / \mathrm{h}\right)$ & 39,52 \\
\hline Água produzida & $\left(\mathrm{m}^{3} / \mathrm{h}\right)$ & 22,81 \\
\hline Gás residual de alta & $(\mathrm{kmol} / \mathrm{h})$ & 1934 \\
\hline Gás residual de baixa & $(\mathrm{kmol} / \mathrm{h})$ & 4,30 \\
\hline Conversão de $\mathrm{CO}_{2}$ & $(\%$ reator $)$ & 32,36 \\
\hline
\end{tabular}

Fonte: Elaboração própria.

Verifica-se pelos dados da tabela 5.1 , que foram produzidos $325,44 \mathrm{~m}^{3} / \mathrm{d}$ de petróleo sintético, que corresponde a 2047 barris por dia, confirmando a viabilidade da produção de petróleo sintético a partir da carga utilizada, utilizando o processo GTL. O petróleo produzido possui densidade de $722,9 \mathrm{~kg} / \mathrm{m}^{3}$ e ${ }^{\circ} \mathrm{API}$ igual a 46,44 , considerado um petróleo leve, com bom valor comercial, caso venha a ser comercializado separado. A composição do petróleo produzido é apresentada na tabela 5.2. 
Tabela 5.2 - Composição do petróleo produzido pela simulação do caso base.

\begin{tabular}{|c|c|c|}
\hline COMPONENTE & FRAÇÃO MOLAR & PRODUTO \\
\hline $\mathrm{H}_{2} \mathrm{O}$ & 0,01 & \multirow{5}{*}{ IMPUREZAS } \\
\hline $\mathrm{H}_{2}$ & 0,00 & \\
\hline $\mathrm{CO}$ & 0,00 & \\
\hline $\mathrm{O}_{2}$ & 0,00 & \\
\hline $\mathrm{CO}_{2}$ & 0,02 & \\
\hline $\mathrm{CH}_{4}$ & 0,00 & \multirow{2}{*}{ GAS NATURAL } \\
\hline $\mathrm{C}_{2} \mathrm{H}_{6}$ & 0,00 & \\
\hline $\mathrm{C}_{3} \mathrm{H}_{8}$ & 0,01 & \multirow{2}{*}{ GLP } \\
\hline $\mathrm{C}_{4} \mathrm{H}_{10}$ & 0,02 & \\
\hline $\mathrm{C}_{5} \mathrm{H}_{12}$ & 0,04 & \multirow{6}{*}{ NAFTA } \\
\hline $\mathrm{C}_{6} \mathrm{H}_{14}$ & 0,06 & \\
\hline $\mathrm{C}_{7} \mathrm{H}_{16}$ & 0,08 & \\
\hline $\mathrm{C}_{8} \mathrm{H}_{18}$ & 0,10 & \\
\hline $\mathrm{C}_{9} \mathrm{H}_{20}$ & 0,10 & \\
\hline $\mathrm{C}_{10} \mathrm{H}_{22}$ & 0,10 & \\
\hline $\mathrm{C} 11-\mathrm{C} 14$ & 0,26 & QUEROSENE \\
\hline $\mathrm{C} 15-\mathrm{C} 24$ & 0,19 & GASÓLEO \\
\hline C25-C30 & 0,02 & PARAFINAS \\
\hline
\end{tabular}

Fonte: Elaboração própria.

Alem do petróleo, produto desejado, o processo produziu também 1934 $\mathrm{kmol} / \mathrm{h}$ de gás residual de alta pressão (GRAP) e 4,3 kmol/h de gás residual de baixa pressão (GRBP) que não podem ser lançados na atmosfera e deverão ser reciclados a fim reduzir os gastos com insumos para o processo.

O consumo de gás natural pelo processo é oriundo de vários consumidores sendo: $687,8 \mathrm{kmol} / \mathrm{h}$ (36\%) pela combustão catalítica, 696,2 kmol/h (37\%) pela carga do reator de reforma, 354,5 kmol/h (19\%) pelo forno aquecedor de carga e 157,8 $\mathrm{kmol} / \mathrm{h}(8 \%)$ pelas turbinas dos compressores de gás de síntese. Logo, verifica-se que a maior parte do gás natural é consumida para ajuste da proporção entre a

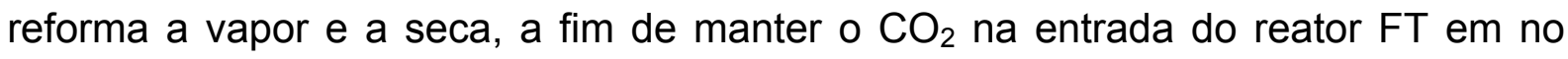


máximo $10 \%$, assim como é utilizado como combustível para fornecimento de energia ao reator de reforma. O consumo do reator de reforma pode ser reduzido com o reciclo das correntes de gás residual, como será detalhado mais adiante.

Para obtenção da relação $\mathrm{H}_{2} / \mathrm{CO}$ de 2,18 , foram necessários $948,48 \mathrm{~m}^{3} / \mathrm{d}$ de água doce (vapor). A vazão de água doce necessária para o reator de reforma pode ser reduzida pela utilização da água produzida na síntese $\mathrm{FT}$, que tem vazão de $547,44 \mathrm{~m}^{3} / \mathrm{d}$.

O resfriamento dos reatores da síntese de FT consumiu $1905,36 \mathrm{~m}^{3} / \mathrm{d}$ de água circulante que foi transformada em $79232 \mathrm{~kg} / \mathrm{h}$ de vapor superaquecido a $1711 \mathrm{kPa}$ e $205^{\circ} \mathrm{C}$.

Foram alimentados ao processo $1051 \mathrm{kmol} / \mathrm{h}$ de CO2, através da corrente de alimentação do processo e do gás natural consumido. Por outro lado, $2183 \mathrm{kmol} / \mathrm{h}$ saem do processo através dos gases de combustão do forno, turbinas dos compressores e turbinas de geração de energia elétrica para alimentação dos sistemas de utilidades. Para cada $\mathrm{kmol} / \mathrm{h}$ de $\mathrm{CO}_{2}$ capturado pelo processo, simulado no caso base, 2,08 kmol/d são emitidos. A tabela 5.3 apresenta a participação de cada etapa do processo na emissão de $\mathrm{CO}_{2}$.

Tabela 5.3 - Emissões de $\mathrm{CO}_{2}$ - simulação do caso base.

\begin{tabular}{|l|c|c|}
\hline \hline \multicolumn{1}{|c|}{ Corrente / Sistema } & Vazão (kmol/h) & $\%$ \\
\hline \hline Combustão Catalítica & 933 & 42,75 \\
\hline Gás Residual de Alta & 565 & 25,88 \\
\hline Gás Residual de Baixa & 2 & 0,10 \\
\hline Petróleo & 1 & 0,07 \\
\hline Forno e Compressão. & 681 & 31,21 \\
\hline \hline
\end{tabular}

Fonte: Elaboração própria. 


\subsection{INTEGRAÇÃO MÁSSICA DO PROCESSO}

A partir do caso base simulado, foram analisadas dez alternativas para recuperação das correntes de gás residual do processo, sendo uma alternativa sem membranas e uma com membranas para recuperação de $H_{2}$, variando-se as proporções entre queima e reciclo para o reator de reforma de 0 a $100 \%$, em intervalos de $20 \%$. Os resultados são apresentados nas tabelas 5.4 e 5.5 , a seguir:

Tabela 5.4 - Resultados da simulação para a alternativa sem membrana.

\begin{tabular}{|c|c|c|c|c|c|c|}
\hline \multirow{2}{*}{ Indice / Variável } & \multirow{2}{*}{ Unidade } & \multicolumn{5}{|c|}{ Alternativa } \\
\hline & & 1 & 2 & 3 & 4 & 5 \\
\hline Investimento & USD & $95.680 .341,66$ & $106.583 .955,26$ & 128.742 .056 .70 & 159.354 .839 .59 & 183.768 .945 .86 \\
\hline VPL & USD & $(99.800 .927,99)$ & $(137.898 .388,92)$ & $(196.372 .844,90)$ & $(237.818 .323,75)$ & $(292.098 .037,41)$ \\
\hline Gás Combustivel Consumido & $\mathrm{kmolih}$ & 1511 & 1797 & 2513 & 4005 & 5597 \\
\hline Carga Alimentada & $\mathrm{kmol} / \mathrm{h}$ & 1460 & 1403 & 1259 & 961,1 & 642,5 \\
\hline Petróleo Produzido & $m^{3} / h$ & 17,76 & 19,97 & 25,85 & 38,70 & 51,91 \\
\hline Petróleo Produzido & barril/d & 2681 & 3014 & 3902 & 5842 & 7836 \\
\hline $\mathrm{CO}_{2}$ Produzido & $\mathrm{kg} / \mathrm{h}$ & 108728 & 117929 & 138982 & 181230 & 227286 \\
\hline Conversäo Global de $\mathrm{CO}_{2}$ & - & $-1,40$ & $-1,57$ & $-1,95$ & $-2,65$ & $-3,33$ \\
\hline Eficiencia Energética & - & 0,3191 & 0,3194 & 0,3242 & 0,3347 & 0,3374 \\
\hline Razäo Investimento/Óleo prod. & USD/bbl/d & $35.684,54$ & 35.362 .51 & $32.992,19$ & $27.279,48$ & 23.451 .59 \\
\hline Razão Energia cons /Óleo prod. & kJjibarril & $1,64.10^{7}$ & $1,64.10^{7}$ & $1,61.10^{7}$ & $1,56.10^{7}$ & $1,55.10^{7}$ \\
\hline Razäo GC cons.óleo prod. & kmolibarril & 13,5 & 14,3 & 15,5 & 16,5 & 17,1 \\
\hline
\end{tabular}

Fonte: Elaboração própria.

Tabela 5.5 - Resultados da simulação para a alternativa com membrana.

\begin{tabular}{|c|c|c|c|c|c|c|}
\hline \multirow{2}{*}{ Indice / Variável } & \multirow{2}{*}{ Unidade } & \multicolumn{5}{|c|}{ Alternativa } \\
\hline & & 6 & 7 & 8 & 9 & 10 \\
\hline Investimento & USD & $123.071 .887,16$ & $132.309 .604,12$ & $144.310 .883,36$ & $158.330 .404,37$ & 173.655 .577 .83 \\
\hline VPL & USD & $(104.176 .545,56)$ & $(117.668 .025,41)$ & $(143.536 .174,38)$ & $(166.225 .580,67)$ & $(212.833 .743,35)$ \\
\hline Gás Combustivel Consumido & $\mathrm{kmol} / \mathrm{h}$ & 2285 & 2673 & 3280 & 4192 & 5379 \\
\hline Carga Alimentada & $\mathrm{kmol} / \mathrm{h}$ & 1305 & 1227 & 1106 & 923,6 & 686,2 \\
\hline Petróleo Produzido & $m^{3} / \mathrm{h}$ & 24,92 & 28,28 & 33,26 & 40,84 & 50,18 \\
\hline Petróleo Produzido & barril/d & 3762 & 4268 & 5021 & 6165 & 7576 \\
\hline $\mathrm{CO}_{2}$ Produzido & $\mathrm{kg} / \mathrm{h}$ & 126564 & 137126 & 154411 & 179642 & 212377 \\
\hline Conversão Global de $\mathrm{CO}_{2}$ & - & $-1,71$ & $-1,90$ & $-2,19$ & $-2,59$ & $-3,07$ \\
\hline Eficiencia Energética & - & 0,3369 & 0,3396 & 0,3401 & 0,3414 & 0,3390 \\
\hline Raza̋o Investimento/óleo prod. & USD/bblid & 32711,99 & 30997,08 & 28740,65 & 25682,16 & 22922,92 \\
\hline Razăo Energia cons./Óleo prod. & kJibarril & $1,56.10^{7}$ & $1,55.10^{7}$ & $1,54.10^{7}$ & $1,54.10^{7}$ & $1,55.10^{7}$ \\
\hline Razäo GC cons. IÓleo prod. & kmolibarril & 14,6 & 15,0 & 15,7 & 16,3 & 17,0 \\
\hline
\end{tabular}

Fonte: Elaboração própria.

Durante as rodadas de simulação dos casos avaliados, verificou-se não ser possível encaminhar $80 \%$ do gás residual de alta pressão para consumo como gás combustível, devido essa proporção superar a vazão de gás natural requerida pelo 
processo. Dessa forma, para os casos 1 e 6 , o reciclo máximo de gás residual de alta pressão será $77,67 \%$ e $75,69 \%$, respectivamente.

Todas as alternativas analisadas até esta parte do estudo apresentaram VPL negativo, assim como conversões negativas de $\mathrm{CO}_{2}$, isto é, o processo como um todo produziu mais $\mathrm{CO}_{2}$ do que efetivamente foi alimentado ao processo. $\mathrm{Na}$ próxima etapa do estudo, a integração energética das correntes de processo tenderá a reduzir o consumo de utilidades e, com isso, reduzirá os gastos com utilidades, favorecendo a elevação do VPL do processo.

Pelos dados obtidos, verificou-se que, quanto maior o reciclo para o reator de reforma, tanto do gás residual de alta pressão para primeira alternativa, quanto do rejeito da membrana na segunda alternativa, maior a produção de petróleo (figura 5.1). Isso se deve a maior disponibilidade de carga alimentada ao processo, causado pelo aumento na vazão de reciclo.

Figura 5.1 - Produção de petróleo nas alternativas analisadas.

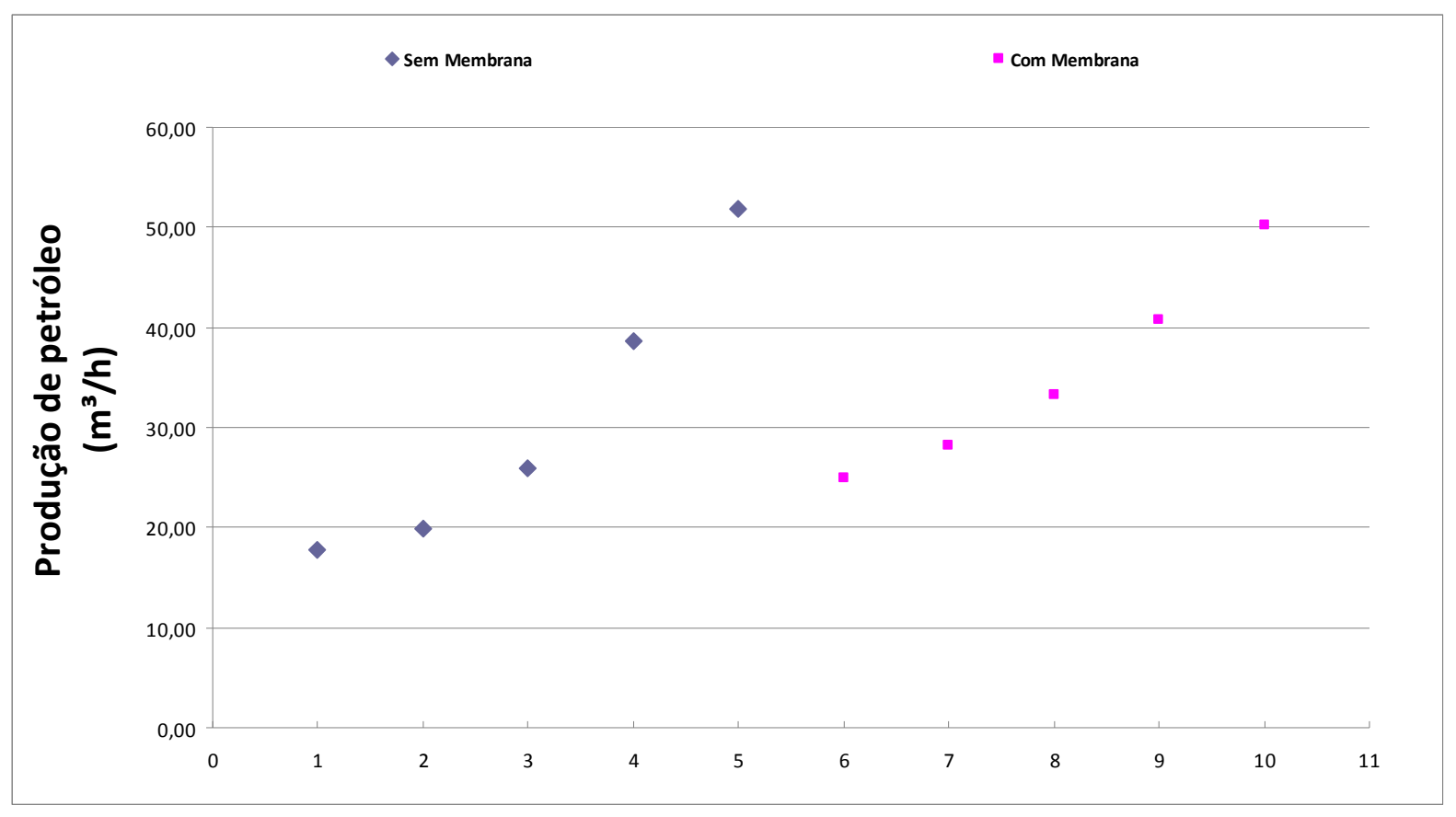

Fonte: Elaboração própria. 
Porém, verifica-se também que o aumento do reciclo de gás residual para o reator de reforma, aumenta o consumo de gás natural requerido (Figura 5.2) e reduz ainda mais a conversão de $\mathrm{CO}_{2}$ do processo (Figura 5.3).

Figura 5.2 - Consumo de gás natural das alternativas analisadas.

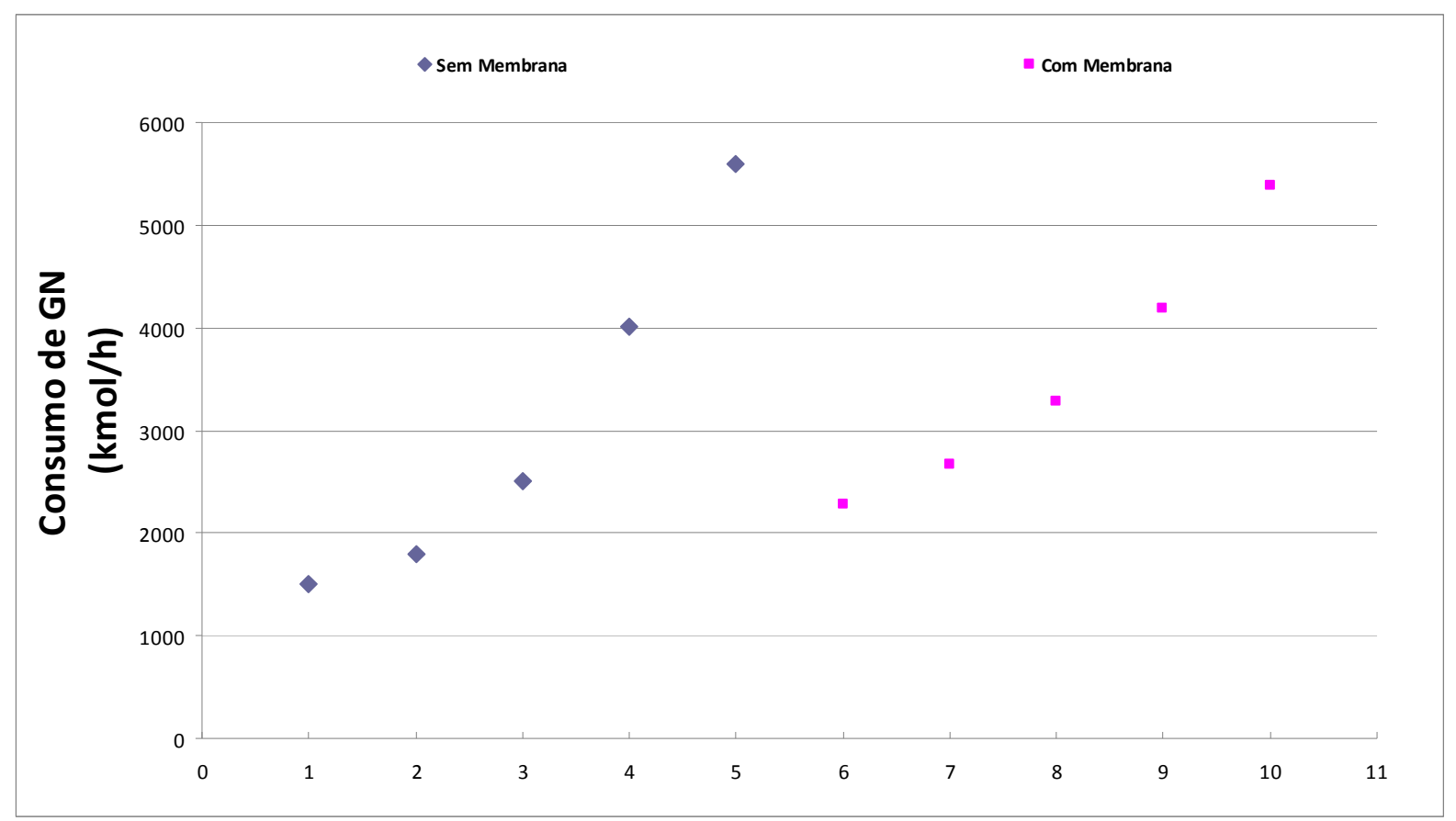

Fonte: Elaboração própria.

Figura 5.3 - Conversão de $\mathrm{CO}_{2}$ para as alternativas analisadas.

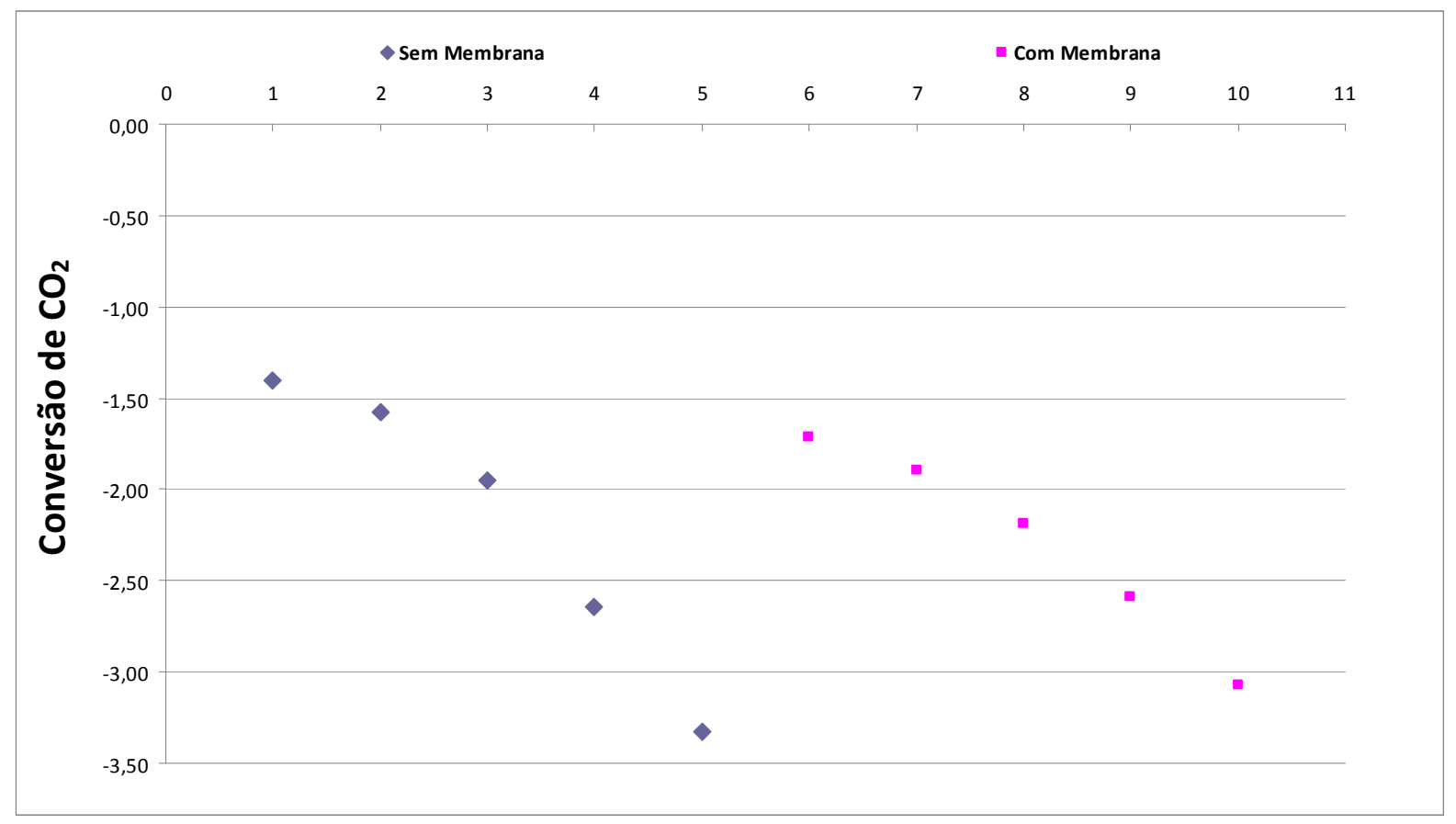

Fonte: Elaboração própria. 
Isso pode ser explicado pelo aumento das vazões dentro da planta, que elevam a necessidade energética requerida para aquecimento da carga, assim como para as reações de reforma e compressão do gás de síntese. $O$ aumento de vazões na planta também causa a elevação do custo de investimento do processo, causado pelo aumento nas dimensões dos equipamentos (figura 5.4).

Figura 5.4 - Custo de investimento das alternativas analisadas.

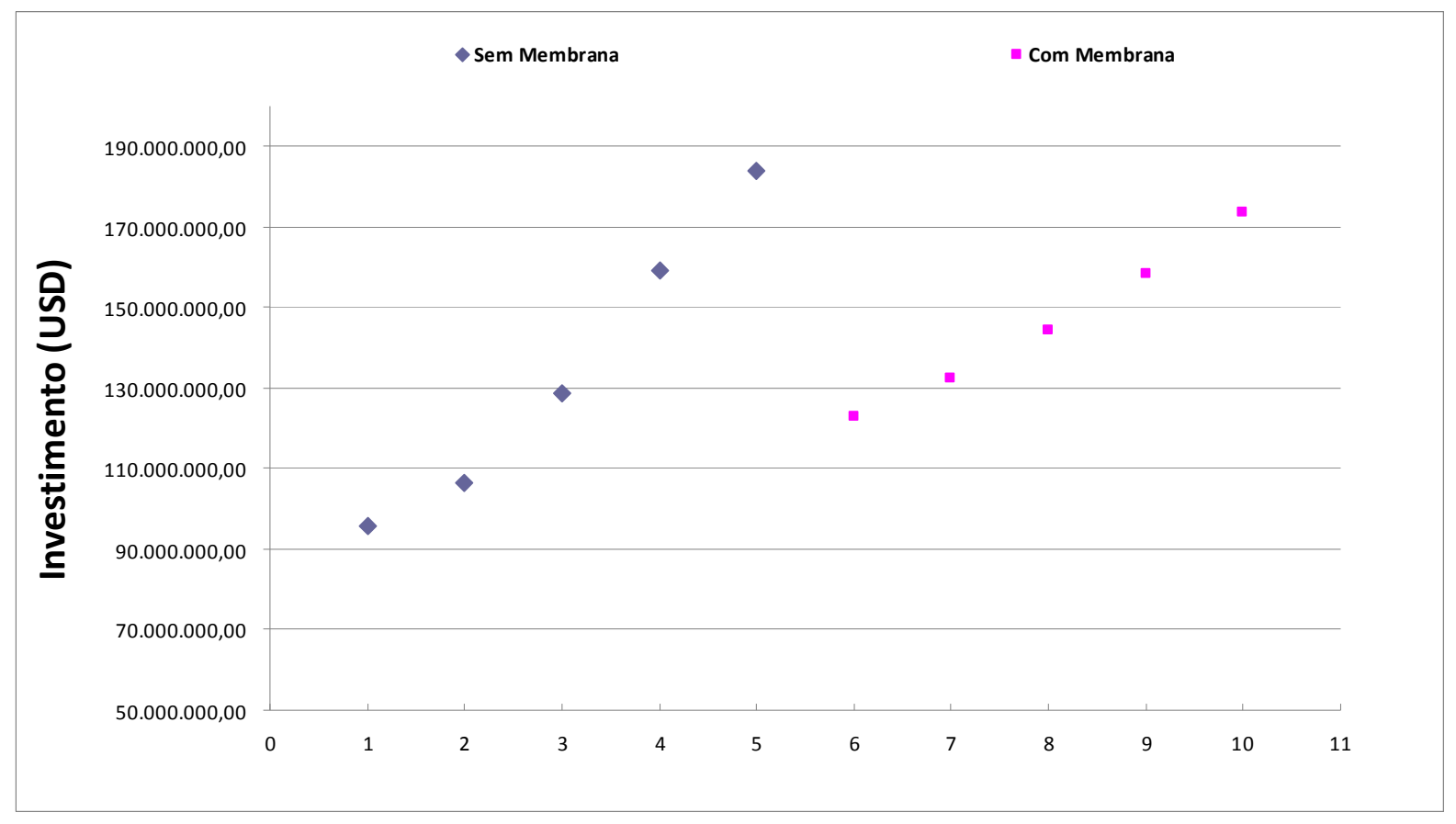

Fonte: Elaboração própria.

Com o aumento do reciclo de gás residual para o reator de reforma, o VPL do processo diminui (Figura 5.5). Essa redução é causada pelo maior consumo de gás natural, tanto na matéria-prima quanto no consumo de utilidades e tratamento de efluentes, que possui forte impacto no balanço econômico da planta, assim como também é causado pelo aumento no custo de investimento, valor utilizado como referência para cálculo de diversas outras despesas do processo. 
Figura 5.5 - Valor presente liquido (VPL) das alternativas analisadas.

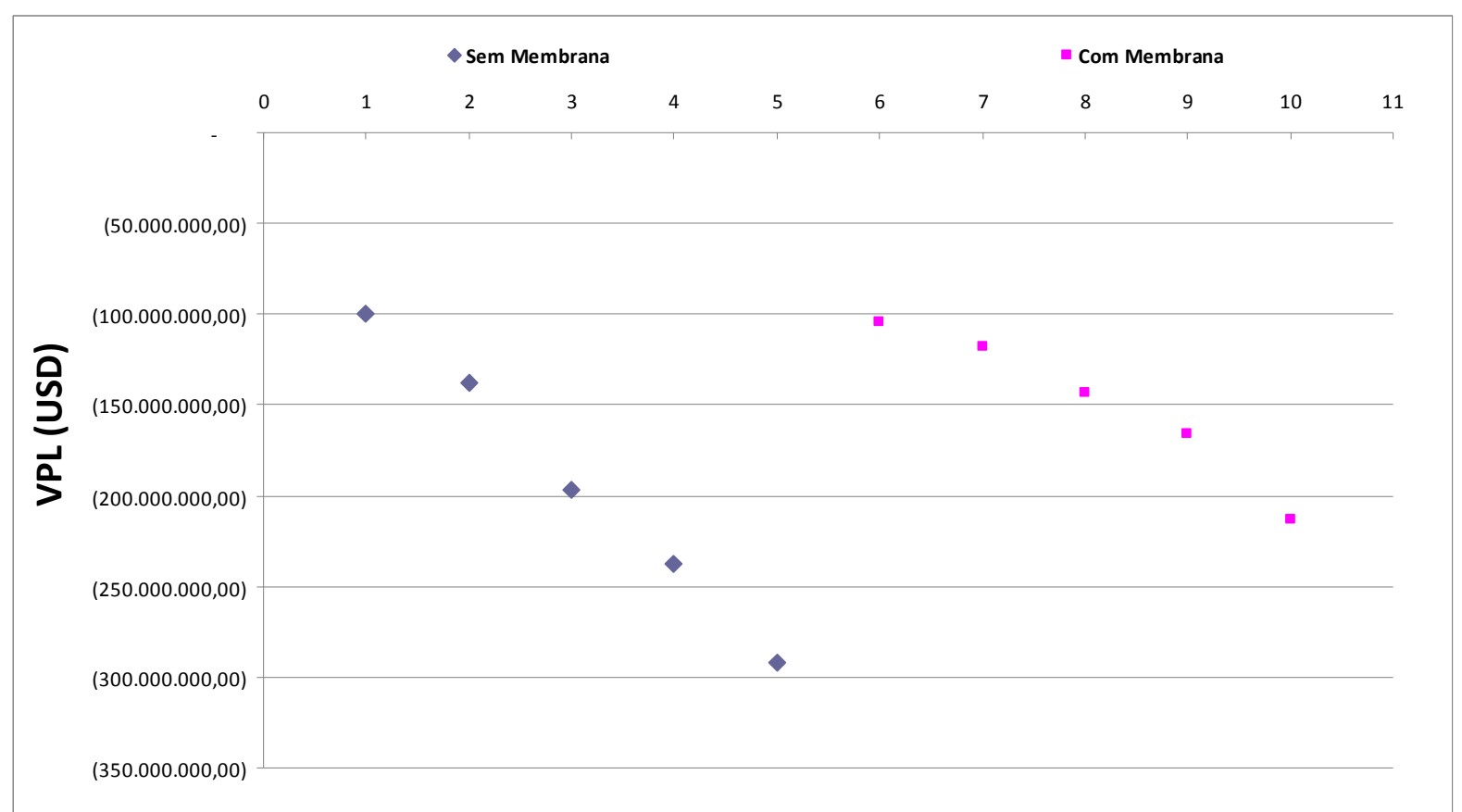

Fonte: Elaboração própria.

Pelo exposto até aqui, as opções de máxima queima, tanto para a alternativa sem membranas (alternativa-1) quanto para a alternativa com membranas (alternativa-6), são as melhores opções de reciclo da corrente de gás residual de alta pressão do processo.

Em complemento, a alternativa sem membrana foi a que apresentou maior VPL, menor consumo de gás combustível, menor emissão de $\mathrm{CO}_{2}$ e maior conversão de $\mathrm{CO}_{2}$, sendo essa a alternativa tecnicamente escolhida para seguir para a próxima etapa do estudo, a avaliação energética.

A corrente de gás residual de baixa pressão foi reciclada diretamente para a combustão catalítica, pelos motivos citados no capítulo anterior.

Após a seleção da alternativa 1 como a mais tecnicamente interessante, foi realizado o reciclo da água produzida. O principal resultado do reciclo da água produzida foi a redução do consumo de água da unidade assim como da vazão para 
tratamento de efluentes e consequente redução dos custos operacionais do processo.

\subsection{INTEGRAÇÃO ENERGÉTICA DO PROCESSO}

Para a integração energética do processo proposto foi utilizada a tecnologia pinch (ou método do ponto de estrangulamento - MPE), aplicada à alternativa de integração mássica número um, identificada como a melhor alternativa de reciclo no subcapitulo anterior.

A análise energética do processo foi dividida em duas etapas, sendo a primeira a determinação do consumo mínimo de utilidades quentes e frias e determinação do ponto de menor diferença de temperatura (temperatura pinch) e a segunda a síntese de trocadores de calor do processo.

O primeiro passo foi o levantamento dos dados relevantes das correntes que trocam calor no processo, conforme apresentado na Tabela 5.6.

Tabela 5.6 - Dados das correntes de processo que participaram da analise.

\begin{tabular}{|c|c|c|c|c|c|c|c|}
\hline \multicolumn{4}{|c|}{ Correntes Frias } & \multicolumn{2}{|c|}{ Entrada } & \multicolumn{2}{|c|}{ Saida } \\
\hline Ordem & TAG & Descrição & Vazão (kg/h) & $\mathrm{Te}\left({ }^{\circ} \mathrm{C}\right)$ & $\mathrm{CPe}\left(\mathrm{kJ} / \mathrm{kg} \cdot{ }^{\circ} \mathrm{C}\right)$ & Ts $\left({ }^{\circ} \mathrm{C}\right)$ & $\mathrm{CPs}\left(\mathrm{kJ} / \mathrm{kg} .{ }^{\circ} \mathrm{C}\right)$ \\
\hline 1 & $F-01$ & Aquecedor de carga (reator de reforma) & 131675 & 50 & 2,53 & 790 & 2,40 \\
\hline \multicolumn{4}{|c|}{ Correntes Quentes } & \multicolumn{2}{|c|}{ Entrada } & \multicolumn{2}{|c|}{ Saida } \\
\hline Corrente & TAG & Descrição & $\operatorname{Vazão~}(\mathrm{kg} / \mathrm{h})$ & $\mathrm{Te}\left({ }^{\circ} \mathrm{C}\right)$ & $\mathrm{CPe}\left(\mathrm{kJ} / \mathrm{kg} .{ }^{\circ} \mathrm{C}\right)$ & Ts $\left({ }^{\circ} \mathrm{C}\right)$ & $\mathrm{CPs}\left(\mathrm{kJ} / \mathrm{kg} \cdot{ }^{\circ} \mathrm{C}\right)$ \\
\hline 2 & P-01 & Resfriador saida do reator de reforma & 131677 & 790 & 2,47 & 35 & 2,56 \\
\hline 3 & $\mathrm{P}-02$ & Resfriador da descarga do $1^{\circ} \mathrm{stg}$ do compressor & 107307 & 187,5 & 2,23 & 35 & 2,22 \\
\hline 4 & P-04 & Resfriador saida do reator FT & 105276 & 220 & 1,98 & 95 & 2,52 \\
\hline 5 & P-05 & Resfriador de petróleo produzido & 13309 & 95 & 2,40 & 50 & 2,19 \\
\hline 6 & P-06 & Resfriador de vapor reator FT & 100143 & 205 & 4,51 & 35 & 4,31 \\
\hline
\end{tabular}

Fonte: Elaboração própria.

Em seguida, os dados das correntes quentes foram ajustados em função do mínimo diferencial de temperatura para elaboração do diagrama de intervalos de temperaturas (Figura 5.6). 
Figura 5.6 - Diagrama de intervalos de temperaturas.

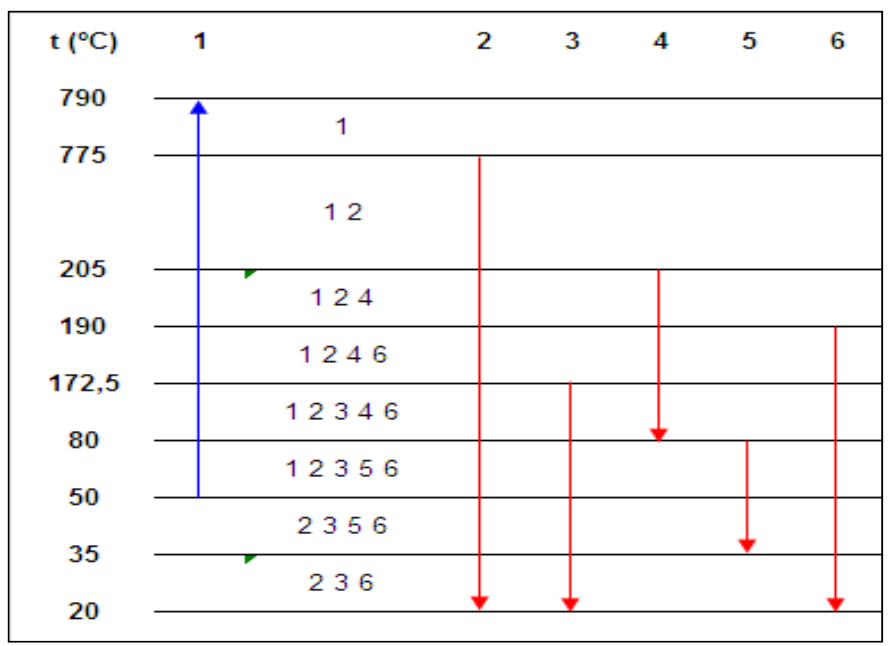

Fonte: Elaboração própria.

Em cada intervalo foi calculado balanço de energia trocado, utilizando o balanço do $\mathrm{MCp}$ das correntes que participam do intervalo, multiplicado pelo intervalo de temperatura. A partir desse balanço foi construído o diagrama de cascata para apresentação dos resultados referentes ao consumo mínimo de utilidades (Figura 5.7).

Figura 5.7 - Diagrama de cascata de troca térmica

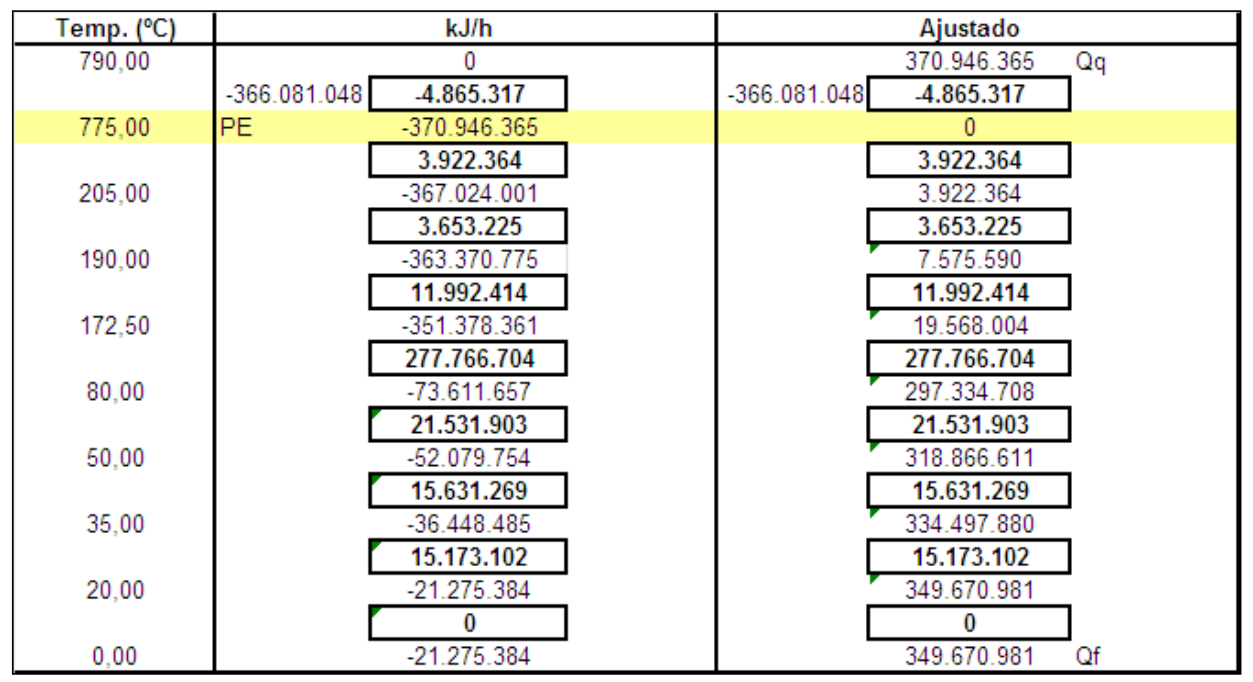

Fonte: Elaboração própria. 
Como pode ser observado no diagrama, o balanço apresentou pontos com valor residuais negativos, acrescentando-se o valor do residual mais negativo como utilidade quente ao processo.

A figura apresentou os valores de $370.946 .365 \mathrm{~kJ} / \mathrm{h}$ em sua entrada e 349.670.981 kJ/h em sua saída, sendo a mínima utilidade quente e fria requeridas, respectivamente. O ponto onde o resíduo assumiu o valor zero, ou seja, sem passagem de energia, é o ponto de equilíbrio ou pinch point, que no caso foi $775^{\circ} \mathrm{C}$.

De posse do valor mínimo de utilidades requeridas, do ponto de equilíbrio, do diferencial mínimo de temperatura (DMT) adotado e respeitando as regras para síntese de redes de trocadores, a seguinte rede integrada foi elaborada. (Figura 5.8)

Figura 5.8 - Rede integrada de trocadores de calor

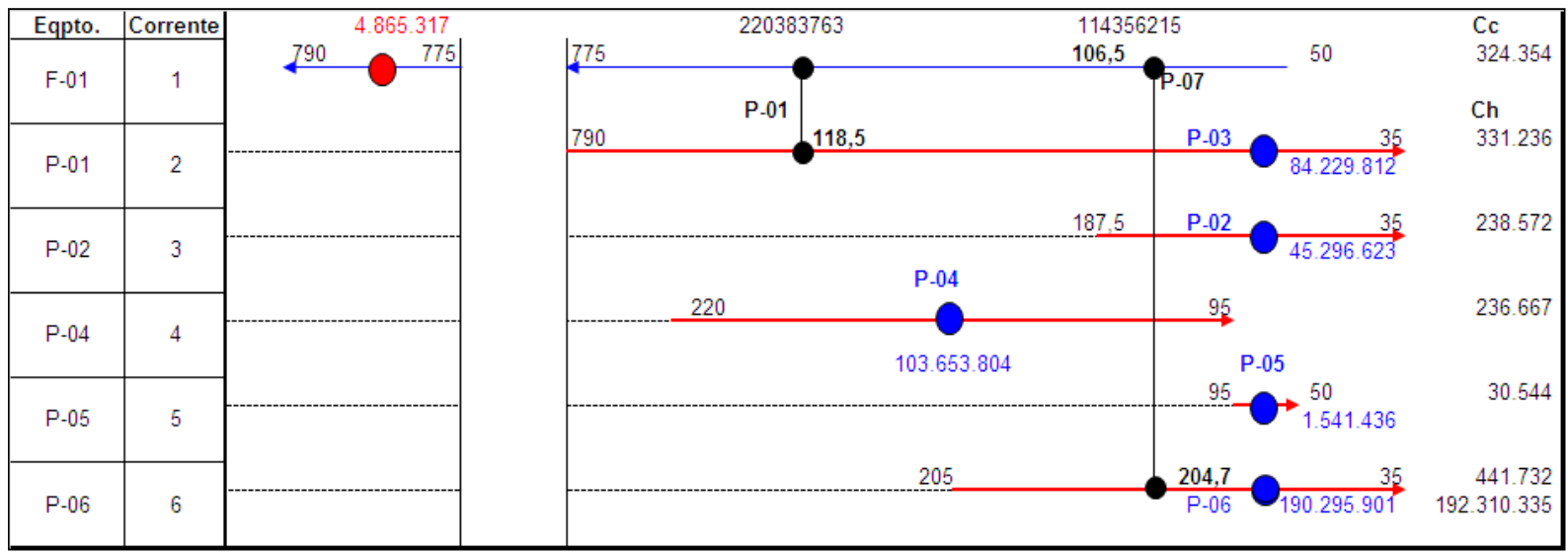

Fonte: Elaboração própria.

Como resultado da integração dos trocadores do processo, verificou-se que o numero de trocadores de calor aumentou de 5 para 7 e que não mais foi necessário a utilização de um forno para aquecimento da carga, devido à integração da corrente de carga com a saída do reator de reforma e também com o retorno de vapor do sistema de resfriamento do reator FT. A troca de calor com a corrente de saída do reator de reforma, a $790^{\circ} \mathrm{C}$, proporcionou o aquecimento da carga até $775^{\circ} \mathrm{C}$, respeitando o DMT adotado de $15^{\circ} \mathrm{C}$. O calor requerido para aquecimento da carga de $775^{\circ} \mathrm{C}$ até $790^{\circ} \mathrm{C}, 4.865 .317 \mathrm{~kJ} / \mathrm{h}$, foi obtido a partir da combustão catalítica, no próprio reator de reforma. 
Em comparação com as necessidades mínimas de utilidades quentes e frias, o processo atingiu a meta em relação às utilidades quentes e apresentou uma necessidade um pouco acima da mínima para as utilidades frias, conforme apresentado na tabela 5.7 .

Tabela 5.7 - Resultados da integração de trocadores de calor do processo

\begin{tabular}{|lrrr|}
\hline & PROCESSO & MÍNIMO & \multicolumn{1}{c|}{ DIFERENÇA } \\
\hline \hline Qq & 370.946 .365 & 370.946 .365 & 0 \\
\hline Qf & 425.017 .576 & 349.670 .981 & 75.346 .594 \\
\hline
\end{tabular}

Fonte: Elaboração própria.

O fato de o mínimo consumo de utilidades frias não ter sido atingido pode ser creditado ao fato de não terem sido realizadas trocas de calor com correntes divididas (splits) durante a síntese de trocadores.

Com base na síntese da rede de trocadores apresentada na figura 5.8, o fluxograma integrado, mássica e energeticamente, foi desenvolvido (Figura 5.9)

Figura 5.9 - Fluxograma final do processo proposto

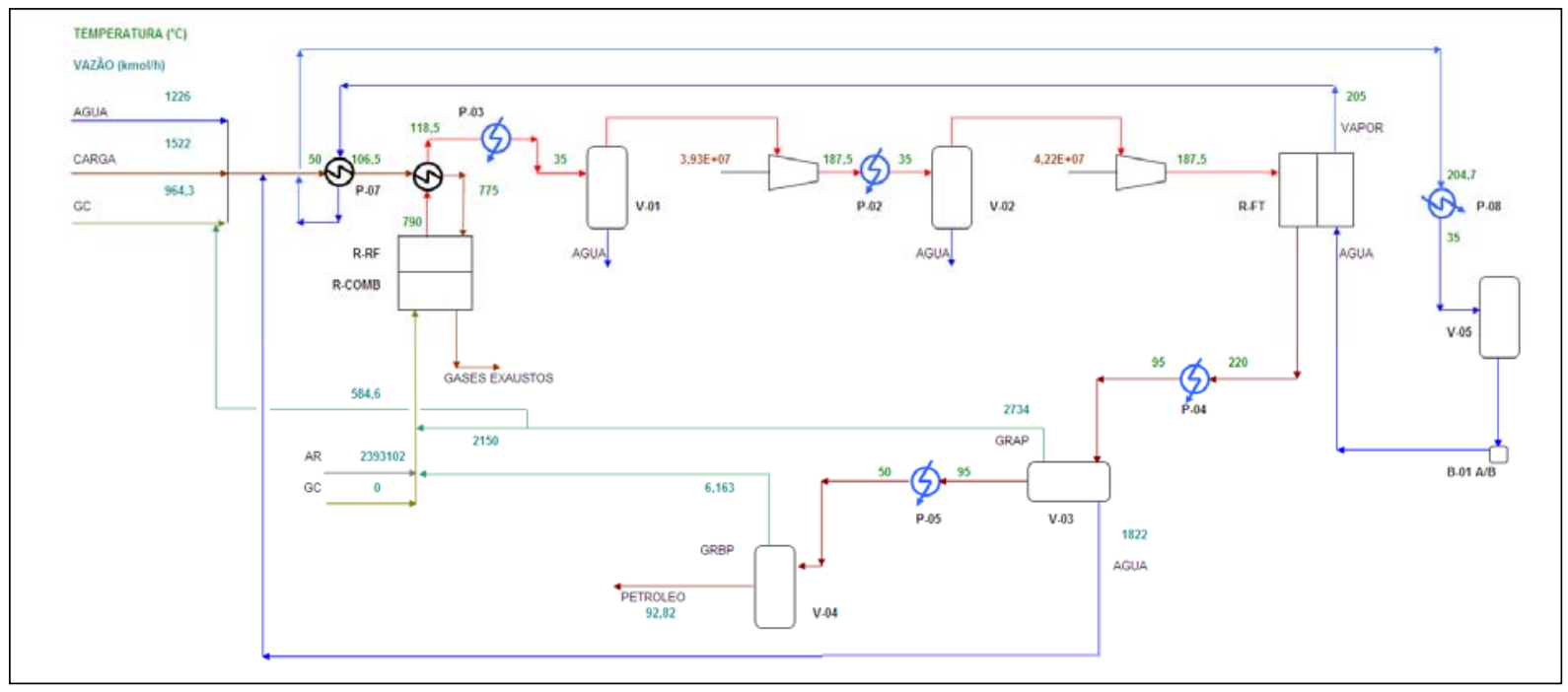

Fonte: Elaboração própria.

O fluxograma integrado foi simulado no Hysys 7.3 e os dados obtidos utilizados para a realização da análise econômica. Os resultados obtidos foram 
comparados com as melhores alternativas antes da integração energética e os resultados estão apresentados na tabela 5.8 .

Tabela 5.8 - Resumo dos resultados obtidos com a integração energética do processo.

\begin{tabular}{|c|c|c|c|c|}
\hline \multirow{2}{*}{ Indice I Variável } & \multirow{2}{*}{ Unidade } & \multicolumn{3}{|c|}{ Alternativa } \\
\hline & & 1 & 6 & Integrado \\
\hline Investimento & USD & $95.680 .341,66$ & 123.071 .887 .16 & $96.897 .813,33$ \\
\hline VPL & USD & $(99.800 .927,99)$ & $(104.176 .545,56)$ & $154.676 .200,49$ \\
\hline Gás Combustivel Consumido & $\mathrm{kmol} / \mathrm{h}$ & 1511 & 2285 & 1200 \\
\hline Carga Alimentada & $\mathrm{kmol} / \mathrm{h}$ & 1460 & 1305 & 1522 \\
\hline Petróleo Produzido & $m^{3} / h$ & 17,76 & 24,92 & 19,62 \\
\hline Petróleo Produzido & barril/d & 2681 & 3762 & 2961 \\
\hline $\mathrm{CO}_{2}$ Produzido & $\mathrm{kg} / \mathrm{h}$ & 108728 & 126564 & 90257 \\
\hline Conversẫo Global de $\mathrm{CO}_{2}$ & - & $-1,40$ & $-1,71$ & $-1,02$ \\
\hline Eficiencia Energética & - & 0,3191 & 0,3369 & 0,4070 \\
\hline Razẫo Investimento/Óleo prod. & USD/bbl/d & 35684,54 & 32711,99 & 32723,33 \\
\hline Razâo Energia cons/óleo prod. & kJlbarril & $1,64.10^{7}$ & $1,56.10^{7}$ & $1,28.10^{7}$ \\
\hline Razão GC cons /Óleo prod. & kmolibarril & 13,5 & 14,6 & 9,7 \\
\hline
\end{tabular}

Fonte: Elaboração própria.

Os dados do processo integrado indicaram que a integração energética foi determinante para viabilidade econômica do projeto econômica do projeto. Com a integração energética ocorreu o aumento do VPL, aumentou-se a conversão de $\mathrm{CO}_{2}$ e reduziu-se sua emissão.

O custo de investimento relativo do projeto de USD $32.723,33 / \mathrm{bbl} / \mathrm{d}$ foi coerente com a faixa de produção indicada por um dos fabricantes da tecnologia compacta.

Mesmo com a produção abaixo da obtida no caso que utilizava membranas (alternativa-6), como já dito anteriormente, a redução do consumo do gás natural influenciou na redução dos gastos com matéria prima, assim como nas demais despesas operacionais, muitas delas influenciadas diretamente pelo consumo de gás natural.

A retirada do forno foi uns dos fatores que mais impactou na redução do consumo de gás combustível pelo processo, assim como pela redução das emissões e aumento da conversão de $\mathrm{CO}_{2}$. 
Com a integração, outro fato relevante foi o aumento da eficiência energética do processo, que saltou de $31,91 \%$ para $40,70 \%$, isso que dizer que, algo em torno de $40 \%$ da energia alimentada ao processo é convertida em energia, na forma de petróleo sintético. O consumo relativo de energia, ou seja, a energia gasta para produção de cada barril de petróleo também foi reduzida de $1,64.10^{7} \mathrm{~kJ} / \mathrm{bbl}$ para $1,28 \cdot 10^{7} \mathrm{~kJ} / \mathrm{bbl}$.

Mesmo com as integrações, mássicas e energéticas, apesar dos resultados melhorarem significativamente, o processo continuou apresentando um balanço negativo de $\mathrm{CO}_{2}$. Para o processo integrado, temos que para cada molécula de $\mathrm{CO}_{2}$ convertida em petróleo sintético, duas são emitidas para a atmosfera, demonstrando que o processo proposto, da forma como está, não atende ao critério de viabilidade ambiental. O maior e principal emissor de $\mathrm{CO}_{2}$ é o reator de combustão com $85,06 \%$ do volume emitido, seguido das turbinas dos compressores com $14,85 \%$ e do petróleo produzido com $0,09 \%$.

O resumo dos principais dados técnicos, construtivos e econômicos dos equipamentos utilizados na alternativa escolhida (integrada) é apresentado com detalhes no apêncice $A$. 


\section{CONCLUSÕES}

Neste trabalho foi analisada a viabilidade técnica e econômica da produção de petróleo sintético a partir de uma corrente rica em $\mathrm{CO}_{2}$, rejeito do processo de separação por membranas em uma unidade de processamento primário de petróleo e gás.

Após a simulação do caso base, a análise das opções de reciclo de gás residual do processo indicou ser interessante maximizar o uso dessas correntes como gás combustível, em detrimento do seu uso como reciclo para o reator de reforma catalítica.

Mesmo com a maximização da queima das correntes de gás residual, o VPL dessas alternativas continuou sendo negativo e a análise por integração energética e síntese de trocadores foi necessária.

Verificou-se que a integração energética das correntes que trocam calor no processo foi essencial para a viabilidade econômica do processo. Com ela o calor atrelado a algumas correntes de processo que necessitavam de resfriamento pode ser utilizado para aquecimento da corrente fria e, com isso, o forno, presente nos casos sem integração energética, e necessário para aquecimento da carga do reator de reforma, pode ser substituído por um trocador que reaproveitou o calor presente na corrente de saída desse mesmo reator. Com isso, o custo de investimento e o custo operacional do processo foram consideravelmente reduzidos.

Com o fluxograma final obtido a partir das análises realizadas nesse trabalho, foi possível produzir 2961 barris de petróleo por dia, com retorno financeiro ao final da vida útil do processo (VPL) de USD 154.676.200,49 e custo de implementação de USD $32.723,33$ por bbl/dia de capacidade de produção, coerente com valores indicados por uma das empresas detentoras da tecnologia de produção compacta de petróleo sintético. 
Do ponto de vista das emissões de $\mathrm{CO}_{2}$ verificou-se que o processo proposto produz aproximadamente o dobro da quantidade de $\mathrm{CO}_{2}$ que efetivamente é convertida no processo, não sendo viável em relação à viabilidade ambiental do projeto. Do volume total emitido, a grande maioria é oriunda do reator de combustão, sugerindo que melhorias nessa etapa do processo ainda são necessárias. 


\section{CONTINUIDADE DO TRABALHO}

O estudo de outras tecnologias para a etapa de produção de gás de síntese, como por exemplo, a utilização da reforma autotérmica pode trazer ganhos, tanto ambientais, como econômicos, pois pode dispensar a necessidade do fornecimento de energia e, com isso, do reator de combustão.

A utilização da tecnologia de oxi-combustão, que utiliza oxigênio puro ao invés de ar na combustão catalítica, é uma opção para redução da emissão de $\mathrm{CO}_{2}$ pelo processo. Essa tecnologia gera um produto de combustão composto basicamente de $\mathrm{CO}_{2}$ e $\mathrm{H}_{2} \mathrm{O}$, que podem ser utilizados como carga do processo ou reinjetado no reservatório.

A modelagem rigorosa da etapa de produção do petróleo sintético, síntese FT, utilizando modelos cinéticos complexos e mais recentes, pode trazer maior precisão aos resultados, em especial em relação a produção de metano e etano, assim como a conversão de $\mathrm{CO}_{2}$ nessa etapa, visto que o modelo utilizado nesse estudo, apesar de trazer uma boa aproximação em seus resultados, apresenta alguns desvios em relação a esses componentes. 
AASBERG-PETERSEN, K. et al. Technologies for large-scale gas conversion. Catalysis Today, n. 221, p. 379-387. 2001.

AASBERG-PETERSEN, $\mathrm{K}$. et al. Recent developments in autothermal reforming and pre-reforming for synthesis gas production in GTL applications, Fuel Processing Technology, v. 83, p. 253-261. 2003.

ALMEIDA, E.L.F., BOMTEMPO, J. V., BICALHO R. G. Viabilidade das plantas GTL: uma análise de sensibilidade das variáveis determinantes. $4^{\circ}$ Congresso Latino Americano e do Caribe de Gás e Eletricidade, 26-28 de abril, Rio de Janeiro. 2004

BAKER, R.W.; LOKHANDWALA, K. Natural gas processing with membranes: An overview. Industrial \& Engineering Chemistry Research, v.47, p.2109-2121, California. 2008

BAKKERUD, P. K. Update on synthesis gas production for GTL. Catalysis Today, n. 106, p.30-33. 2005.

BASINI, L. Issues in $\mathrm{H}_{2}$ and synthesis gas technologies for refinery, GTL and small and distributed industrial needs. Catalysis Today, n. 106, p. 34-40. 2005.

BAXTER, L. Modular GTL as an Offshore Associated Gas Solution. Deep Offshore Technology International, Amsterdam. 2010.

BHARADWAJ S.S., SCHMIDT L.D. Catalytic partial oxidation of natural gas to syngas. Fuel Processing Technology, v. 42, p.109-127. 1995.

BREED A., DOHERTY M. F., GADEWAR S., GROSSO P., LORKOVIC I. M., MCFARLAND E.W., WEISS M.J. Natural gas conversion to liquid fuels in a zone reactor. Catalysis Today, v. 106, p.301-304. 2005.

CHEN, T. Investigation of Catalytic Autothermal Reforming Process for Hydrogen Production. Institute of Nuclear Energy Research, Taiwan; University of Britisch Columbia, Canada. 2005

CHEM SYSTEMS. Stranded Gas Utilization: Methane Refineries of the Future, New York. 2001.

DE KLERK, A. de. Hydroprocessing peculiarities of Fischer-Tropsch syncrude. Catalysis Today, v. 130, p.439-445. 2008

DELAI, A.K.; DAVIS, B.H. Fischer-Tropsch synthesis:A review of water effects on the performances of unsupported and supported Co catalysts. Applied Catalysis A: General, v.348, p.1-15. 2008. 
DIJK, Henricus A.J. Van. The Fischer-Tropsch synthesis: A mechanistic study using transient isotopic tracing. Tese (Doutorado) - Technische Universiteit Eindhoven, Eindhoven. 2001.

DRY, M. E. The Fischer-Tropsch Process - Commercial Aspects. Catalysis Today, v.3, p.183-206. 1990.

DRY, M. E. The Fischer-Tropsch Process: 1950-2000. Catalysis Today, v.71, p. 227-241. 2002.

EIA - U.S. Energy Information Administration. Annual Energy Outlook 2013 - With Projections to 2040. DOE/EIA-0383, Appendix B, Table B1, p.161. 2003.

EL-HALWAGI, M.M. Process Integration. Department of Chemical Engineering, Texas. 2003

EL-HALWAGI, M.M.; Bao, B.; Elbashir, N.O. Simulation, integration and economic analysis of gas-to-liquid processes. Fuel Processing Technology, v.91, p.703-713. 2010.

ESPINOZA, R.L.; STEYNBERG, A.P.; JAGER, B.; VOSLOO, A.C. Low temperature Fischer-Tropsch synthesis from a Sasol perspective. Applied Catalysis $A$ : General, v.186, p.13-26. 1999.

FERRO, F; TEIXEIRA, P. Os Desafios do Pré-Sal. Edições Câmara, Cadernos de Altos Estudos n5, Camara dos Deputados, Brasília. 2009.

FORMIGLI, J. M. Pre-Salt Reservoirs Offshore Brazil: Perspectives and Challenges. Petrobras oral presentation at Offshore Technology Conference, Houston, Texas, USA. 2007.

Disponível em: www.investidorpetrobras.com.br/lumis/portal

Acesso em: 20 jan. 2013.

GEERLINGS, J.J.C.; WILSON, J.H.; KRAMER, G.J.; KUIPERS, H.P.C.E.; HOEK, A.; HUISMAN, H.M. Fischer-Tropsch technology - from a active site to commercial process. Applied Catalysis A: General, v.186, p.24-40. 1999.

GEROSA, T.M. O Estudo da Utilização do Gás Natural no Brasil Como Insumo Para a Industria Química e Petroquímica: Modelagem de uma Planta GásQuímica. Dissertação (Mestrado em Energia) - Programa Interunidades de PósGraduação em Energia, Universidade de São Paulo, São Paulo. 2007.

HAYAKAWA, H.; TANAKA, H.; FUGIMOTO, K. Studies on catalytic performance of precipitated iron/silica catalyst for Fischer-Tropsch synthesis. Applied Catalysis A: General, v.328, p.117-123. 2007.

HAYWARD, P. The next generation. Fundamentals of Gas to Liquids, Petroleum Economist, p.45-47, Londres, 2005. 
EYDENRICH, R. Howard Weil Energy Conference, abr. 2005. Disponível em: <http://www.sasol.com/sasol_internet/downloads/howardWeilConference_Apr05_111 2340279010.pdf>.

Acesso em: 05 jan. 2012.

HIGMAN, C., VAN DER BURGT M., 2003, Feedstocks and Feedstock Characteristics. Elsevier Science, Gasification, Gulf Professional Publishing, 1 ed., chapter 4, Burlington, MA, USA. 2003.

IYER, M. V.; NORCIO, L.P.; KUGLER, E.L.; DADYBURJOR, D.B. Kinetic Modeling for Methane Reforming with Carbon Dioxide overa Mixed-Metal Carbide Catalyst. Industrial \& Engineering Chemistry Research, v. 42, p. 2712-2721. 2003.

IPCC - Intergovernmental Panel on Climate Changes. Carbon Dioxide Capture and Storage. Special Report, New York, USA, 2005.

KESHAV T.R., BASU S. Gas-to-liquid technologies: India's perspective. Fuel Processing Technology, v.88, p.493-500. 2007.

KNOTTENBELT, C. Mossgas "Gas to Liquid” Diesel Fuels - an Environmentally Friendly Option. Catalysis Today, n. 71, p.437-445. 2002.

KUSMIYATI, N.A.S.A. Production of gasoline range hydrocarbons from catalytic reaction of methane in the presence of ethylene over W/HZSM-5. Catalysis Today, v.106, p.271-274. 2005.

LAAN, G. P. Van. Kinetics, Selectivity and Scale Up of the Fischer-Tropsch Synthesis. Tese (Doutorado) - Faculteit Wiskunde en Natuurwetenschappen, Rijksuniversiteit Groningen, Groningen, 1999.

MAITRA, A.M.; EDWARDS, J.H. The chemistry of methane reforming with carbon dioxide and its current and potential applications. Fuel Processing Technology, v. 42, p. 269-289. 1995.

MATAR, S.; HARCH, L.F. Chemistry of Petrochemical Processes. $2^{\circ}$ edição, Gulf Publishing Company. 2000

MARSCHNER, F; RENNER, H.J. Gas Production - Steam Reforming of Natural Gas and Others Hydrocarbons. Parte integrante da Ullmann's Encyclopedia of Industrial Chemistry. 2002.

MARTÍNES, A.; LÓPEZ, C.; MÁRQUEZ, F.; DIAZ, I. Fischer-Tropsch synthesis of hydrocarbons over mesoporous Co/SBA-15 catalysts: the influence of metal loading, cobalt precursor, and promoters. Journal of Catalysis, v. 220, p. 486-499. 2003

MARTÍNES, A.; ROLLÁN, J.; ARRIBAS, M.A.; CERQUEIRA, H.S.; COSTA, A.F.; AGUIAR, E.F.S. A detailed study of the activity and deactivation of zeolites in hybrid Co/SiO2-zeolite Fischer-Tropsch. Journal of Catalysis, v.249, p.162-173. 2007 
MOULIJN, J.A.; MAKKEE, M.; DIEPEN, A. VAN; Chemical Process Technology. John Wiley \& Sons, Chichester, Inglaterra. 2001.

PEÑA, M.A. GÓMEZ J.P. FIERRO J.L.G. New catalytic routes for syngas and hydrogen production. Applied Catalysis A: General, v.144, p.7-57. 1999.

PERRY, J.; PERRY, R.; GREEN, D. Perry's chemical engineers handbook. . 8.ed. McGraw-Hill, New York. 2008.

PINDYCK R. S., RUBINFELD D. L. Microeconomia. Ed. Pearson - Prentice Hall, $6^{\circ}$ edição. 2005.

RENTECH, INC. General Catalysts Characteristics. 2006. Disponível em: <http://www.rentech.com/process-technology-comparisons.htm>.

Acesso em: 13 nov 2011.

RICE S.F., MANN D.P. Autothermal Reforming of Natural Gas to Synthesis Gas. KBR Paper \#2031 - SANDIA National Laboratories REPORT, Apendix A, abril. 2007.

RICHES P. CompactGTL: A tailored and revolutionary solution to associated gas problems in oilfield development. GTLtec Conference, Qatar. 2007

ROBERTSON E. P. Options for gas-to- liquids technology in Alaska. Idaho National Engineering and Environmental Laboratory Bechtel BWXT Idaho, Idaho. 1999

SEADER, et al. Products and Process Design Principles. $2^{a}$ edição. John Wiley and Sons, Inc. 2003.

SILVA, J.F. Catalisadores Suportados em Peneiras Moleculares Micro e Mesoporosas para a Síntese de Fischer-Tropsch. Tese (Doutorado em Química Inorgânica) Departamento de Química, Pontifícia Universidade Católica do Rio de Janeiro, Rio de Janeiro. 2004.

SONG X., GUO Z. Technologies for direct production of flexible H2/CO synthesis gas. Energy Conversion and Management, v. 47, pp. 560-569. 2006.

SOUSA-AGUIAR, E. F.; APPEL, L. G.; MOTA, C. Natural gas chemical transformations: The path to refining in the future. Catalysis Today, v. 101, p. 37. 2005.

STELMACHOWSKI M., NOWICKI L. Fuel from the synthesis gas - the role of process Engineering. Applied Energy, v. 74, pp. 85-93. 2003.

STEYNBERG, A. P.; ESPINOZA, R,L,; JAGER, B.; VOSLOO, A.C. High temperature Fischer-Tropsch synthesis in commercial practice. Aplied Catalysis A: General, v. 186, p. 41-54. 2004. 
STEYNBERG, A. P.; Dry M.E. Fischer-Tropsch technology. Studies in surface science and catalysis-152, Elsevier, 2004.

SUPP, E.; BREJC, M.; LIEBNER, W. Gas production - Noncatalitic Partial Oxidation and Special Gasification Processes for Higher'Boiling Hydrocarbons. Parte integrante da Ullmann's Encyclopedia of Industrial Chemistry. 2002.

TONKOVICH, A.Y., PERRYA, S., WANGB, Y., QIUA, D., LAPLANTEA, T., ROGERSA, W.A., Microchannel Process Technology for Compact Methane Steam reforming, Chemical Engineering Science, v. 59, p. 4819 - 4824. 2004,

TURTON, et al. Analysis, Synthesis, and Design of Chemical Processes. $4^{a}$ edição. Upper Sadle River: Prentice Hall, 2012.

VOSLOO, A. C. Fischer Tropsch: a Futuristic View. Fuel Processing Technology, n. 71 , p. $149-155.2001$.

YANG, Y.; XIANG, H.W; XU, Y.Y; BAI, L.; LI, Y.W. Effect of potassium promoter on precipitated iron-manganese catalyst for Fischer-Tropsch synthesis. Applied Catalysis A: General, v 266, p.181-194. 2004.

WAN, H.J.; WU, B.S.; TAO, Z.C; LI, T.Z; AN, X.; XIANG, H.W.; LI, Y.W. Study of an iron-based Fischer-Tropsch synthesis catalyst incorporated with $\mathrm{SiO}_{2}$. Journal of Molecular Catalysis A: Chemical, v. 260, p. 255-263, 2006.

WILHELM, D. J. et al. Syngas Production to Gas to Liquids Applications: Technologies, Issues and Outlook. Fuel Processing Technology, n. 71, p. 139-148. 2001.

ZENNARO, R. Recent advances in gas-to-liquids technologies. Society of Petroleum Engineers - Italian Section, p. 21. 2009.

ZHANG, J.; Research and development of nickel based catalysts for carbon dioxide reforming of methane. Tese de doutorado, Univerisity of Saskatchewan, Canadá, 2008 
APÊNDICE - A

DADOS DE EQUIPAMENTOS - PROCESSO INTEGRADO 


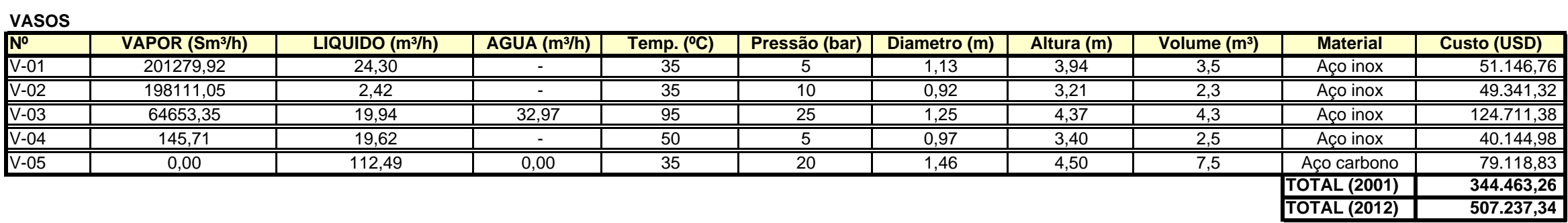

TROCADORES DE CALOR

\begin{tabular}{|c|c|c|c|c|c|c|c|c|c|c|}
\hline $\mathbf{N}^{\circ}$ & Corrente & Vazão (kmol/h) & T ent. $\left({ }^{\circ} \mathrm{C}\right)$ & T sai. $\left({ }^{\circ} \mathrm{C}\right)$ & Pressão (bar) & Energia (kJ/h) & Area $\left(\mathrm{m}^{2}\right)$ & Tipo & Material & Custo (USD) \\
\hline \multirow{2}{*}{ P-01 } & Saida do R-RF-01 & 9858,58 & 790,0 & 118,5 & 5 & \multirow{2}{*}{$2,36.10^{8}$} & 3035,63 & \multirow{2}{*}{$\begin{array}{c}\text { Circuito Impresso } \\
\text { (PCHE) }\end{array}$} & \multirow[b]{2}{*}{ Aço Inox } & $3.918 .314,38$ \\
\hline & \begin{tabular}{|l|} 
Carga R-RF-01 \\
\end{tabular} & 6118,98 & 106,5 & 775,0 & 5 & & 3035,63 & & & $3.918 .314,38$ \\
\hline \multirow{2}{*}{ P-02 } & Saida do R-RF-01 & 8512,78 & 187,5 & 35,0 & 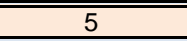 & \multirow{2}{*}{$4,53.10^{7}$} & \multirow{2}{*}{328,42} & \multirow{2}{*}{$\begin{array}{c}\text { Circuito Impresso } \\
\text { (PCHE) }\end{array}$} & \multirow{2}{*}{ Aço Inox } & \multirow{2}{*}{$703.403,60$} \\
\hline & Agua de Resfriamento & 38864,54 & 25,0 & 40,0 & 20 & & & & & \\
\hline \multirow{2}{*}{ P-03 } & Descarga C-01A & 4655,38 & 220,0 & 95,0 & 20 & \multirow{2}{*}{$8,42.10^{7}$} & \multirow{2}{*}{938,40} & Circuito Impresso & \multirow{2}{*}{ Aço Inox } & \multirow{2}{*}{$1.456 .703,69$} \\
\hline & Agua de Resfriamento & 72269,25 & 25,0 & 40,0 & 20 & & & $(\mathrm{PCHE})$ & & \\
\hline \multirow{2}{*}{ P-04 } & Saida de óleo V-03 & 98,99 & 95,0 & 50,0 & 25 & \multirow{2}{*}{$1,04.10^{8}$} & \multirow{2}{*}{329,62} & Circuito Impresso & \multirow{2}{*}{ Aço Inox } & \multirow{2}{*}{$704.998,23$} \\
\hline & Agua de Resfriamento & 88935,05 & 25,0 & 40,0 & 20 & & & (PCHE) & & \\
\hline \multirow{2}{*}{ P-05 } & Saida de óleo V-04 & 9858,58 & 118,5 & 35,0 & 25 & \multirow{2}{*}{$1,54.10^{6}$} & \multirow{2}{*}{15,00} & Circuito Impresso & \multirow{2}{*}{ Aço Inox } & \multirow{2}{*}{$195.107,08$} \\
\hline & Agua de Resfriamento & 1322,55 & 25,0 & 40,0 & 20 & & & (PCHE) & & \\
\hline \multirow{2}{*}{ P-06 } & Vapor Saturado R-FT & 6231,77 & 205,0 & 204,7 & 25 & \multirow{2}{*}{$1,90.10^{8}$} & 638,15 & \multirow{2}{*}{$\begin{array}{c}\begin{array}{c}\text { Circuito Impresso } \\
\text { (PCHE) }\end{array} \\
\end{array}$} & \multirow{2}{*}{ Aço Inox } & $193.977,17$ \\
\hline & Agua de Resfriamento & 163274,05 & 25,0 & 40,0 & 20 & & 638,15 & & & $193.977,17$ \\
\hline \multirow{2}{*}{ P-07 } & Vapor Saturado R-FT & 6231,77 & 204,7 & 35,0 & 20 & \multirow{2}{*}{$1,14.10^{8}$} & \multirow{2}{*}{339,63} & \multirow{2}{*}{ Casco e Tubo } & Acr Carcono & \multirow{2}{*}{$34.773,20$} \\
\hline & \begin{tabular}{|l|} 
Carga R-RF-01 \\
\end{tabular} & 6118,98 & 49,5 & 106,5 & 5 & & & & Aço Cardơno & \\
\hline & & & & & & & & & $\begin{array}{l}\text { TOTAL (2001) } \\
\text { TOTAL (2012) }\end{array}$ & $\begin{array}{l}11.319 .568,90 \\
16.668 .564 .18\end{array}$ \\
\hline
\end{tabular}

COMPRESSORES

\begin{tabular}{|c|c|c|c|c|c|c|c|c|c|}
\hline & Equipamento & Vazão (kmol/h) & Pres.Ent.(bar) & Temp. Ent $\left({ }^{\circ} \mathrm{C}\right)$ & Pres.Sai.(bar) & Temp. Sai. $\left({ }^{\circ} \mathrm{C}\right)$ & Energia (KJ/h) & Material & Custo (USD) \\
\hline C-01A & Comp. $1^{\circ}$ estágio & 8512,78 & 2,4 & 35 & 7,5 & 187,5 & $3,93.10^{7}$ & \multirow{2}{*}{ Aço Inox } & $3.464 .617,71$ \\
\hline C-01B & Comp. $2^{\circ}$ estágio & 8378,76 & 7,4 & 35 & 25,1 & 201,2 & $4,22.10^{8}$ & & $3.597 .391,97$ \\
\hline & & & & & & & & \begin{tabular}{|l|} 
TOTAL (2001) \\
TOTAL (2012)
\end{tabular} & $\begin{array}{r}7.062 .009,68 \\
10.399 .120,56\end{array}$ \\
\hline
\end{tabular}

TURBINAS
\begin{tabular}{|l|l|c|c|c|}
\hline \multicolumn{2}{|c|}{ Equipamento } & Energia (KJ/h) & Material & Custo (USD) \\
\hline TG-01A & Turbina do C-01A & $3,93.10^{7}$ & \multirow{2}{*}{ Aço Inox } & $17.093 .167,76$ \\
& & $18.136 .563,40$ \\
\hline TG-01B & Turbina do C-01B & $4,22.10^{8}$ & TOTAL (2001) & $\mathbf{3 5 . 2 2 9 . 7 3 1 , 1 6}$ \\
\hline
\end{tabular}

\begin{tabular}{|c|c|c|c|c|c|c|c|c|c|}
\hline & Equipamento & Alimentação (kmol/h) & T ent. $\left({ }^{\circ} \mathrm{C}\right)$ & T sai. $\left({ }^{\circ} \mathrm{C}\right)$ & Pressão (bar) & Area $\left(\mathrm{m}^{2}\right)$ & Tipo & Material & Custo (USD) \\
\hline R-RF-01 & REFORMA & 6118,98 & 775 & 790 & 5 & 6168,27 & Milicanais & Fecralloy & $9.111 .757,30$ \\
\hline R-FT-01 & FISCHER-TROPSCH & 8378,76 & 201,2 & 220 & 25 & 1673,72 & Milicanais & Fecralloy & $2.711 .119,75$ \\
\hline & & & & & & & & \begin{tabular}{|l} 
TOTAL (2001) \\
TOTAL (2012)
\end{tabular} & $\frac{11.822 .877,05}{17.409 .707,61}$ \\
\hline
\end{tabular}

BOMBAS
\begin{tabular}{|c|c|c|c|c|r|}
\hline $\mathbf{N}^{\circ}$ & Delta P (bar) & Vazão $\left(\mathbf{m}^{3} / \mathbf{h}\right)$ & Energia (KW) & Material & \multicolumn{1}{c|}{ Custo (USD) } \\
\hline B-01-A & 3 & 112,49 & 4489 & Aço Carbono & 7249,93 \\
\hline B-01-B & 3 & 112,49 & 4489 & Aço Carbono & 7249,93 \\
\hline
\end{tabular}

